\title{
Test Application of a Semi- Objective Approach to Wind Forecasting for Wind Energy Applications
}

H. L. Wegley

W. J. Formica

July 1983

Prepared for the U.S. Department of Energy under Contract DE-AC06-76RLO 1830

Pacific Northwest Laboratory Operated for the U.S. Department of Energy by Battelle Memorial Institute 


\title{
DISCLAIMER
}

This report was prepared as an account of work sponsored by an agency of the United States Government. Neither the United States Government nor any agency thereof, nor any of their employees, makes any warranty, express or implied, or assumes any legal liability or responsibility for the accuracy, completeness, or usefulness of any information, apparatus, product, or process disclosed, or represents that its use would not infringe privately owned rights. Reference herein to any specific commercial product, process, or service by trade name, trademark, manufacturer, or otherwise, does not necessarily constitute or imply its endorsement, recommendation, or favoring by the United States Government or any agency thereof. The views and opinions of authors expressed herein do not necessarily state or reflect those of the United States Government or any agency thereof.

\author{
PACIFIC NORTHWEST LABORATORY \\ operated by \\ BATTELLE \\ for the \\ UNITED STATES DEPARTMENT OF ENERGY \\ under Contract DE-AC06-76RLO 1830
}

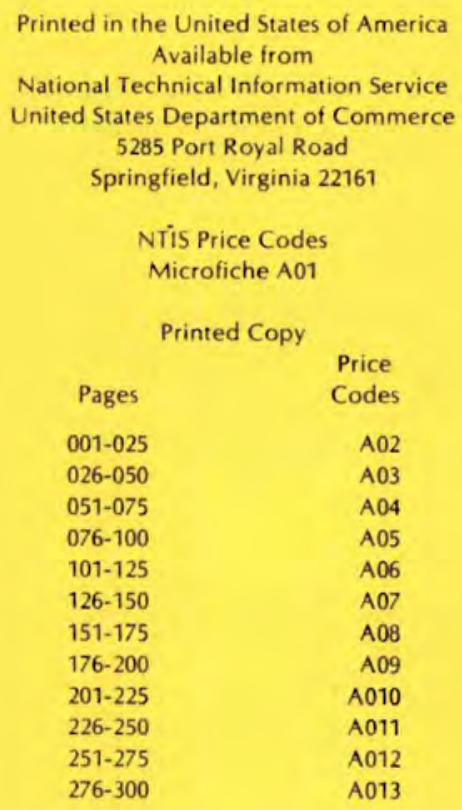


PNL -4403

UC-60

\section{TEST APPLICATION OF A SEMI-OBJECTIVE APPROACH TO WIND FORECASTING FOR WIND ENERGY APPLICATIONS}

H. L. Wegley

W. J. Formica

July 1983

Prepared for the U. S. Department of Energy under Contract DE-ACO6-RLO 1830

Pacific Northwest Laboratory Richland, Washington 99352 


\section{$\underline{\text { ACKNOWLEDGMENTS }}$}

The authors would like to acknowledge the efforts of Debbie Atkin for arranging the figures and tables, Rosemary Ellis for typing the manuscript, Scott Heflick for developing the software used to build the forecast data files and the work of all the forecasters: Ora Gifford, Don Newland, Gregg Andrews, Gary Reinecke, Marc Schwartz, and Gene Preston. 
A semi-objective (S-O) approach to wind forecasting for wind energy applications has been developed previously and documented in Learning to Forecast Wind at Remote Sites for Wind Energy Applications (Notis et al. 1983). The S-0 procedure has now been tested and refined by applying the procedure at three Department of Energy (DOE) candidate wind turbine sites. The primary purpose of the S-0 approach is for use by trained meteorologists to produce 24-hour forecasts of hourly average wind speeds for inclusion in utilities' daily load forecasts. Accurate 24-hour wind forecasts would permit more reliance upon wind power generation and, in general, produce a shift in unit commitment away from the more costly forms of power generation.

In the first 60 to 90 days of the test application, the S-0 forecasts were "fine tuned" at each site to produce forecasts superior to (and much more suited for wind energy use than) any routinely available or conventional wind forecasts. Furthermore, the accuracy of the S-0 forecasts (after tuning) was comparable to or greater than model output statistics. Model output statistics (MOS) was used for comparison because it is considered to be a state-of-the-art approach to wind forecasting. (However, MOS forecasts for wind energy use are neither routinely available nor currently feasible to develop for most utilities.)

It is recommended that future work include the development of reliable relationships between hourly average wind speeds and actual wind turbine power output, thereby making the wind speed forecasts of more direct use to utilities. The result of such work is planned for incorporation into a follow-on report that verifies the wind forecasts in terms of wind turbine power output rather than wind speed. In addition, future work should be directed toward the application of appropriate short-term forecasting techniques to produce forecasts of sub-hourly winds for use by utility dispatchers/dispatching algorithms. 


\section{CONTENTS}

SUMMARY. ............................. $i$ i

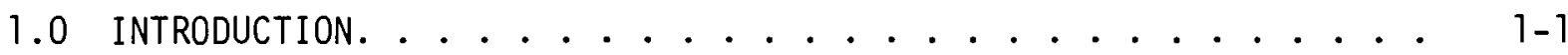

2.0 FORECASTING PROCEDURES. . . . . . . . . . . . . 2-1

2.1 PROCEDURES FOR BLOCK ISLAND. ........... 2-1

2.2 PROCEDURES FOR FINLEY. . . . . . . . . . . . 2-3

2.3 PROCEDURES FOR SAN GORGONIO. . . . . . . . . 2-7

2.4 PROCEDURES FOR ISSUING FORECASTS . . . . . . . . 2-10

2.5 PROCEDURES FOR PROVIDING FEEDBACK TO FORECASTERS . . . . . 2-11

3.0 FORECASTING VERIFICATION. . . . . . . . . . . . . 3-1

3.1 STATISTICAL MEASURES . . . . . . . . . . . . 3-1

3.2 VERIFICATION RESULTS FOR BLOCK ISLAND. . . . . . . . 3-3

3.3 VERIFICATION RESULTS FOR FINLEY. . . . . . . . . 3-6

3.4 VERIFICATION RESULTS FOR SAN GORGONIO. . . . . . . 3-12

3.5 VERIFICATION RESULTS WITH AND WITHOUT REAL-TIME FEEDBACK . . 3-17

4.0 FORECAST COMPARISONS. . . . . . . . . . . . 4-1

4.1 SUBJECTIVE FORECASTS . . . . . . . . . . . . . 4-1

4.2 DEVELOPMENT OF MODEL OUTPUT STATISTICS FORECASTS . . . . . 4

4.3 SEMI-OBJECTIVE VERSUS SUBJECTIVE FORECASTS . . . . . . 4 4-4

4.4 SEMI-OBJECTIVE VERSUS MOS FORECASTS. . . . . . . . . 4-6

5.0 CONCLUSIONS AND RECOMMENDATIONS . . . . . . . . . .

6.0 REFERENCES. ........................ . . 6-1

APPENDIX A: ORIGINAL FORECAST GUIDELINES USED AT BLOCK ISLAND, RHODE ISLAND, FINLEY AFB, NORTH DAKOTA, SAN GORGONIO PASS, CALIFORNIA. . . . . . . . . . . . . . . A-1

APPENDIX B: REVISED FORECAST GUIDELINES FOR BLOCK ISLAND, RHODE ISLAND, FINLEY AFB, NORTH DAKOTA, SAN GORGONIO PASS, CALIFORNIA. ................... B-

APPENDIX C: HEIDKE SKILL SCORE COMPUTATION. .......... C C-1

APPENDIX D: STATISTICAL ANALYSIS FOR THE PERIOD FEBRUARY THROUGH JULY $1982 \ldots \ldots$. . . . . . . . . . . . . . D-1

APPENDIX E: SELECTION OF A NORMALIZING STATISTIC FOR COMPARISON OF WIND SPEED FORECASTING ERRORS . . . . . . . . . E E-1 



\section{$\underline{\text { FIGURES }}$}

1-1 Hypothetical 24-Hour Load Forecast ............ 1-2

1-2 Example of an Accurate 24-Hour Wind Power Forecast . . . . . 1-3

1-3 Hypothetical 24-Hour Schedule of Power Generation Made $1-5$

1-4 Hypothetical Power Generation (Including Wind Generation)

With No Wind Forecasting ............... . . 1-6

1-5 Hypothetical Power Generation with the Use of Reliable Wind

Forecasts. . . . . . . . . . . . . . . 1 1-7

1-6 Three Sites for Which Semi-Objective Wind Forecasts Were Developed and Tested ................ 1-9

2-1 Block Island, Rhode Island Site Location . . . . . . . . 2-2

2-2 Observed Hourly Mean Wind Speeds for the Period February Through July 1982 at Block Island, Rhode Island. . . . . . . 2-4

2-3 Finley Air Force Base, North Dakota Site Location. . . . . . 2-5

2-4 Observed Hourly Mean Wind Speeds for the Period February Through July 1982 at Finley AFB, North Dakota. . . . . . . 2-6

2-5 San Gorgonio Pass, California Site Location. . . . . . . . 2-8

2-6 Observed Hourly Mean Wind Speeds for the Period February Through July 1982 at San Gorgonio Pass, California . . . . . 2-9

3-1 Wind Forecasting Skill Patterns at Block Island. . . . . . . 3-4

3-2 Normalized Root Mean Square Error as a Function of Forecast
Projection Hour at Block Island. . . . . . . . . . . . 3-5

3-3 Normalized Root Mean Square Error as a Function of Local Standard Time at Block Island. . . . . . . . . . . . 3-7

3-4 Wind Forecasting Skill Patterns at Finley AFB. . . . . . . . 3-8

3-5 Forecast Bias Measured at Finley AFB . . . . . . . . . . 3-9

3-6 Normalized Root Mean Square Error as a Function of Local Standard Time at Finley AFB. . . . . . . . . . . . 3-10 
3-7 Normalized Root Mean Square Error as a Function of Forecast Projection Hour at Finley AFB. . . . . . . . . ....

3-8 Wind Forecasting Skill Patterns at San Gorgonio Pass . . . . 3-13

3-9 Example Plots of Observed and Forecast Hourly Averaged Wind Speed Depicting Hour-to-Hour Variability in the Observed Wind Speeds at San Gorgonio Pass, California . . . . . . . .

3-10 Normalized Root Mean Square Error as a Function of Forecast Projection Hour at San Gorgonio Pass . . . . . . . . . .

3-11 Normalized Root Mean Square Error as a Function of Local Standard Time at San Gorgonio Pass . . . . . . . . . 3-16

4-1 Eleven Sites for Which Subjective Wind Forecasts Were Produced . . . . . . . . . . . . . . . . . .

4-2 Nine Sites for Which MOS Wind Forecasts Were Developed and Tested . . . . . . . . . . . . . . . . .

4-3 Sites for Which Semi-Objective and MOS Wind Forecasts Were Compared .................... . . . . 4-7

4-4 Block Island Weekly NRMSE Trend in MOS Wind Speed Forecasts. . 4-11

4-5 Block Is land Weekly NRMSE Trend in Semi-Objective Wind Speed Forecasts. ................. 4-12

4-6 Huron Weekly NRMSE Trend in MOS Wind Speed Forecasts . . . . 4-13

4-7 Finley Weekly NRMSE Trend in Semi-Objective Wind Speed Forecasts. . . . . . . . . . . . . . . 4 4-14

4-8 San Gorgonio Weekly NRMSE Trend in MOS Wind Speed Forecasts. . 4-15

4-9 San Gorgonio Weekly Trend in Semi-Objective Wind Speed

Forecasts. . . . . . . . . . . . . . . 4-16

C-1 Wind Speed Category Selection. . . . . . . . . . . . C-2

E-1 Example of a 10-Hr Timing Error in Forecasting the Wind Speed Trend........................ E-3

E-2 Example of an Actual Wind Speed Forecast During a Period of High Hour-to-Hour Wind Speed Variability. .......... E-4

E-3 Example of the Inability to Forecast Accurately Highly Variable Wind Speeds Several Hours in Advance. . . . . . . . . 
E-4 Wind Speed Forecasting RMSE Versus Two Candidate Normalizing Statistics .................... E-8

E-5 Trends in Wind Speed Forecasting RMSE and Two Candidate Normalizing Statistics Depicted by Third Order Polynomials . . . E-9 


\section{TABLES}

3-1 Examples of the Effect Dial-Up Usage Had on Forecast

Accuracy .................... 3-18

3-2 Heidke Skill Scores for the Forecasters. . . . . . . . . . 3-18

4-1 Verification of Semi-Objective Versus Subjective Wind Forecasts for Block Island, Rhode Island, and San Gorgonio, California................. . . . . 4-5

4-2 Verification of Semi-Objective Versus MOS Wind Forecasts for Block Island, Rhode Island .......... 4-8

4-3 Verification of Semi-Objective Wind Forecasts for Finley, North Dakota, Versus MOS Forecasts at Huron, South Dakota. . . 4-8

4-4 Verification of Semi-Objective Versus MOS Wind Forecasts for San Gorgonio Pass, California. . . . . . . . . . . . 4-9

4-5 Comparison of MOS Forecasting Accuracy With Semi-Objective Forecasts for the Period Following Initial Learning (April to

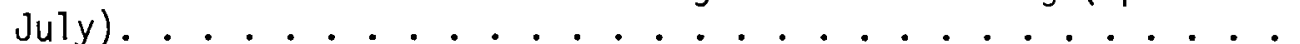

C-1 Sample Contingency Table . . . . . . . . . . . C-3

E-1 MOS Monthly Wind Forecasting Errors and Two Candidate Normalizing Statistics for Three Selected Sites. . . . . . . E-7 


\subsection{INTRODUCTION}

Recent investigations have shown that if significant penetrations of wind energy are made into utility grid systems, accurate 24-hour wind forecasts can make a significant positive contribution to the economics of wind energy (Goldenblatt et a1. 1982). This is not a new idea; earlier, Wende 11 et al. (1978) determined that a 24-hr forecast of hourly average winds would be a primary need of utilities having significant penetrations of wind generation. The usefulness of $24-h r$ wind forecasts in utility operations is described below and depicted, in a simplistic manner, in Figures 1-1 through $1-5$.

Electric utilities generally make daily forecasts of load as shown in Figure 1-1, because variations in load occur more rapidly than most electrical generators can be started. To ensure the reliability of the power system, load forecasts are used to schedule the startup/shutdown of generating equipment.

The daily scheduling (commitment) of generating equipment must account for contingencies such as rapid load fluctuations, errors in the load forecast or failure of a generator. When wind energy is introduced into a utility system in significant amounts, such as $>5 \%$ of the generating capacity, the stochastic nature of the wind produces variations in power generation that, for scheduling purposes, can be treated as variations (fluctuating reductions) in the load. It is then consistent with utility practices to produce wind/wind power forecasts, as shown in Figure 1-2, and to incorporate them into the load forecast to account for the effects of the wind turbine generators.

To meet fluctuations in electrical demand, utilities have traditionally used a 3-level hierarchy of generation consisting of the following: 


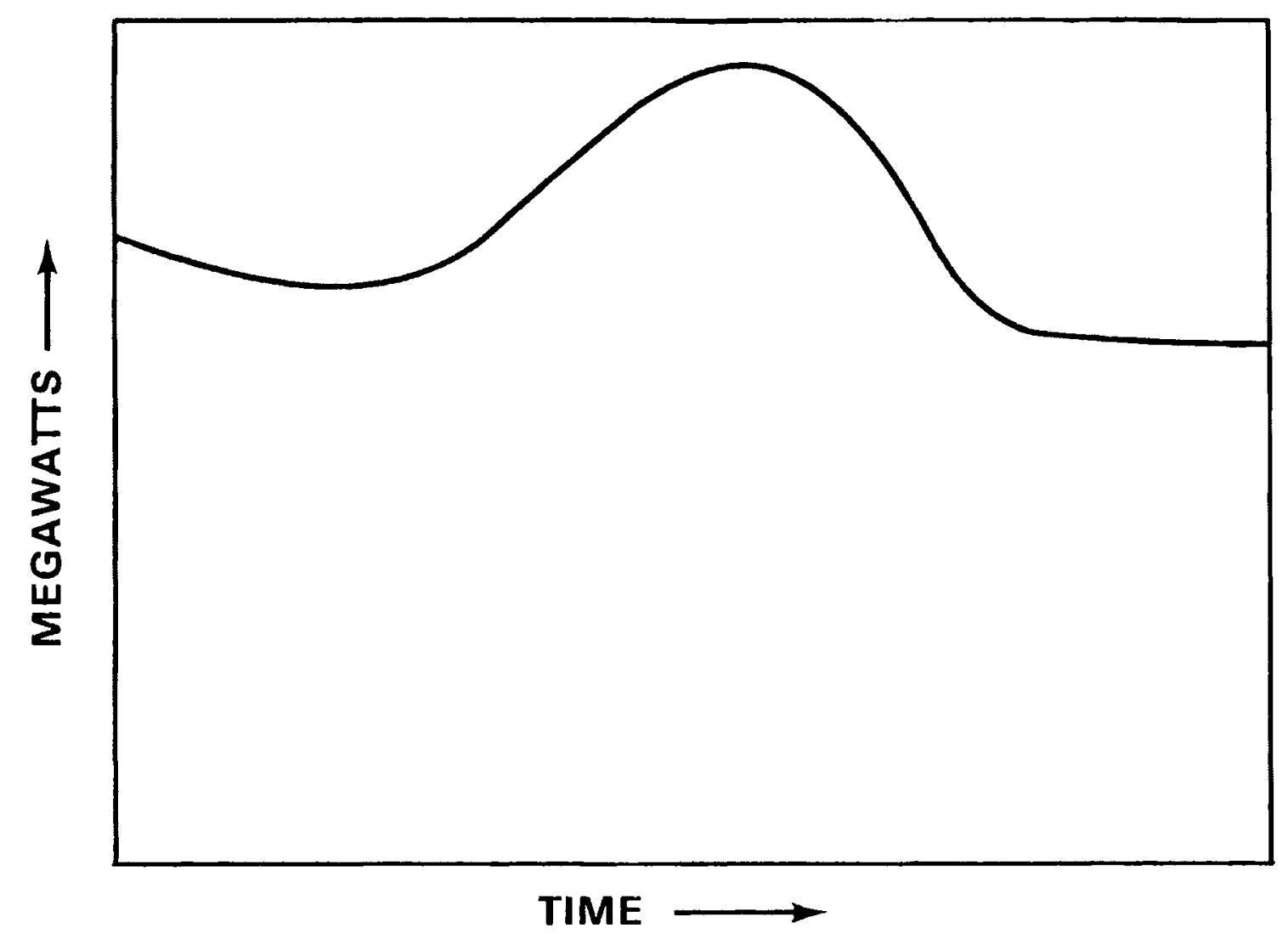

FIGURE 1-1. Hypothetical 24-Hour Load Forecast 


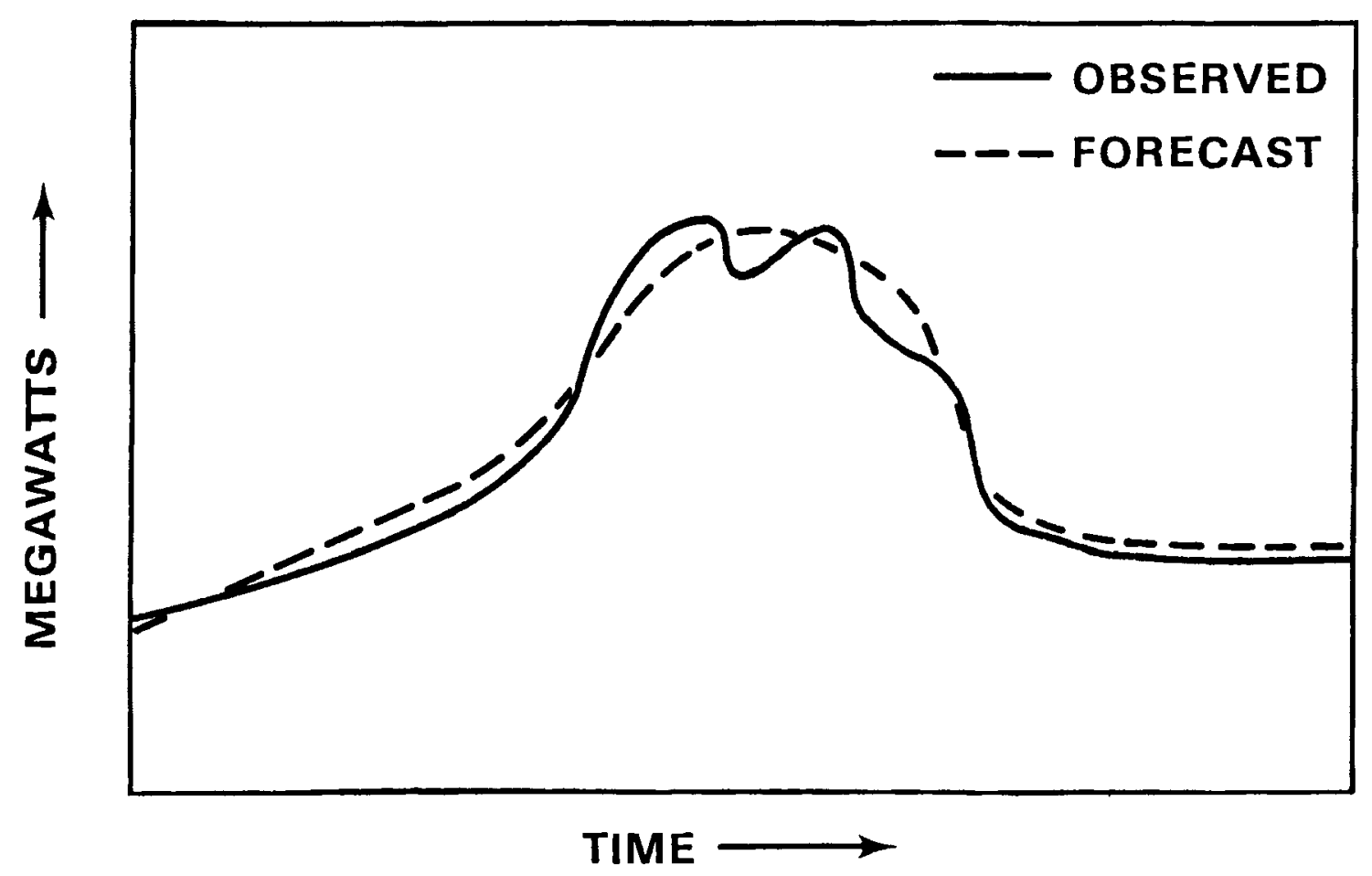

FIGURE 1-2. Example of an Accurate 24-Hour Wind Power Forecast 
Base Generation

- units are frequently coal or nuclear

- units operate 24 hours per day at a constant level

- units provide the most efficient and least costly generation

Intermediate (Swing) Generation

- units are cycled up and down to meet routine changes in power demand

- units are more costly to operate and less efficient than base generation

\section{Peaking Generation}

- units are frequently gas or 0i1-fired turbines

- units are usually expensive to operate

- units are used to satisfy surges in demand and immediate backup requirements.

The scheduled use of the three types of generation (to meet the electrical demand of Figure 1-1) is illustrated in Figure 1-3. Here the wind generation is disregarded in the schedule; no wind forecasts are used. Note that an efficient schedule is planned in which, only at the peak demand time of the day, is the use of much peaking generation planned.

However, if wind energy is used without wind forecasts, then the wind generation depicted in Figure 1-2 might cause the inefficiency shown in Figure 1-4. In Figure 1-4 the swing generation was not used efficiently because the wind power was not planned; thus, a large amount of peaking generation is required. On the other hand, if a reliable wind forecast is available, the wind generation is coordinated with the swing and base generation, as shown in Figure 1-5. The result is more reliance upon wind energy, less use of costly peaking units for backup and, in general, a shift toward lower cost generation.

Previous efforts to develop 24-hr forecasts of hourly average wind speeds have, at best, been marginally adequate for the application depicted 


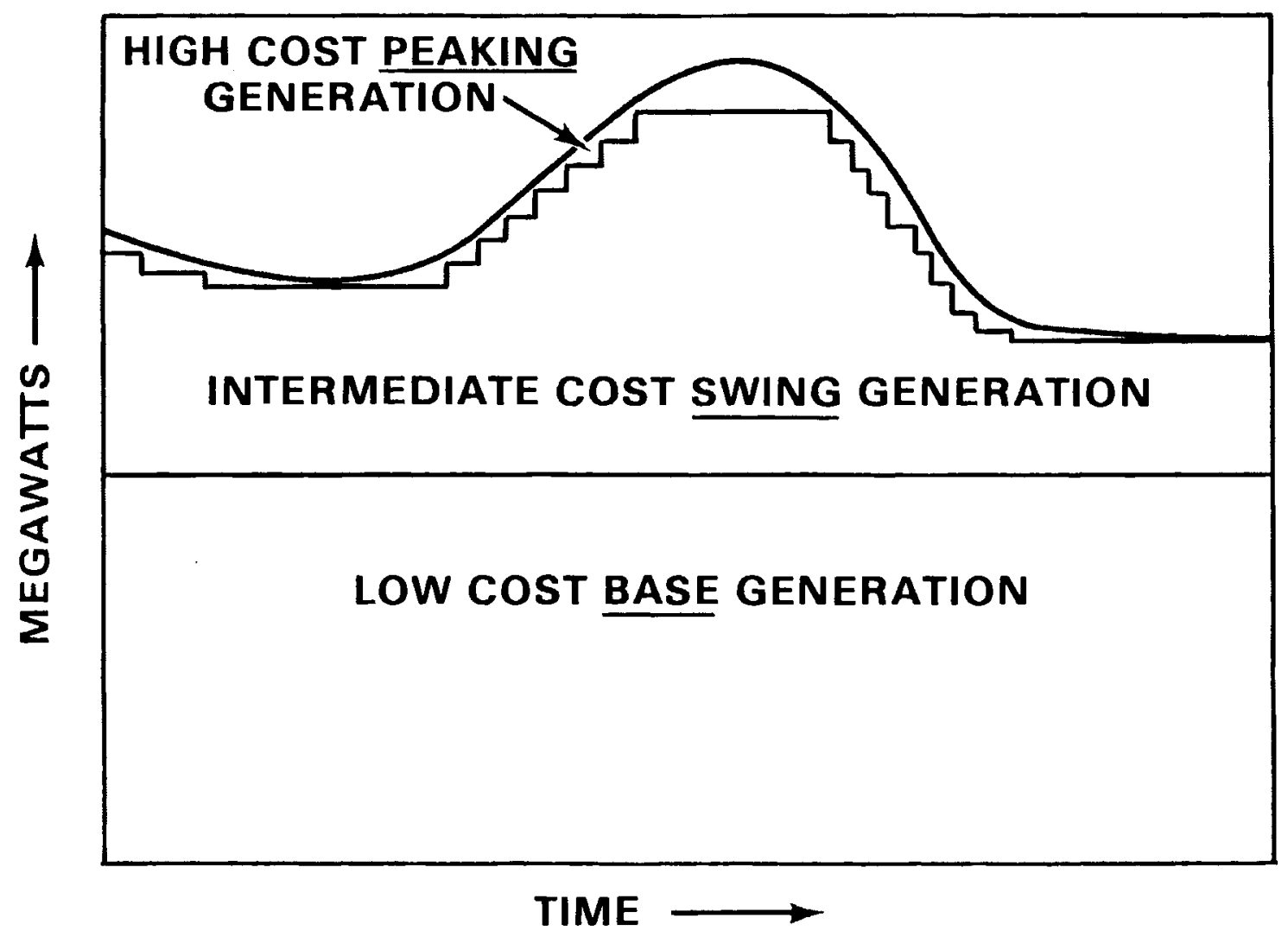

FIGURE 1-3. Hypothetical 24-Hour Schedule of Power Generation Made Without Using Wind Forecasts 


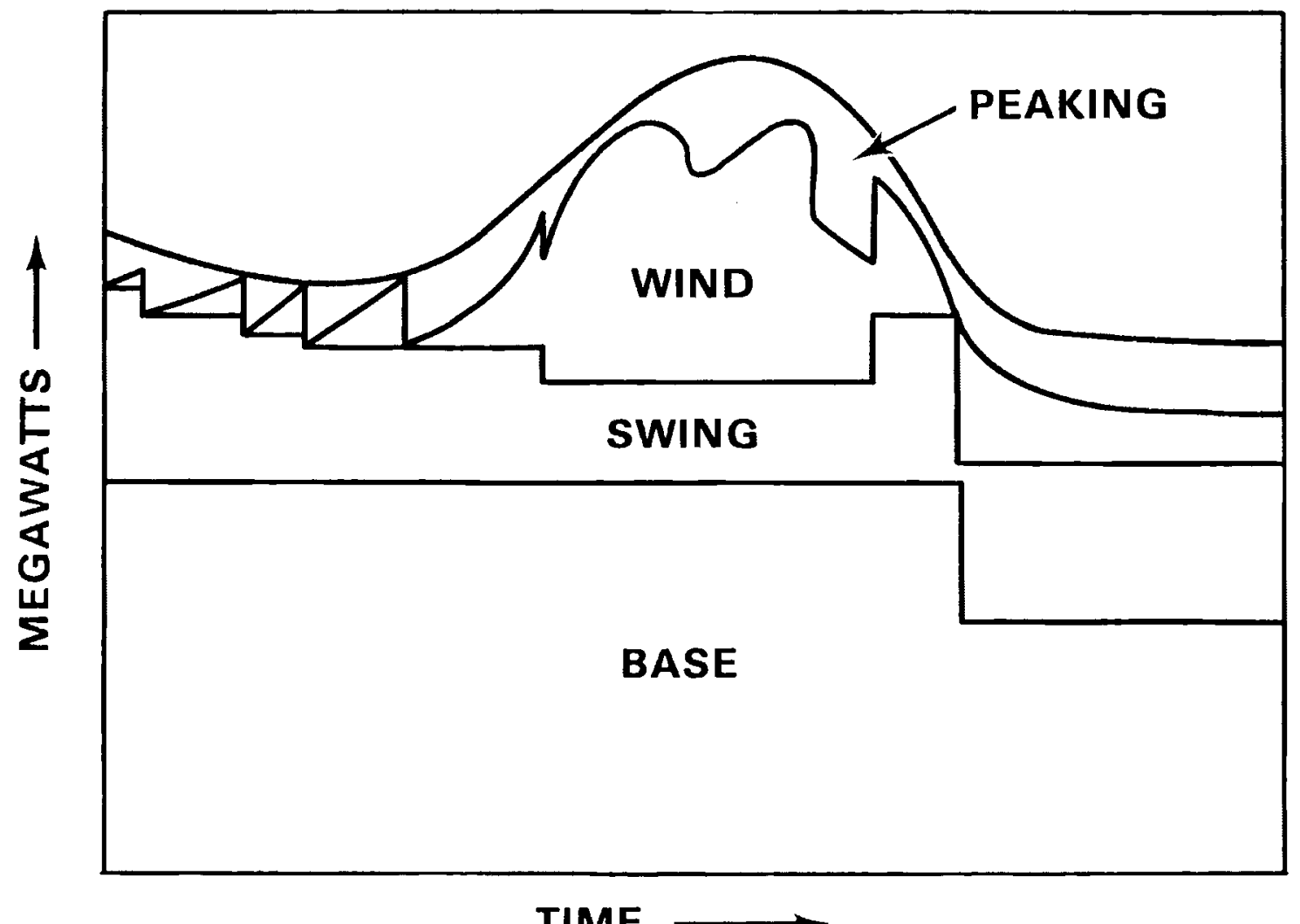

FIGURE 1-4. Hypothetical Power Generation (Including Wind Generation) With No Wind Forecasting 


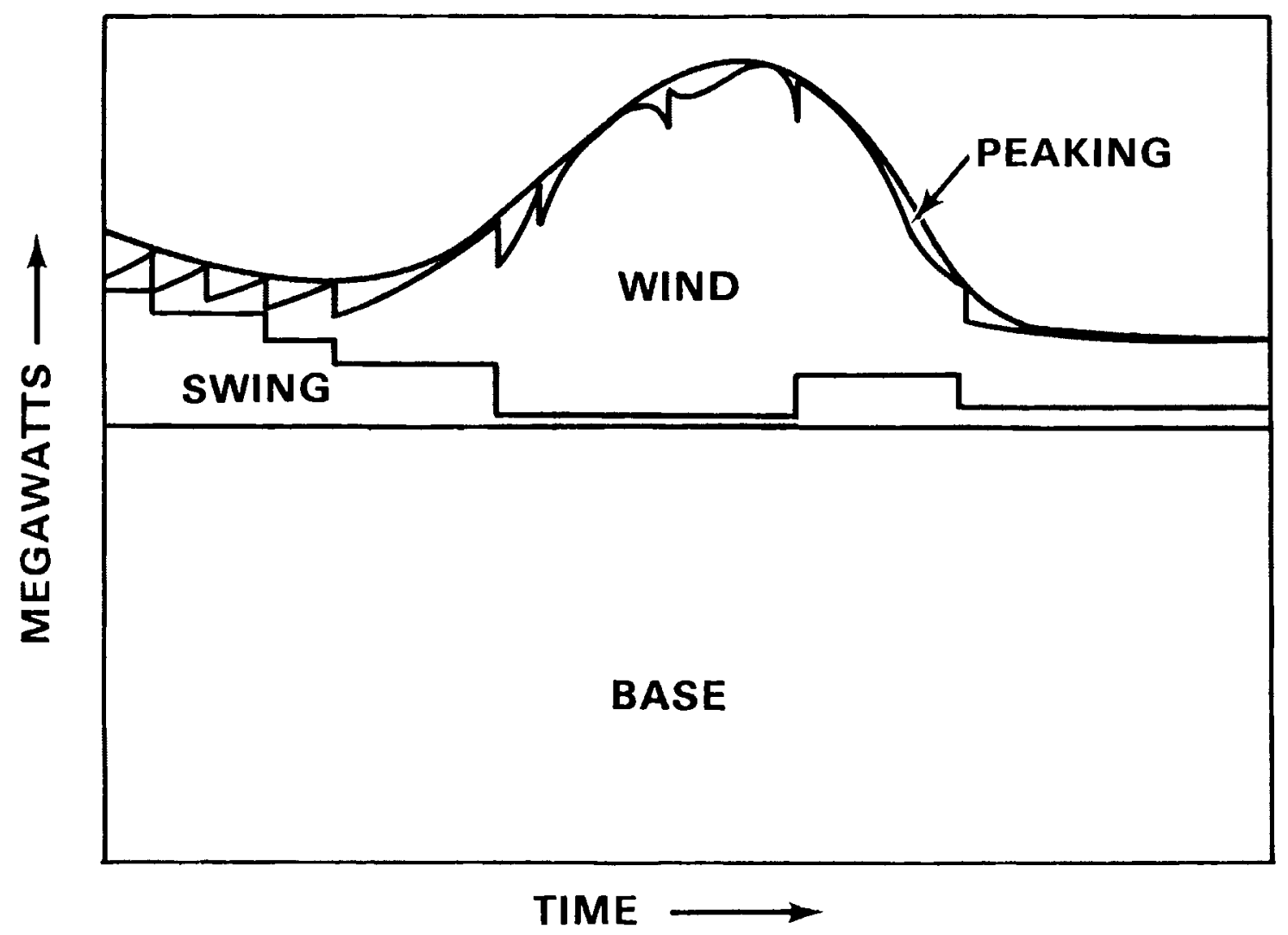

FIGURE 1-5. Hypothetical Power Generation With the Use of Reliable Wind Forecasts 
in Figure 1-5 (Wegley 1982). However, a forecasting method based upon analysis of synoptic weather events and the resultant winds at several Department of Energy (DOE) candidate wind turbine sites (Notis et al. 1983), promises improved accuracy and requires verification.

In an attempt to develop wind forecasts sufficiently accurate to be used in the 24-hr load forecasts, the results of the site-specific analyses described by Notis et al. (1983) were used to develop a semi-objective wind forecasting method for the three sites shown in Figure 1-6.

This report describes the test application of the semi-objective ( $S-0)$ wind forecasting technique at these three locations. The forecasting sites as well as site-specific forecasting procedures are described in Section 2. Section 3 presents verification of the S-0 wind forecasts and interprets the observed verification results. Comparisons are made in Section 4 between S-0 wind forecasting accuracy and that of two previous forecasting efforts that used subjective wind forecasts and model output statistics (MOS). In Section 5 conclusions are drawn regarding the usefulness of the S-0 wind forecasting approach and regarding the need for future efforts in wind forecasting for wind energy applications. 


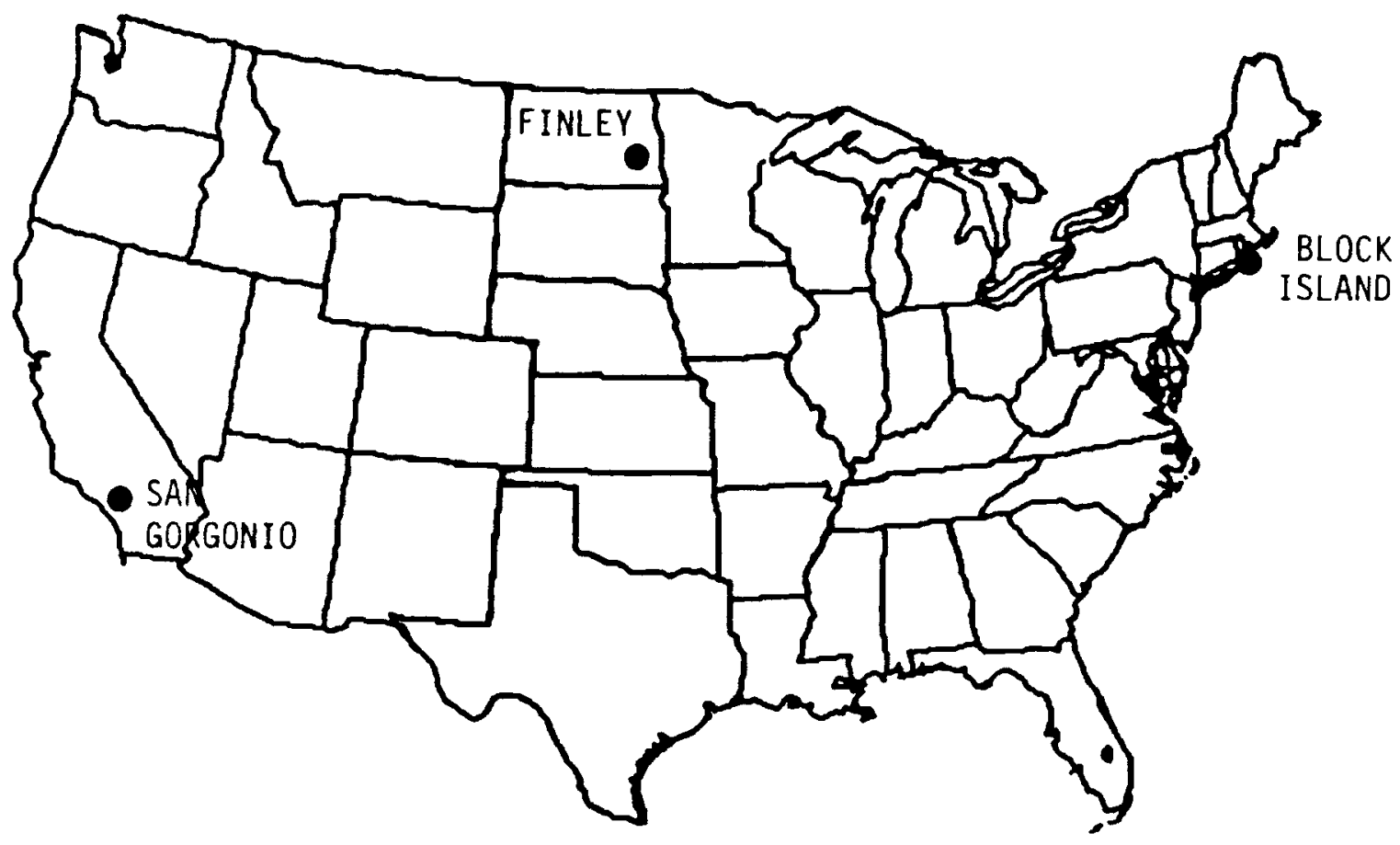

FIGURE 1-6. Three Sites For Which Semi-0bjective Wind Forecasts Were Developed and Tested 



\subsection{FORECASTING PROCEDURES}

The three sites selected for verification of the S-0 wind forecasting method, developed by Notis et al. (1983), were chosen to represent different geographical and topographical regimes. Block Island is a coastal site, Finley is located in the northern Great Plains and the San Gorgonio site lies in a mountain pass.

The original wind predictors selected by Notis et al. (1983) were pressure gradient vectors, synoptic map types and winds aloft (850-mb or 700-mb winds). Each of these predictors can be evaluated directly from weather analyses or prognoses routinely transmitted by the National Meteorological Center (NIC). The forecasting procedure for each site was formulated in terms of these three predictors.

Because it may become undesirable or impractical to develop specific forecasting guidelines for every individual wind turbine location owned by a utility, the wind forecasting procedures originally developed for two of the sites were tested either at a nearby site or at a more distant site in similar terrain and having similar exposure to the prevailing wind. Consequently, revisions to the site-specific forecasting guidelines were necessary during the study to tune the technique to the site. These revisions were not made unless the proposed revision was shown to perform (without failure) significantly better than the previous procedures for at least two occurrences of any problem weather pattern or wind event.

This section describes the procedures used in developing and revising the forecast guidelines for each of the three sites as well as the procedures used in issuing and verifying the S-0 wind forecasts.

\subsection{PROCEDURES FOR BLOCK ISLAND}

Block Island, Rhode Island (Figure 2-1) is located about $12 \mathrm{mi}$ off the eastern tip of Long Island and about $9 \mathrm{mi}$ south of the Rhode Island coast. The island, about $6 \mathrm{mi}$ north-south by $4 \mathrm{mi}$ east-west, slopes gradually upward 
$71^{\circ} 34.33^{\prime} \mathrm{W}$
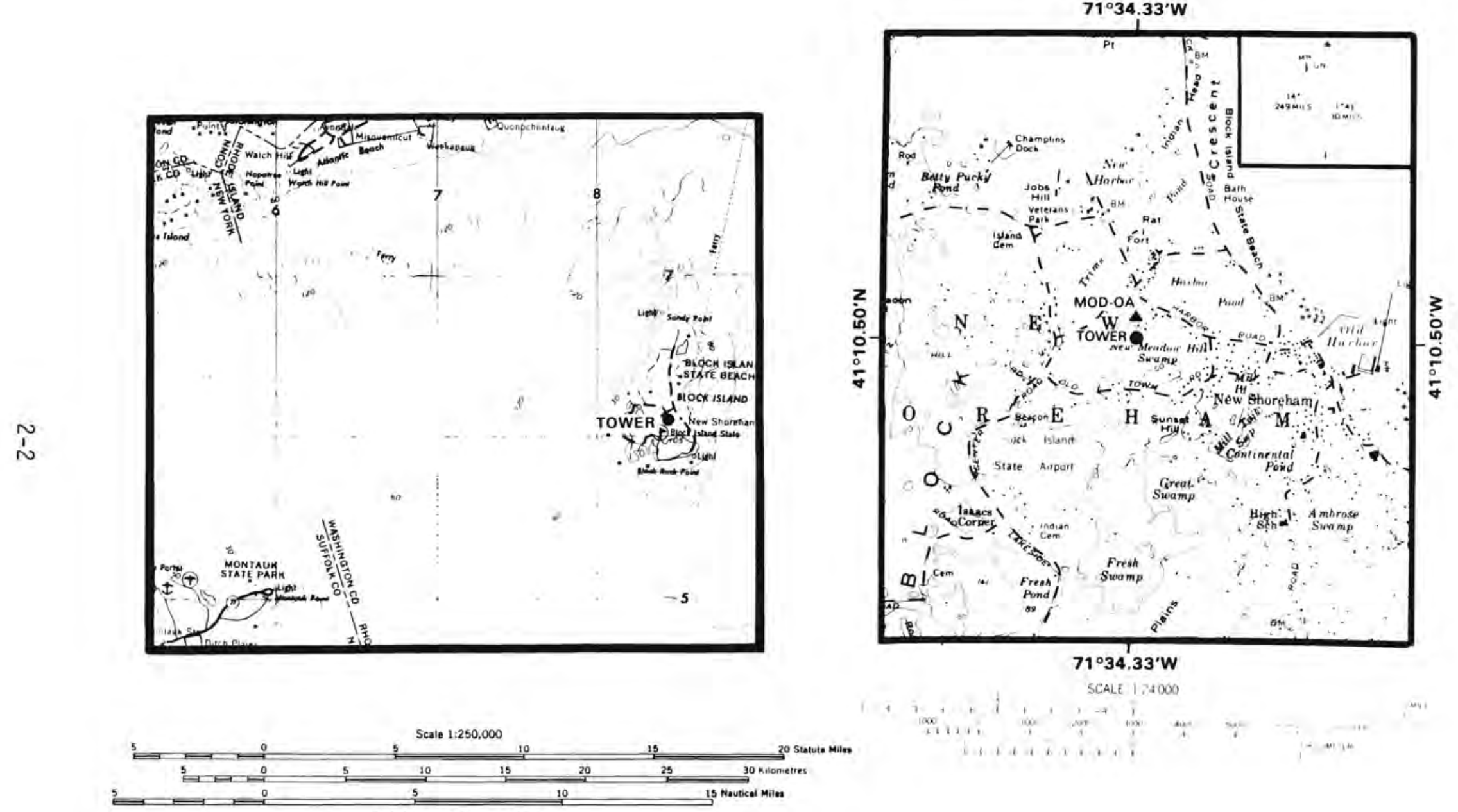

CONTOUR INTERVAL 100 FEET
WITH SUPPLEMENTARY CONTOURS AT 50 FOOT INTERVALS

TRANSVERSE MERCATOR PROJECTION 
to the south and terminates in cliffs of about $150 \mathrm{ft}$ on the southern shore. Maritime shrubs with a few domestic trees in the populated areas characterize the island's vegetation. Because many synoptic systems track through the Northeast, Block Island has two prevailing wind directions, one from the northwest and the other from the south-southwest. The diurnal wind pattern at Block Island (Figure 2-2) is the typical coastal diurnal wind pattern, characterized by afternoon maximum and morning minimum wind speeds.

The wind forecasting guidelines used for Block Island were those originally developed for Montauk Point, New York (see Appendix A). On March 10, 1982, these forecast guidelines were revised (see Appendix B). The revisions, necessary to "fine-tune" the Block Island site, incorporated effects of the difference in location and topography between Block Island and Montauk Point on wind characteristics. The new guidelines combined a description of the synoptic pattern, the pressure difference between two stations and probable wind speed and direction. The revisions made the guidelines more specific as well as easier to understand, interpret and utilize in making forecasts.

\subsection{PROCEDURES FOR FINLEY}

Finley Air Force Base, North Dakota, is located northwest of Fargo and southwest of Grand Forks in the Red River valley (Figure 2-3). The site is on a slightly elevated spot in basically flat terrain and there is less than $20 \mathrm{ft}$ of terrain relief within a $1-\mathrm{mi}$ radius of the site. Channeling by the river valley produces north-south prevailing wind directions and wind speeds with little diurnal variation (Figure 2-4). The vegetation in the area consists primarily of grass. A group of buildings located $1500 \mathrm{ft}$ east of the site is the only obstruction to airflow.

The wind forecasting guidelines used for Finley were those originally developed for Amari110, Texas (see Appendix A). On March 10, 1982, the guidelines for forecasting winds at Finley were revised (see Appendix $B$ ). Because of the great distance between Amarillo, where the guidelines were developed, and Finley, where they were used, the two sites come under 


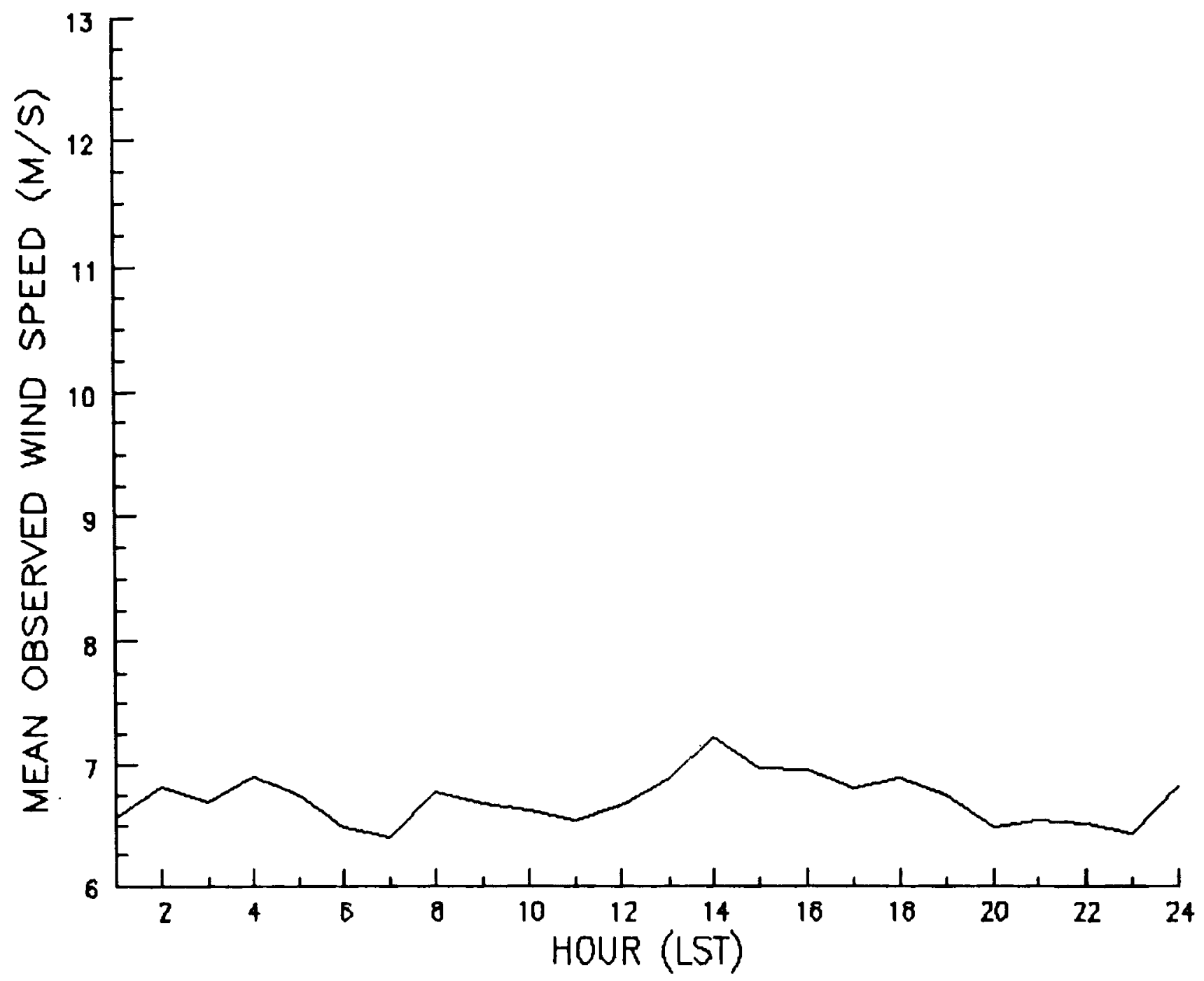

FIGURE 2-2. Observed Hourly Mean Wind Speeds for the Period February Through July 1982 at Block Island, Rhode Island (Hours are local standard time, LST) 


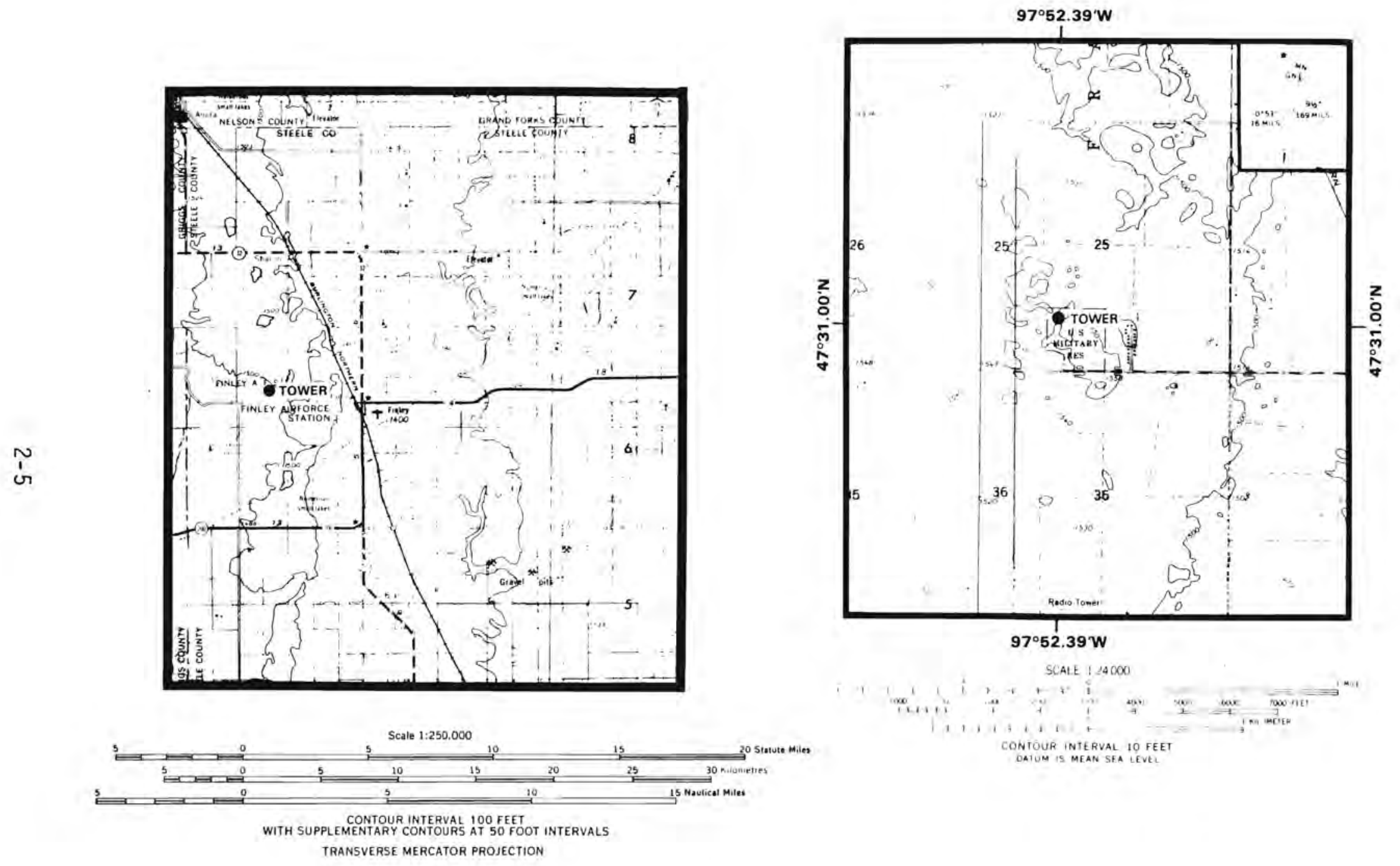

FIGURE 2-3. Finley Air Force Base, North Dakota Site Location 


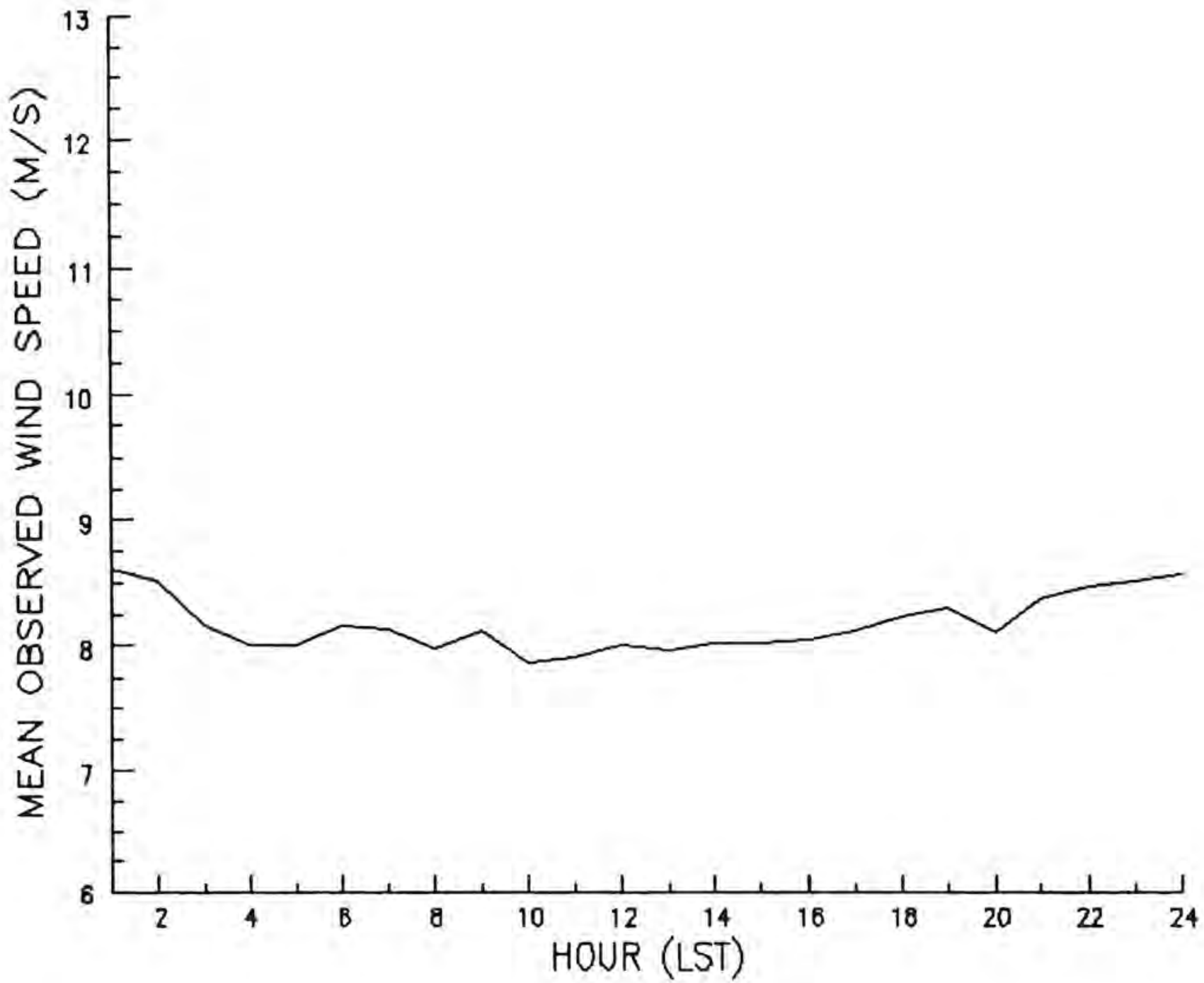

FIGURE 2-4. Observed Hourly Mean Wind Speeds for the Period February Through July 1982 at Finley AFB, North Dakota 
different influencing climatological factors: different storm systems following different tracks, and different pressure gradient-wind relationships. The original forecast guidelines were usefut in a general way, reflecting that wind directions in the central part of the United States are predominantly from the west and that high wind speeds aloft influence the wind speeds near the surface. The original rules developed for Amarillo state that the pressure gradient is not a useful tool; however, the analyses indicated that at Finley the surface pressure gradient was useful to forecast wind speed and direction. The hour-to-hour consistent wind patterns at Finley enabled the forecasters to have a high degree of confidence in their forecasts and this balanced the lack of specific guidelines.

\subsection{PROCEDURES FOR SAN GORGONIO}

The San Gorgonio Pass site (Figure 2-5) lies about $6 \mathrm{mi}$ east of the east-west running pass which is approximately $40 \mathrm{mi}$ east of Riverside, California, and northwest of Palm Springs. The pass, separating the San Jacinto Mountains to the south from the San Bernardino Mountains to the north, is at an elevation of $2600 \mathrm{ft}$ MSL while the site is at $1100 \mathrm{ft}$ MSL. This geography creates a funneling of the maritime air producing strong westerly winds. Figure 2-6 shows the very regular diurnal wind pattern. The weakest winds occur just before noon, increase to peak speed at midnight and then decrease once again. The land in the immediate vicinity of the site is relatively flat with a gentle slope to the southeast. The vegetation is native grass and salt brush. There are no trees in the area.

The wind forecasting guidelines used for San Gorgonio were those originally developed for that site (see Appendix A). On April 2, 1982, the guidelines were upgraded for forecasting winds at San Gorgonio (see Appendix B). Because there were no differences in location or topography to incorporate, forecasting guidelines were added rather than changed. Guidelines were added to account for a reversing pressure gradient between Los Angeles and Las Vegas and to add more detailed guidance for periods when the pressure at Las Vegas is greater than pressure at Los Angeles. Revised pressure gradient 

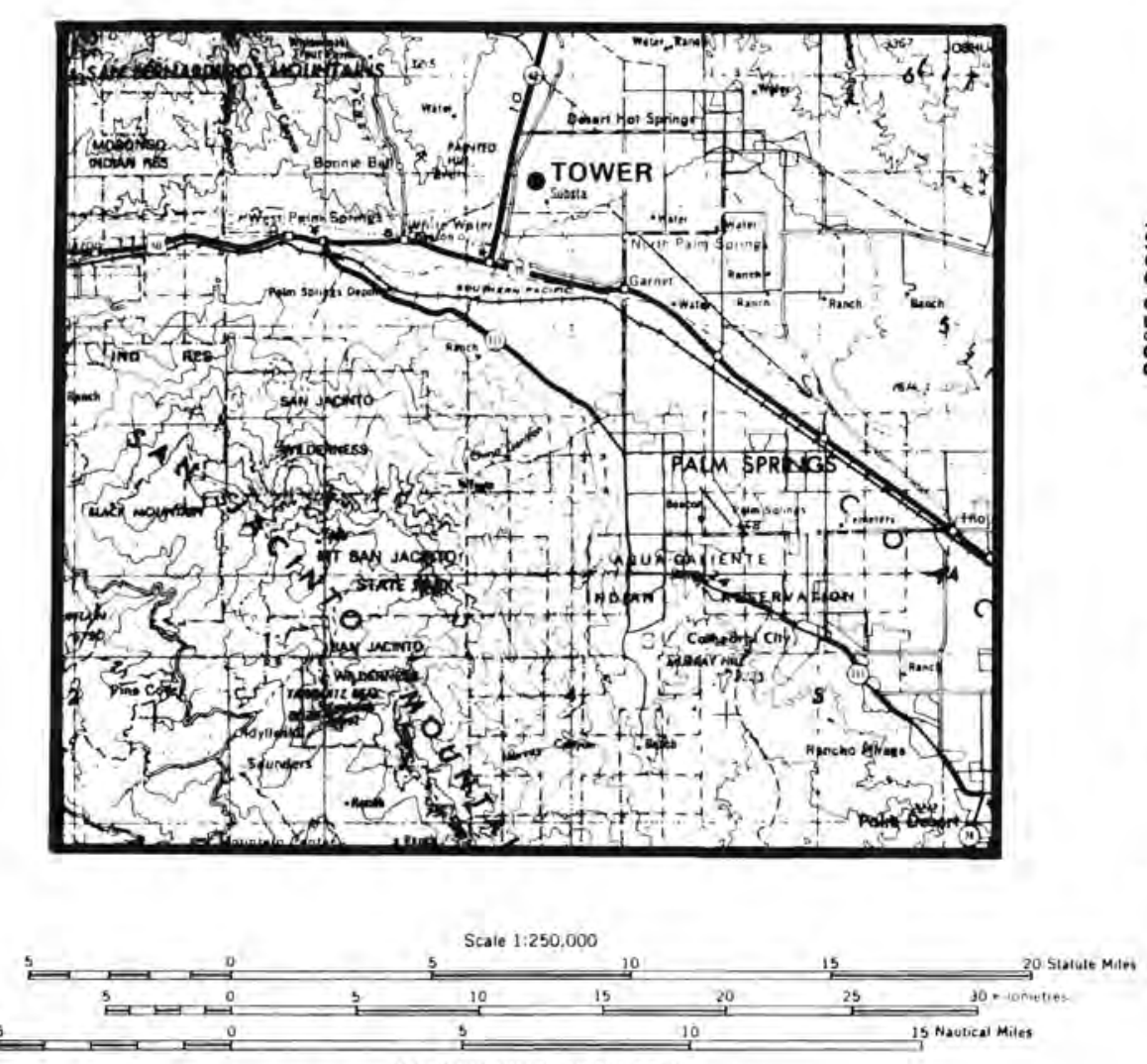

CONTOUR INTERVAL 100 FEET
WITH SUPPLEMENTARY CONTOUAS AT SO FOOT INTERVALS

TRANSVERSE MERCATOR PROJECTION $116^{\circ} 34.83^{\prime} \mathrm{W}$

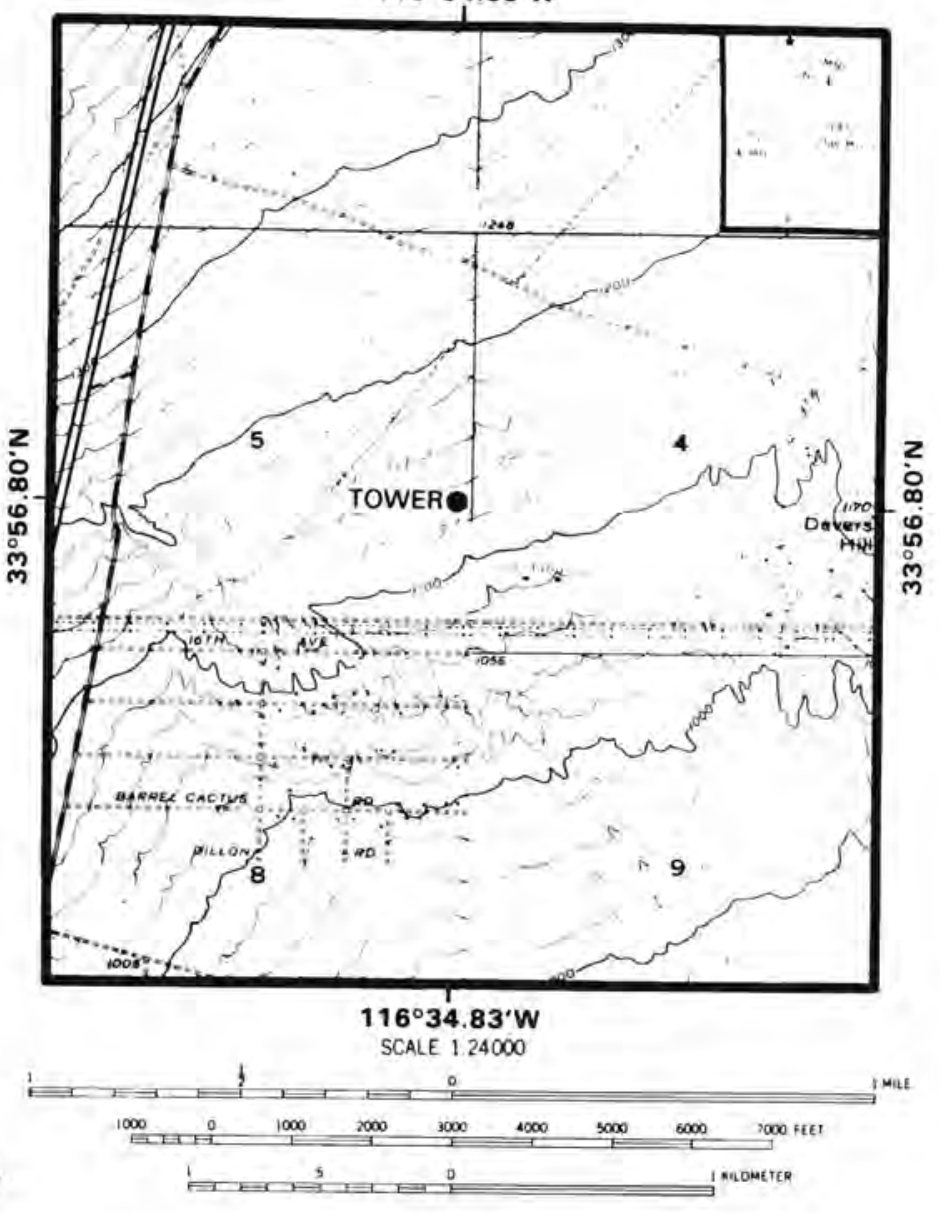

FIGURE 2-5. San Gorgonio Pass, California Site Location 


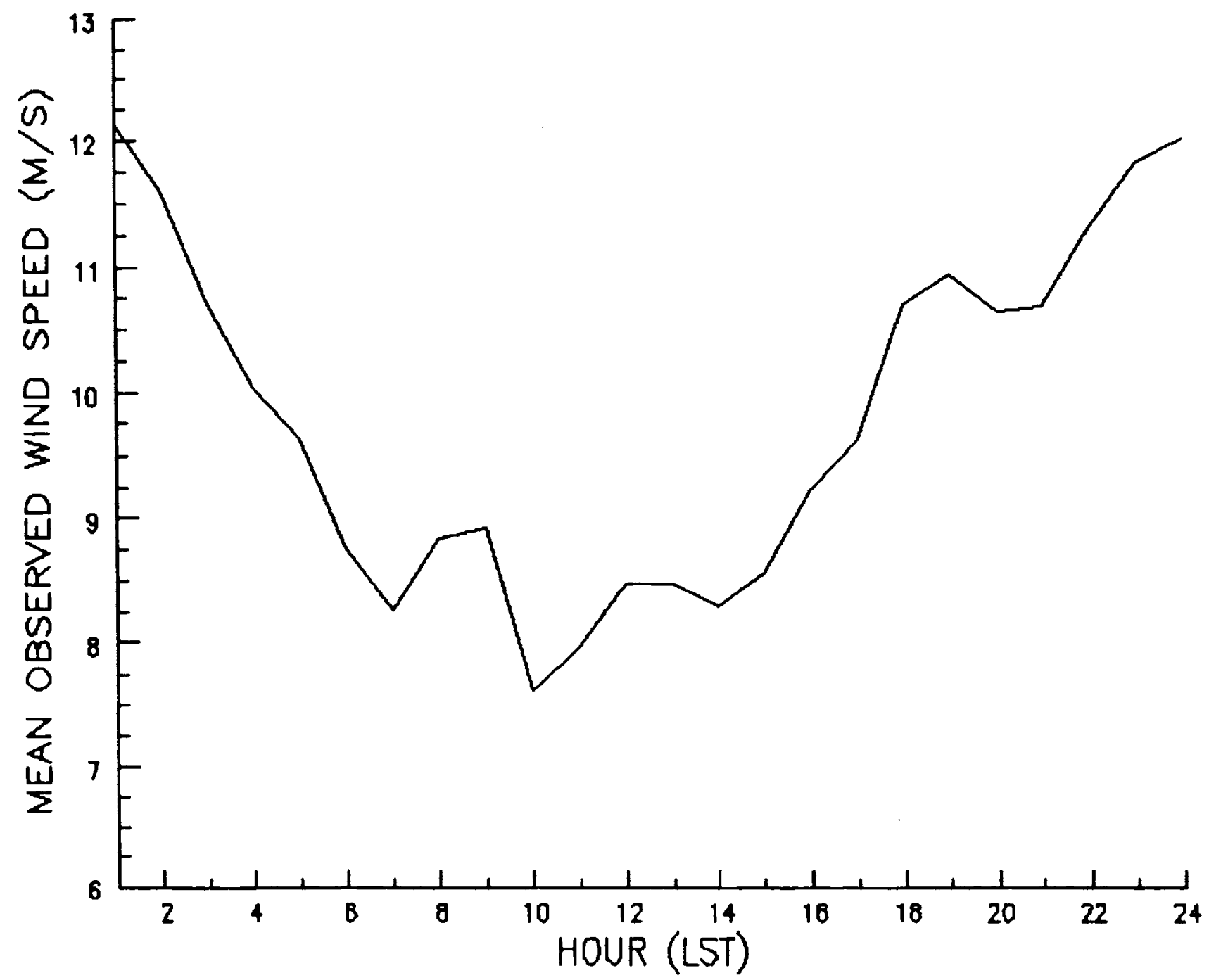

FIGURE 2-6. Observed Hourly Mean Wind Speeds for the Period February Through July 1982 at San Gorgonio Pass, California 
guidelines were specified using routinely reported pressure values from selected sites, rather than isobaric analyses, in order to remove some of the subjectivity involved in extracting predictors from the weather charts.

\subsection{PROCEDURES FOR ISSUING FORECASTS}

The wind forecasts included average hourly wind speed and direction for a 24-hr period following both 0600 and 1800 GMT for all three sites. Wind directions were forecast to the nearest 10 degrees and speeds to the nearest $0.5 \mathrm{~m} / \mathrm{s}$. These twice-daily forecasts were made for the $150-\mathrm{ft}$ level (for comparison, the hub height of a MOD-2 wind turbine is $200 \mathrm{ft}$ ).

The forecasting team consisted of 6 forecasters from the Hanford Meteorological Station located on the Hanford Reservation in southeastern Washington. The forecasters, who rotate 8 -hour shifts on a weekly basis, made both 0600 and 1800 GMT forecasts during the S-0 wind forecasting test period. The facilities available at the station to collect weather information include national teletype Services " $A$ " and " $C$ ", the weather facsimile or NAFAX, the Automation of Field Operations and Services (AFOS) system and the GOES weather satellite laser facsimile circuit. Service "A" provides hourly weather observations, while Service "C" provides the synoptic weather observations. Analyses and prognostic charts for the surface and upper-air and weather satellite pictures come over the NAFAX circuit. AFOS, a relatively new system, is capable of providing all of the aforementioned services with more comprehensive areal coverage except it cannot provide weather satellite pictures.

In addition, before preparing a forecast, the forecaster had access to current wind conditions (direction and speed data) at the site via a telephone-computer hookup (the dial-up). The use of the dial-up system enabled the forecaster to adjust the early portion of his forecast for current conditions. Due to various hardware/software problems, the use of the dialups was 1 imited to $96 \%$ of the time for Block Island, $82 \%$ for Finley, and $46 \%$ for San Gorgonio. (These values are based upon the available data set. For Block Island, the period of available data is from February through the early weeks 
of June; for Finley, from February through July; and for San Gorgonio, from February through Apri1.) The reason for the low dialup availability at San Gorgonio is that the installation of the dialup was not completed until the end of the first month of the study. Lack of the dialup system seemed to retard improvement of forecast accuracy at San Gorgonio since it delayed site tuning of the forecast procedure.

The forecasts were logged into a VAX 11/780 as soon after they were prepared as the forecaster's duties would allow via a computer-telephone link from the forecaster's silent 700 terminal (which has hard copy output). (Once logged, only the authors could gain access to the data.) For quality assurance, software was written to enable the computer to keep track of the time that each forecast was entered. Also, copies of the forecast and observation logs were sent to the authors accompanied by the actual hard copy of the dialup/forecaster interaction.

\subsection{PROCEDURES FOR PROVIDING FEEDBACK TO FORECASTERS}

Feedback to the forecaster was provided in two forms. First, the forecaster, via the dialup system, could retrieve the previous $30 \mathrm{hr}$ of data. This enabled the forecaster to review the previous day's forecasts and verifying observations while they were still fresh in his mind. These observations, logged into the computer in the same manner as the forecasts, were used to verify the S-0 wind forecasts and to perform a statistical error analysis, which provided the second form of feedback. Each week these forecasting error analyses, plus plots of forecast versus observed wind speed, were sent to the forecasters. From this information the forecasters could chart their accuracy, perform post-analysis of busted forecasts, and identify any systematic forecasting errors. From this information, guideline revisions were formed.

During the periods when the dialups were inoperative, no observed realtime data could be retrieved for forecast preparation or verification. When this occurred, the observations were obtained from data collected on cassette tapes at each site. However, these data sets became available only after the 
end of each month. Thus, using this data set delayed feedback to the forecasters for up to 4 weeks. The effect of this delay caused forecast errors to increase since the forecasters were unable to monitor their efforts (see Sections 3.2 and 3.3 ). 


\subsection{FORECASTING VERIFICATION}

Statistical analyses of S-0 forecast accuracy were computed both on a weekly and monthly basis. They were summarized by site alone; by site and forecast time (0600 or 1800 GMT); by forecaster, by site and by forecast time; and finally by site, by hour of day, and by forecast time. The last breakdown type was only computed monthly because weekly samples were too small to be meaningful. Wind direction forecasts, since they are deemed much less important than wind speed forecasts, were not analyzed at this time. Equations and definitions for the statistical measures used in this study and verification results for the three sites are given in the following sections.

\subsection{STATISTICAL MEASURES}

Statistical measures used in the weekly and monthly analyses provided to the forecasters were:

Mean Forecast Wind Speed

$$
\text { MFWS }=\frac{\left.\sum[\text { Forecast wind speeds (FWS })\right]}{\text { Sample size }}
$$

Mean Observed Wind Speed

$$
\text { MOWS }=\frac{\left.\sum[\text { observed wind speeds (OWS })\right]}{\text { Sample size }}
$$

Bias

$$
\text { BIAS = MFWS - MOWS }
$$

Mean Absolute Error

$$
\text { MAE }=\frac{\sum|F W S-O W S|}{\text { Sample Size }}
$$


Root Mean Square Error

$$
\text { RMSE }=\left[\frac{\sum \text { (FWS-OWS) }}{\text { Sample Size }}\right]^{0.5}
$$

Standard Deviation of FWS

$$
\text { SIGMAF }=\left\{\frac{\sum(\text { FWS })^{2}-\frac{\left[\sum(F W S)\right]^{2}}{\text { Sample Size }}}{\text { Sample Size }-1}\right\}^{0.5}
$$

Standard Deviation of OWS

$$
\text { SIGMAO }=\left\{\frac{\sum(\text { OWS })^{2}-\frac{\left[\sum(\text { ows })\right]^{2}}{\text { Sample Size }}}{\text { Sample Size }-1}\right\}^{0.5}
$$

Heidke Skill Score

This skill score is based upon the number of correct forecasts divided by the total number of forecasts tempered by the climatological occurrence of the event. (See Appendix C for a more detailed discussion.)

BIAS is a measure of the amount of over-prediction of wind speed (if the value is positive) or under-prediction of wind speed (if the value is negative). MAE and RMSE are standard methods used to describe accuracy. Standard deviations are measures of variability in the data; the greater the variability, the higher the standard deviation. SIGMAO tells how variable the observed wind speeds are. In addition, it provides information on how difficult it is to correctly forecast the wind speed (see Appendix E). A comparison of SIGMAF and SIGMAO shows in part how well the wind characteristics of the site are understood by the forecaster. Appendix D consists of a table showing the statistical analysis for the period of the study.

Because the passage of different synoptic systems with varying degrees of forecast difficulty creates an inherent amount of variability in the data, several schemes to normalize the errors were developed (see Appendix E). The 
scheme used in this report uses SIGMAO as a normalizer. SIGMAO, as described earlier, is a measure of the variability in the wind and as such is used to predict the difficulty associated with correctly forecasting the wind speed. This new statistical measure is

\section{Normal ized Root Mean Square Error}

$$
\text { NRMSE }=\frac{\text { RMSE }}{\text { SIGMAO }}
$$

\subsection{VERIFICATION RESULTS FOR BLOCK ISLAND}

The initial trend in the learning curve for Block Island (Figure 3-1) is as expected. The normalized RMSE decreases through April but then increases thereafter. The relative increase in error during May is due to a decrease in forecast difficulty (SIGMAO) that was not accompanied by an improvement in forecasting accuracy (decrease in RMSE). The week-to-week feedback the forecasters received for Block Island during April was limited to only the first week. Consequently, the improvement in the forecasts did not parallel the difficulty of making the forecasts. Figure 3-1 does indicate that learning occurred at Block Island since the period March through April showed that forecasting the winds became more difficult (increasing SIGMAO) but the forecasting errors decreased. After the guideline revisions on March 10, 1982, forecast accuracy improved. This provides further evidence of learning. Since the guidelines were now station specific, the total time spent on making the forecasts decreased.

It is usually easier to make a forecast for the next few hours then it is to project 12 or 24 hours into the future. Therefore, it is expected that forecast accuracy will decrease with increasing forecast projection time. In Figure 3-2 this is shown to hold true for the 1800 GMT forecast time up to the eighteenth projection hour. After that, the error decreases. For the 0600 GMT forecast time period, errors increase with projection time for the first 4 hours then decrease for the next 9 hours and then once again begin to increase with the projection hour. For both forecast periods, these periods 

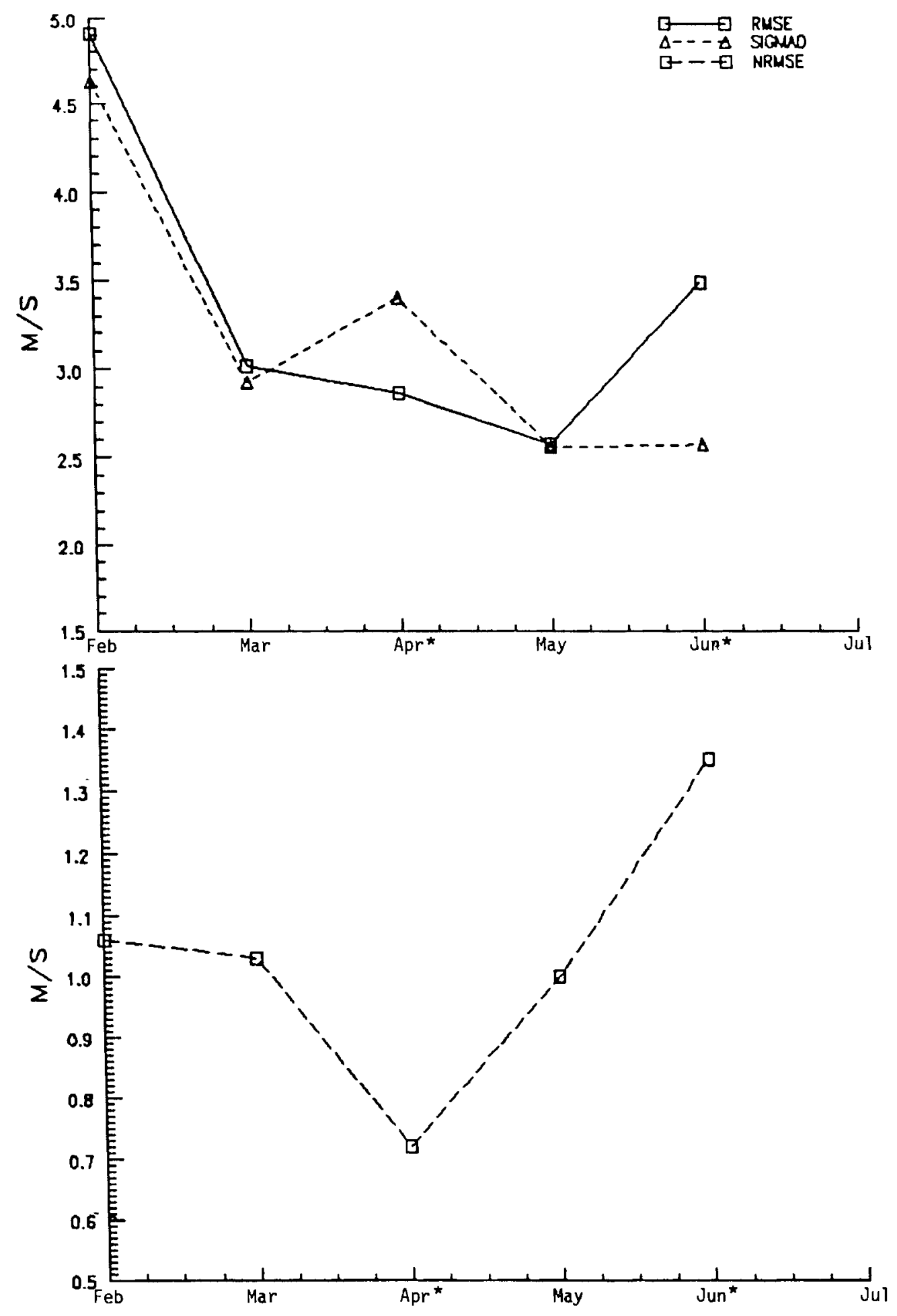

*The sample size was significantly smaller.

FIGURE 3-1. Wind Forecasting Skili Patterns at Block Island 
$\omega$
1
$c$

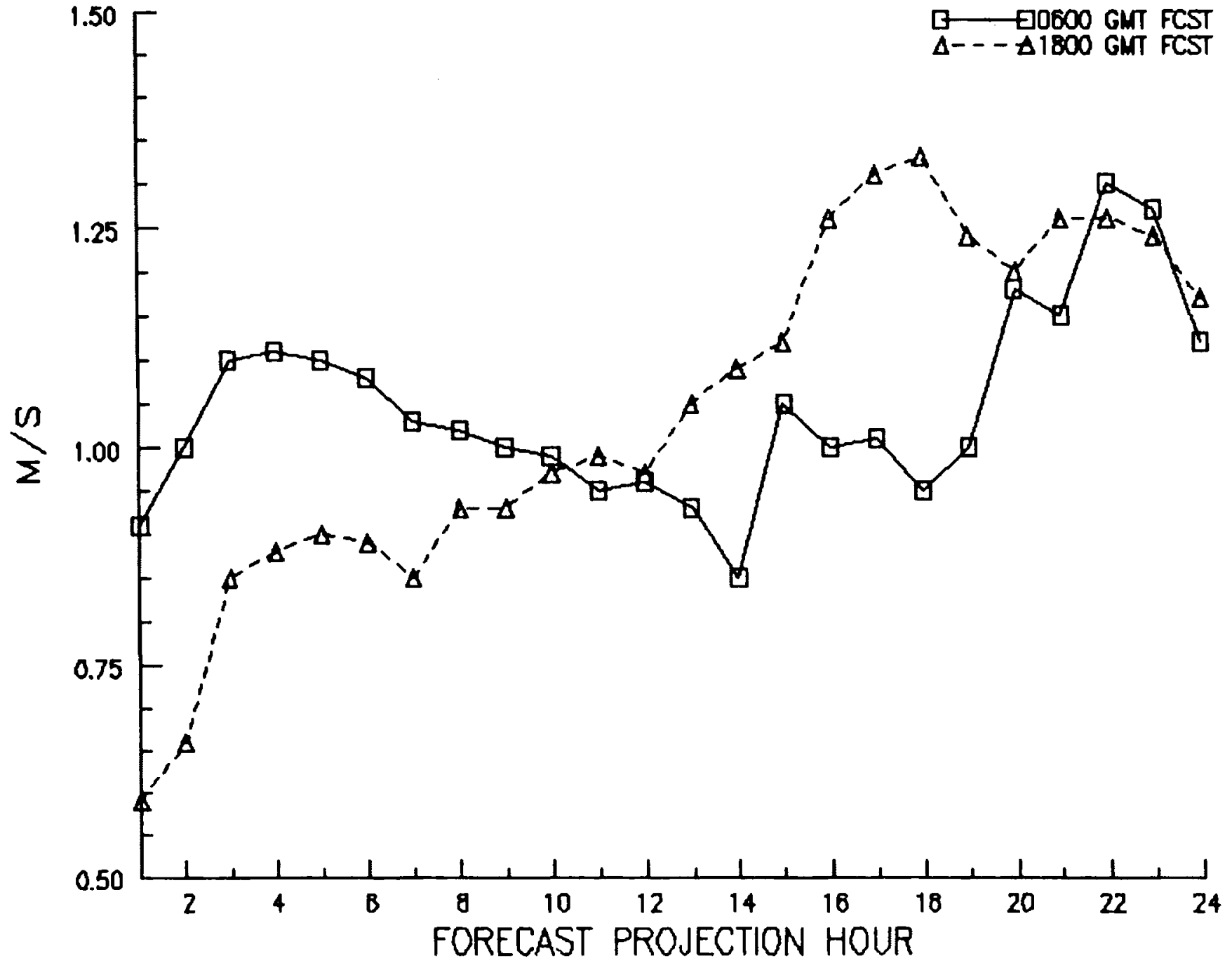

FIGURE 3-2. Normalized Root Mean Square Error as a Function of Forecast Projection Hour at Block Island 
of decreasing error, when replotted according to local standard time (Figure 3-3), coincide with the morning wind speed minima shown in

Figure 2-2. Apparently the land-sea breeze circulation plays an important role in creating this diurnality in forecasting accuracy. The land-sea breeze circulation is a phenomenon associated with coastal sites where the effect of differential heating and cooling of the land and sea produces the sea breeze (from sea to land) during the day and the land breeze at night. During the spring and summer, knowledge of the diurnal land-sea breeze circulation became important. The lower wind speed during the early morning could be relied upon, thereby improving forecast accuracy during the early morning hours.

\subsection{VERIFICATION RESULTS FOR FINLEY}

Figure 3-4 shows the learning curve for Finley and the variability in the observed winds - a measure of the difficulty in forecasting wind events. During February 1982 a stationary high pressure system remained over the area. This uniform pattern led to persistent winds which in turn increased forecast accuracy and caused the errors to be much lower than expected at the beginning of the study. The normalized RMSE at Finley decreased through April as it did at Block Island. During May no data were available to verify the forecasts, and in June there were only limited data, so the amount of forecast errors increased. Without continual feedback as a monitor, the forecasters began to underpredict the wind speed (Figure 3-5). During July the forecasts improved in accuracy even with a trend of increasing forecast difficulty. After the guideline revisions on March 10, 1982, forecast accuracy improved.

Forecast errors for Finley show some evidence of a diurnal trend (Figure 3-6). During the afternoon the errors seem to be at their lowest, and between 1600 and 1700 hours there is a small increase in error for both of the daily forecasts. In Figure 3-7, which shows forecast errors as a function of projection time, several patterns become evident: 


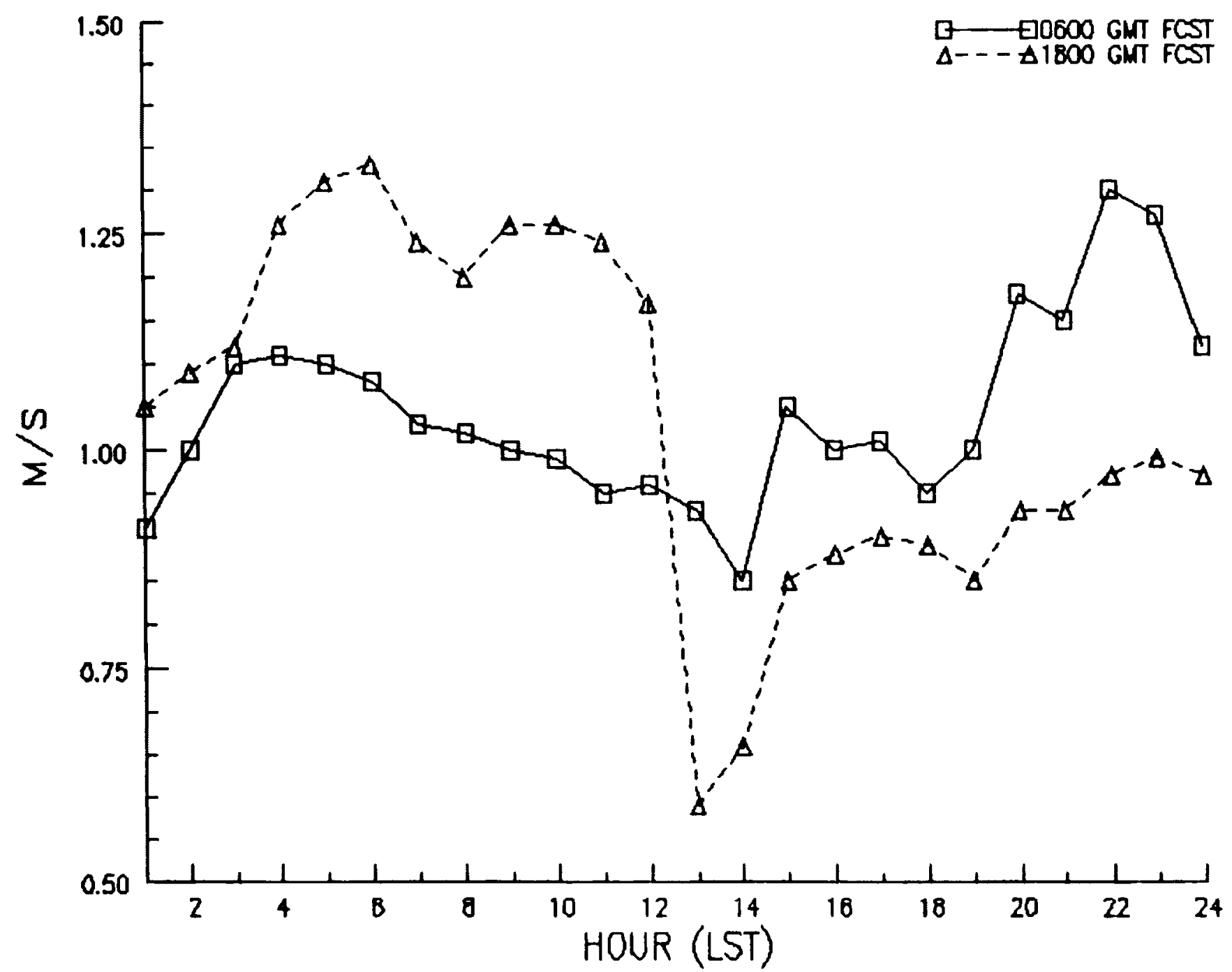

FIGURE 3-3. Normalized Root Mean Square Error as a Function of Local Standard Time at Block Island 

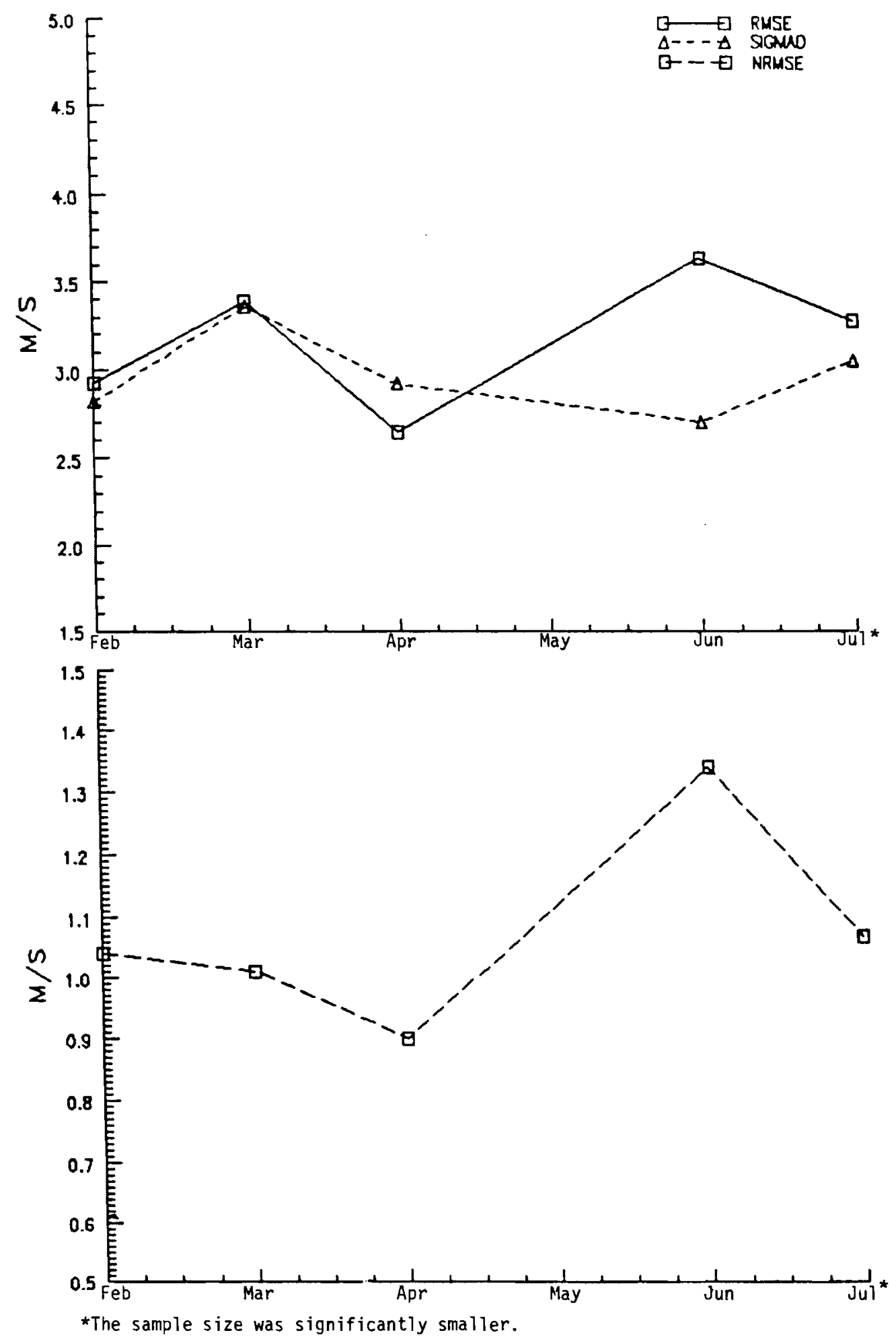

FIGURE 3-4. Wind Forecasting Skill Patterns at Finley AFB 
$\omega$
$b$

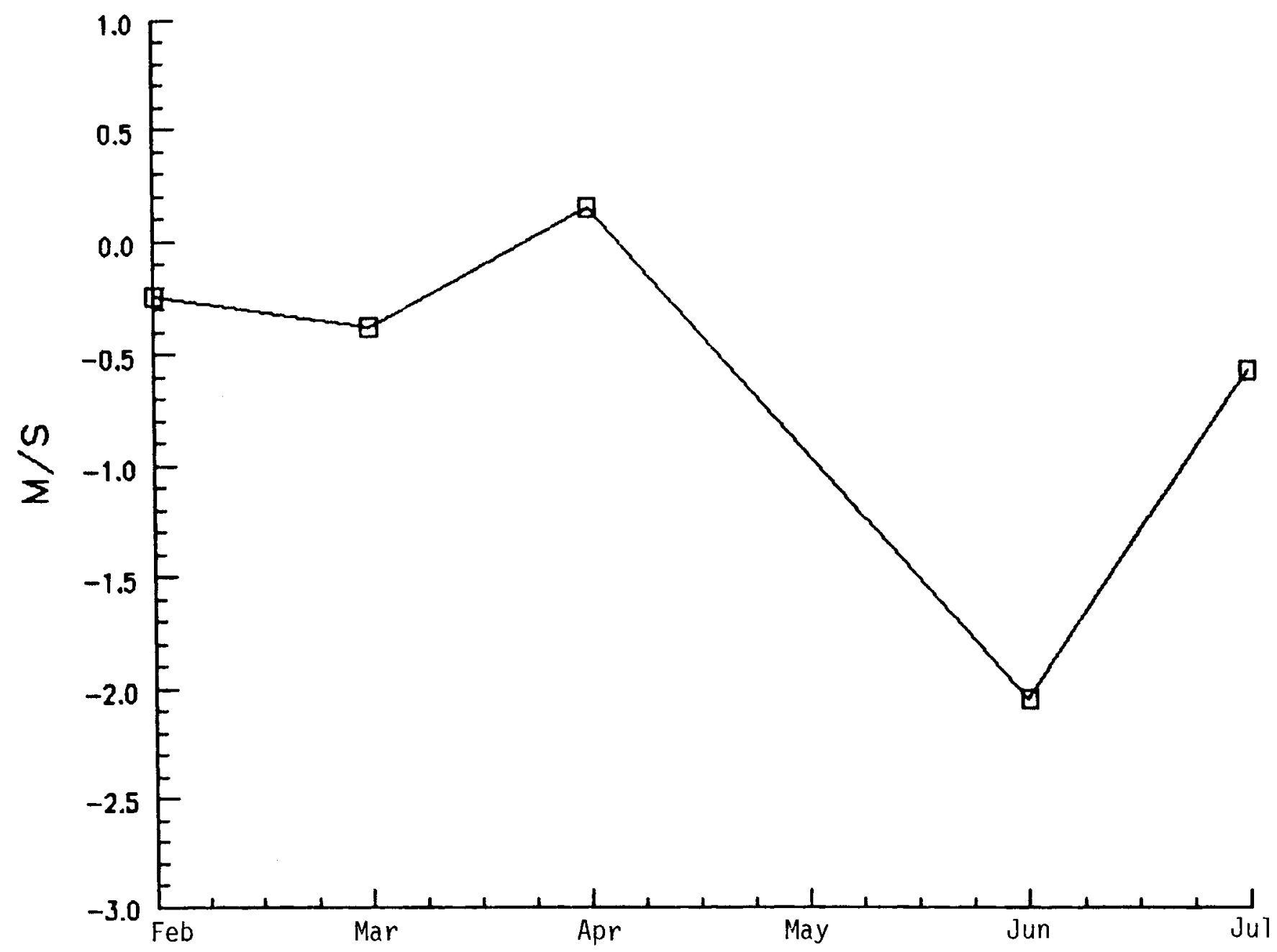

FIGURE 3-5. Forecast Bias Measured at Finley 


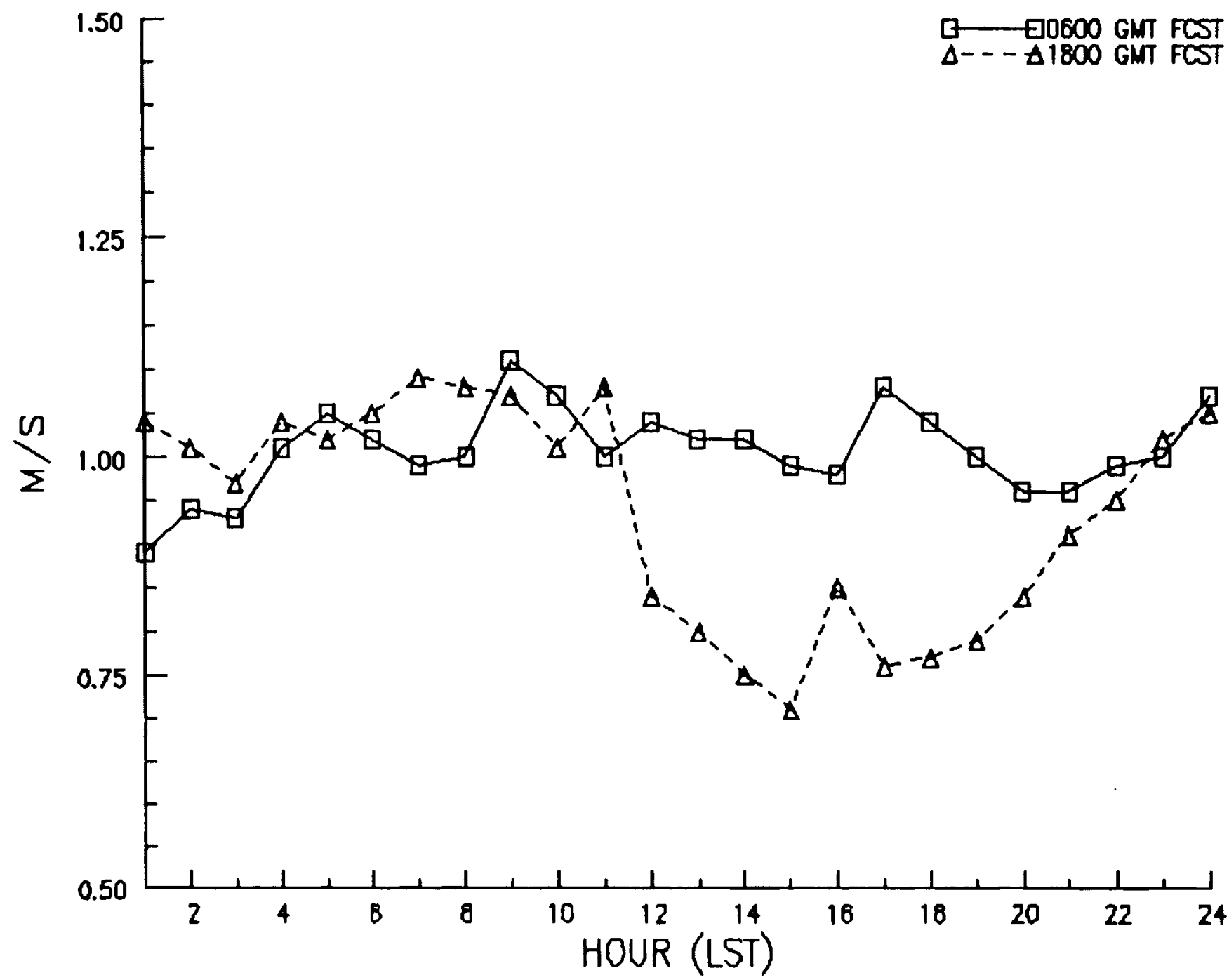

FIGURE 3-6. Normalized Root Mean Square Error as a Function of Local Standard Time at Finley AFB 


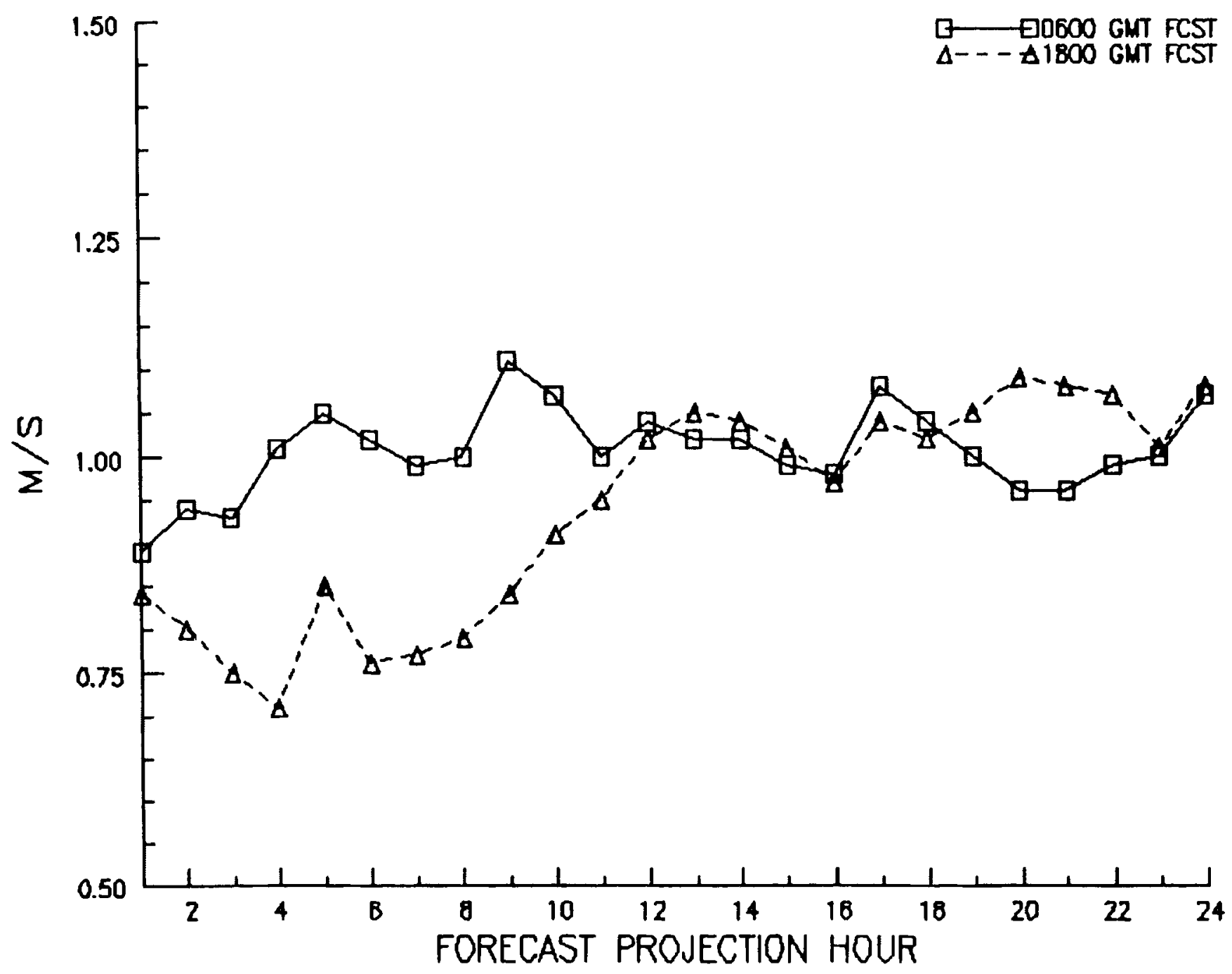

FIGURE 3-7. Normalized Root Mean Square Error as a Function of Forecast Projection Hour at Finley AFB 
- The overall errors increase slightly with time for the 1800 GMT forecast but remain fairly constant for the 0600 GMT forecast.

- There is little difference in errors as a function of projection time between the two daily forecasts especially past the twelfth projection hour.

- Forecast errors are slightly larger for the 0600 GMT forecast.

The first pattern is expected. Since there is no distinct diurnal wind speed pattern at Finley, forecast accuracy is relatively constant. The second pattern emphasizes the minimal wind speed diurnality at this site. The third pattern is attributable to the fact that the forecasters were more pressed for time (due to other shift duties) when issuing the 0600 GMT forecast.

\subsection{VERIFICATION RESULTS FOR SAN GORGONIO}

At San Gorgonio, forecast difficulty increased over the period of study, but the errors showed a continual decrease, evidence that learning did occur (Figure 3-8). After forecasting guideline revisions were incorporated on April 2, 1982, the forecasting accuracy improved. Although there is a diurnal trend in the wind speeds here, the high hour-to-hour variability causes large errors in the speed forecasts. Figure 3-9 shows examples of forecast and observed wind speeds. The forecasts follow the general patterns of the observed wind speeds but miss the embedded variability.

Figure 3-10 shows a plot of forecasting error versus projection hour, and Figure 3-11 shows error versus local standard time. There is a diurnal trend in the errors made at this site shown by maximums in error during the pre-dawn hours. This holds true even for the 0600 GMT forecast time when the peak error occurs between the fifth and seventh projection hour, and then falls off for the next few hours. The difficulty in forecasting from midnight to 9 or $10 \mathrm{a} . \mathrm{m}$. can be attributed to the site location in a mountain pass and its proximity to the sea. At night the wind flow is downslope and down the valley. This mountain-valley effect combined with the land-sea breeze creates a funneling of the wind through the pass. Each of these phenomena can be overcome by winds produced from a larger scale weather 

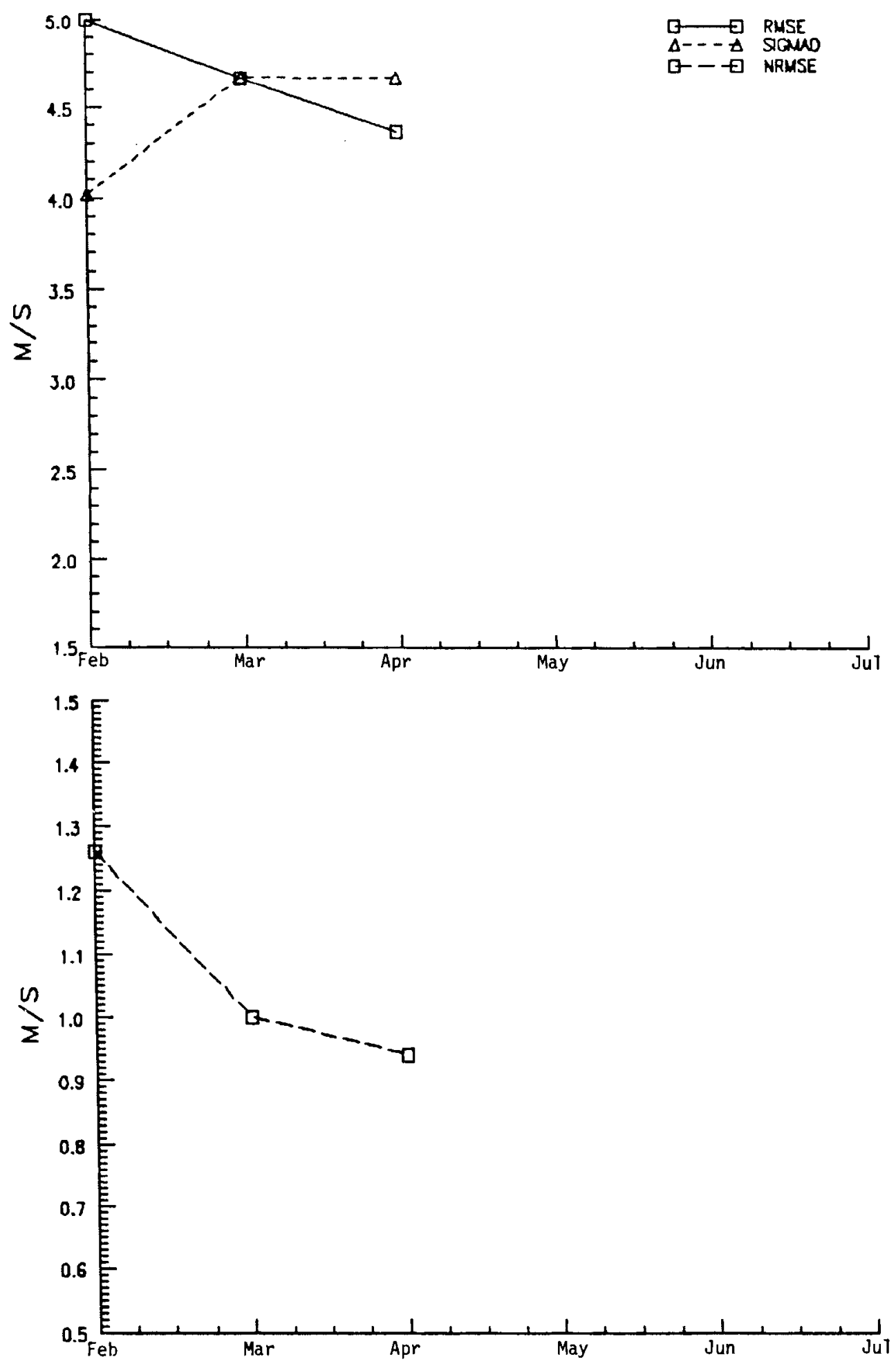

FIGURE 3-8. Wind Forecasting Ski11 Patterns at San Gorgonio Pass 


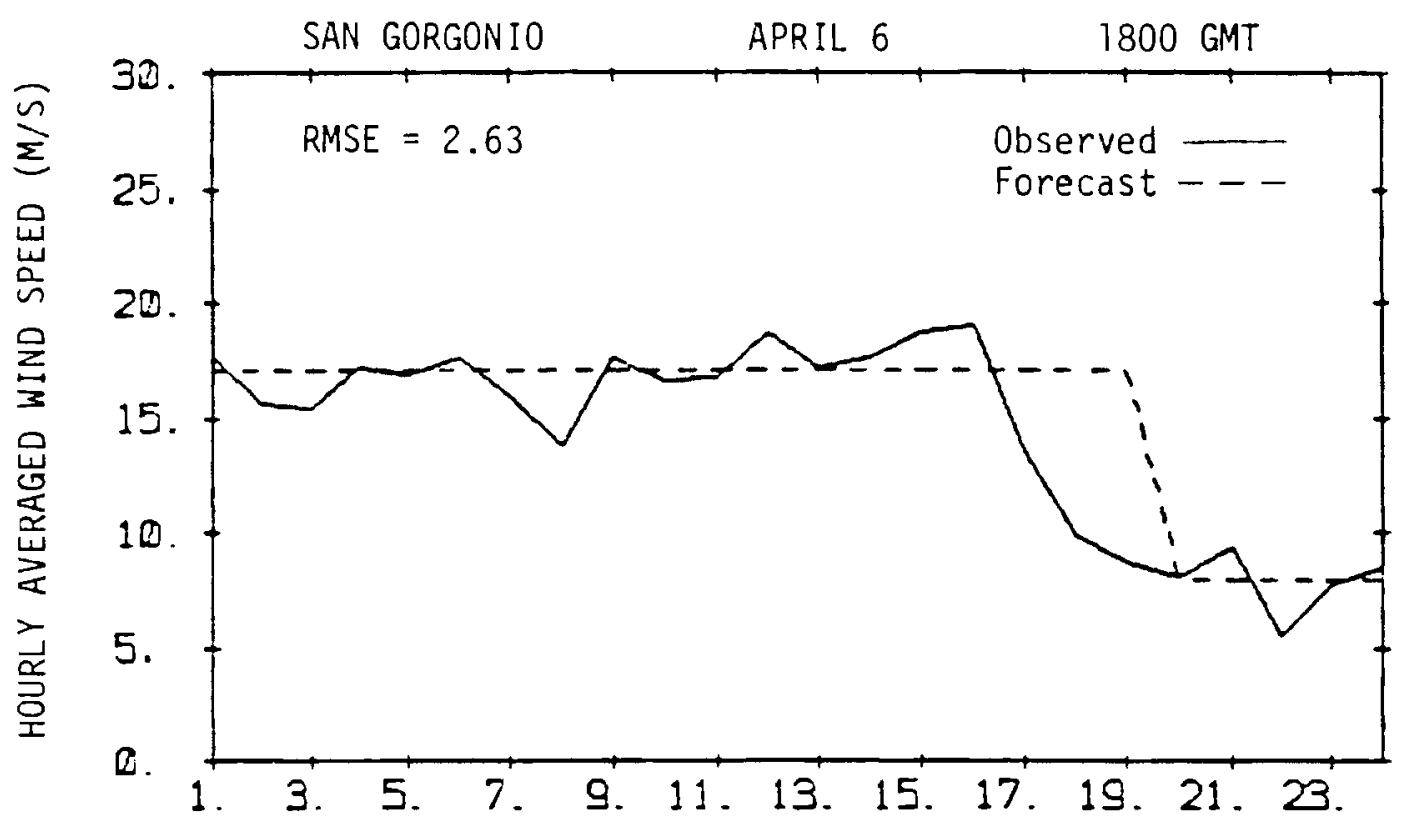

FORECAST PROJECTION (HR)

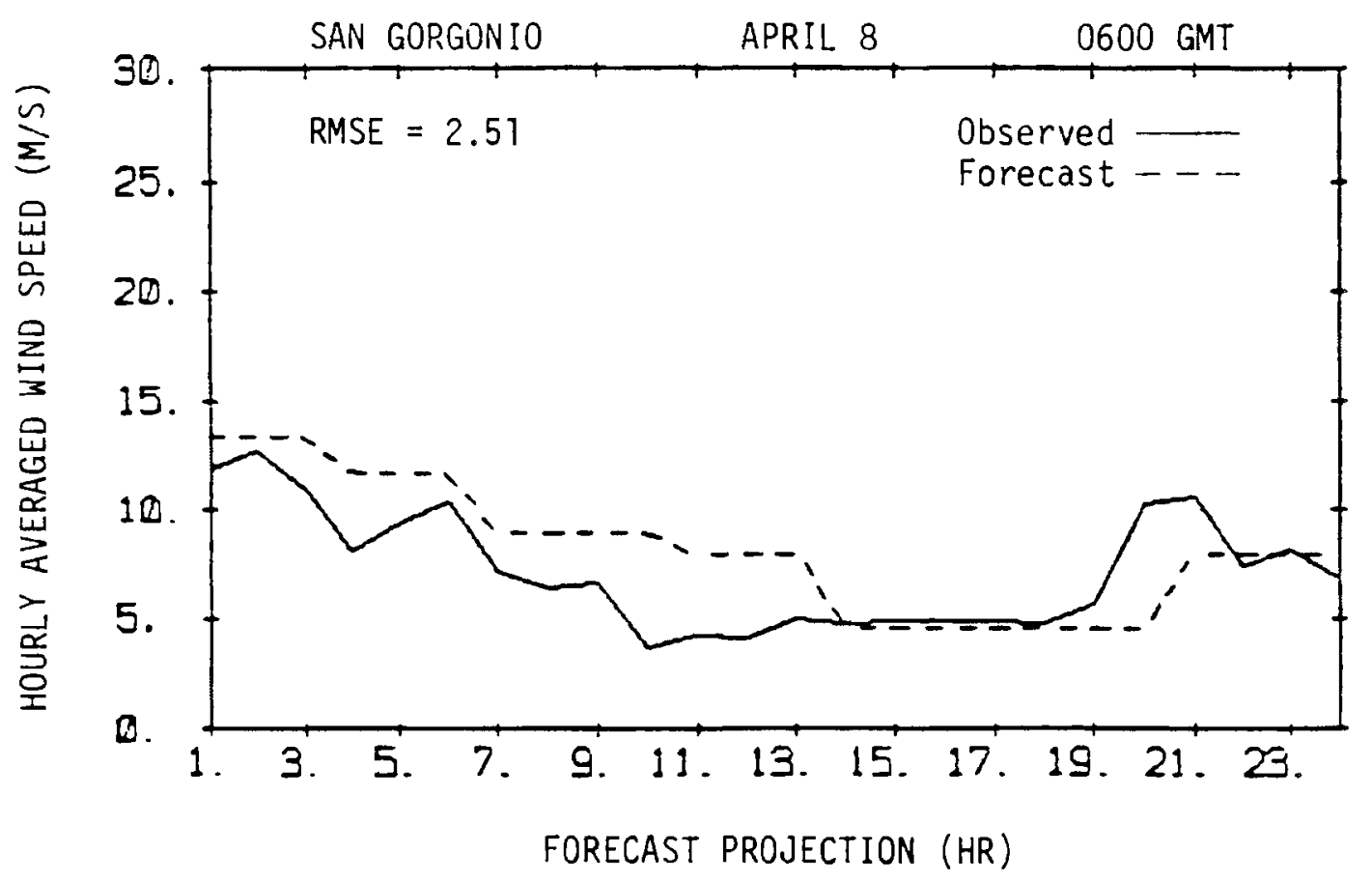

FIGURE 3-9. Example Plots of Observed and Forecast Hourly Averaged Wind Speed Depicting Hour-to-Hour Variability in the Observed Wind Speeds at San Gorgonio Pass, California 


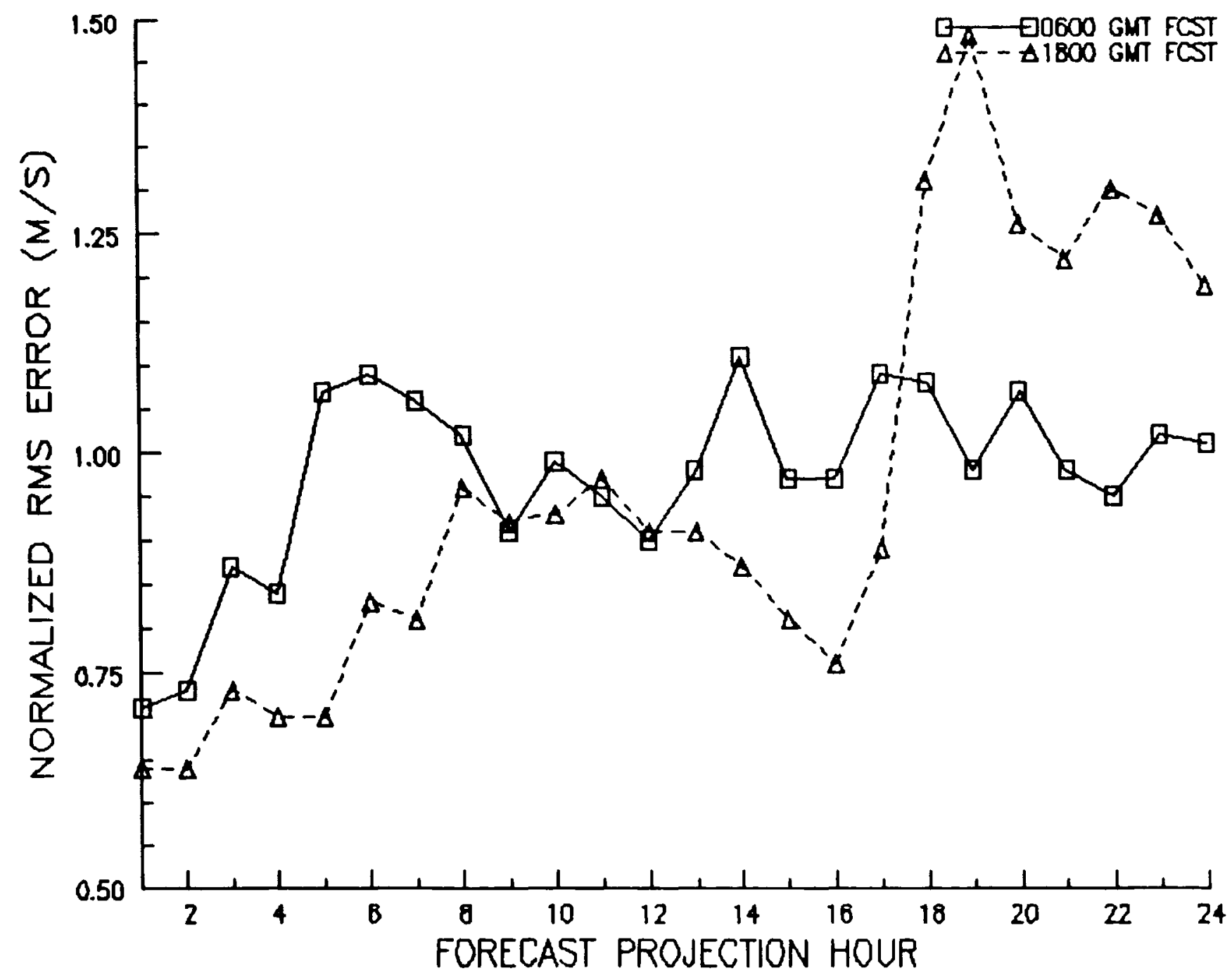

FIGURE 3-10. Normalized Root Mean Square Error as a Function of Forecast Projection Hour at San Gorgonio Pass 


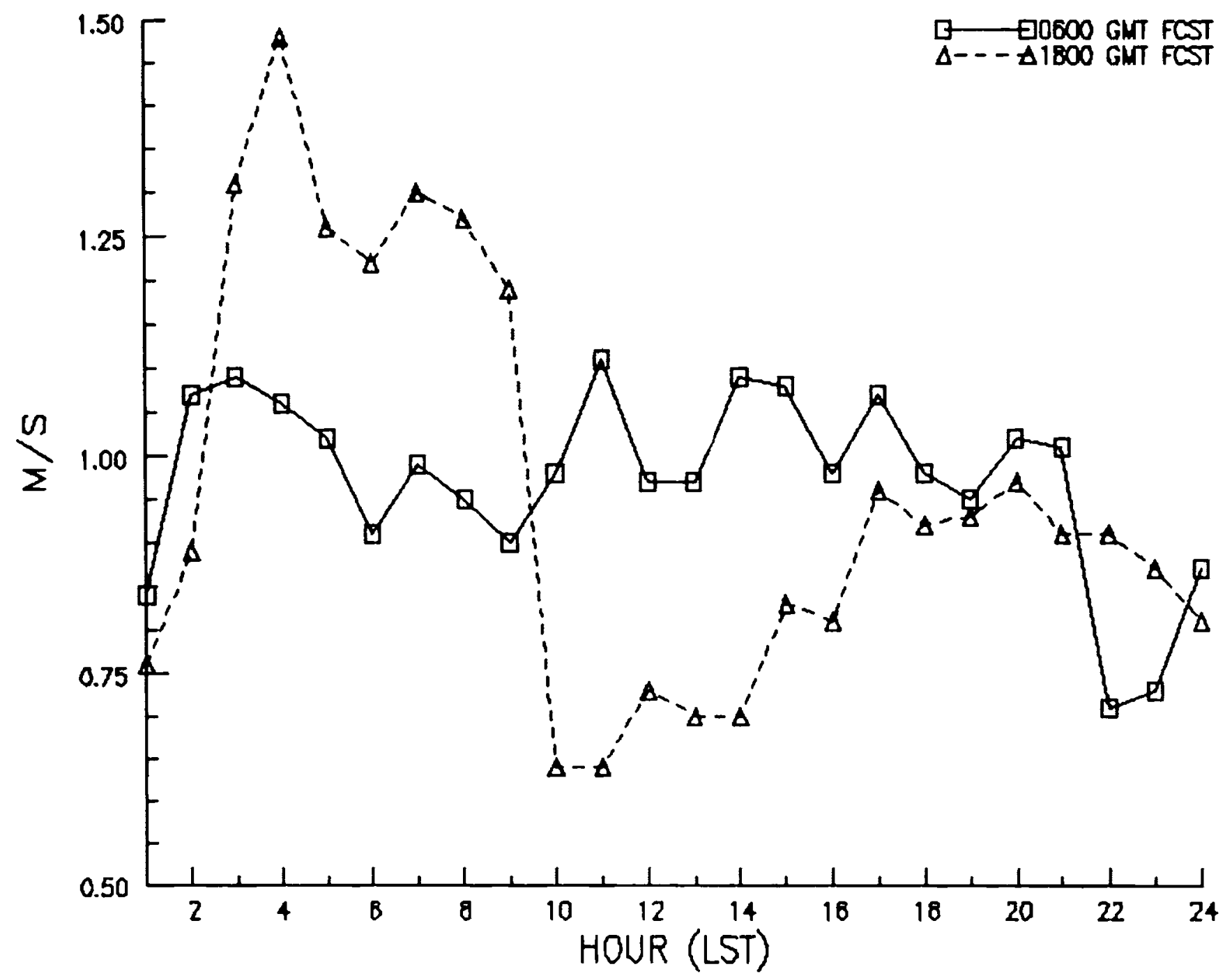

FIGURE 3-11. Normalized Root Mean Square Error as a Function of Loca 1 Standard Time at San Gorgonio Pass 
system. This can cause difficulty in forecasting the winds accurately since it is very easy to mistime or miss this effect entirely.

\subsection{VERIFICATION RESULTS WITH AND WITHOUT REAL-TIME FEEDBACK}

A problem with the subjective forecasts produced in the initial wind forecasting effort (described in Section 4.1) appeared to be the lack of real-time feedback. Wegley (1982) has determined that knowledge of the current site winds is useful at least 6 hours into the forecast period. As part of the study the authors wished to investigate the effect on forecast accuracy when real-time feedback was present. Dialup usage was monitored so that its value could be analyzed. Table 3-1 shows the effect dialup availability had on forecast accuracy. Note the disparity in Table 3-1 between the sample sizes "with dial-up" and "without dial-up". The differences in sample sizes mean that different numbers and types of synoptic situations as well as the work of different forecasters are represented in the sample. The various synoptic situations are associated with different degrees of forecasting difficulty (as illustrated in the table by different SIGMAOs). Furthermore, the skill levels of the forecasters vary (as shown in Table 3-2). Consequently, it is not possible to accurately separate these affects on forecasting accuracy from those attributable solely to the availability of the dial-up feedback. 
TABLE 3-1. Examples of the Effect of Dial-Up Usage on Forecast Accuracy

Finley for 0600 During March

\begin{tabular}{|c|c|c|c|c|c|}
\hline \multicolumn{3}{|c|}{ With Dial-Up } & \multicolumn{3}{|c|}{ Without Dial-Up } \\
\hline RMSE & SIGMAO & $\begin{array}{l}\text { Sample } \\
\text { Size }\end{array}$ & RMSE & SIGMAO & $\begin{array}{c}\text { Sample } \\
\text { Size }\end{array}$ \\
\hline $\begin{array}{l}1.84 \\
1.83 \\
2.04\end{array}$ & $\begin{array}{l}2.77 \\
2.39 \\
2.47\end{array}$ & $\begin{array}{l}27 \\
27 \\
26\end{array}$ & $\begin{array}{l}3.35 \\
3.34 \\
4.41\end{array}$ & $\begin{array}{l}8.94 \\
9.00 \\
7.90\end{array}$ & $\begin{array}{l}4 \\
4 \\
4\end{array}$ \\
\hline
\end{tabular}

San Gorgonio for 0600 GMT During March

$\begin{array}{llllll}4.11 & 4.58 & 16 & 2.64 & 5.71 & 7 \\ 4.91 & 5.55 & 15 & 2.87 & 5.22 & 7 \\ 5.78 & 5.49 & 16 & 3.15 & 4.94 & 7\end{array}$

TABLE 3-2. Heidke Skill Scores for the Forecasters

\begin{tabular}{|c|c|c|}
\hline Forecaster & $\begin{array}{l}\text { Skill } \\
\text { Score }\end{array}$ & $\begin{array}{c}\text { Sample } \\
\text { Size }\end{array}$ \\
\hline 1 & 0.025 & 436 \\
\hline 2 & 0.189 & 2283 \\
\hline 3 & 0.154 & 2003 \\
\hline 4 & 0.184 & 1687 \\
\hline 5 & 0.201 & 2348 \\
\hline 6 & 0.195 & 2172 \\
\hline
\end{tabular}




\subsection{FORECAST COMPARISONS}

Three basic approaches have been examined for producing wind forecasts for wind energy applications: subjective forecasts, model output statistics and a recently developed semi-objective approach. This section compares the development and verification of these three approaches to 24-hr wind forecasting for wind turbine generator (WTG) operations.

\subsection{SUBJECTIVE FORECASTS}

In April 1979, PNL initiated a wind-forecasting project in which 24-hr forecasts were produced by several weather consultants for the eleven DOE candidate WTG sites shown in Figure 4-1. The purpose of this project was to provide a data base for evaluating the reliability and accuracy of subjective wind forecasts for use in WTG operations.

The subjective wind forecasts were produced once daily, at or before 1800 GMT; they included forecasts of hourly average wind speed and direction at the 150-ft level for the 24 hours following 1800 GMT.

\subsection{DEVELOPMENT OF MODEL OUTPUT STATISTICS FORECASTS}

Contemporaneous to the subjective forecasting, deterministic model output statistics (MOS) forecasts were developed by the Techniques Development Laboratory of the National Weather Service for the sites shown in Figure 4-2. As described by Gilhousen (1980), stepwise screening regression (Glahn and Lowry 1972) was performed on output of the Limited Area Fine Mesh (LFM) atmospheric model (Gerrity 1977) to produce forecasting equations for each site and projection time. To avoid excessive computation time as well as the necessity of modifying existing computer codes and to still preserve error trends with time, seven forecast projection times were selected: +9, $+12,+15,+18,+21,+24$ and +30 hours from both 0000 GMT and 1200 GMT.

A set of MOS "primary" forecasting equations were developed in which the observed wind speed at +3 hours from data collection time (i.e., at 0300 and 


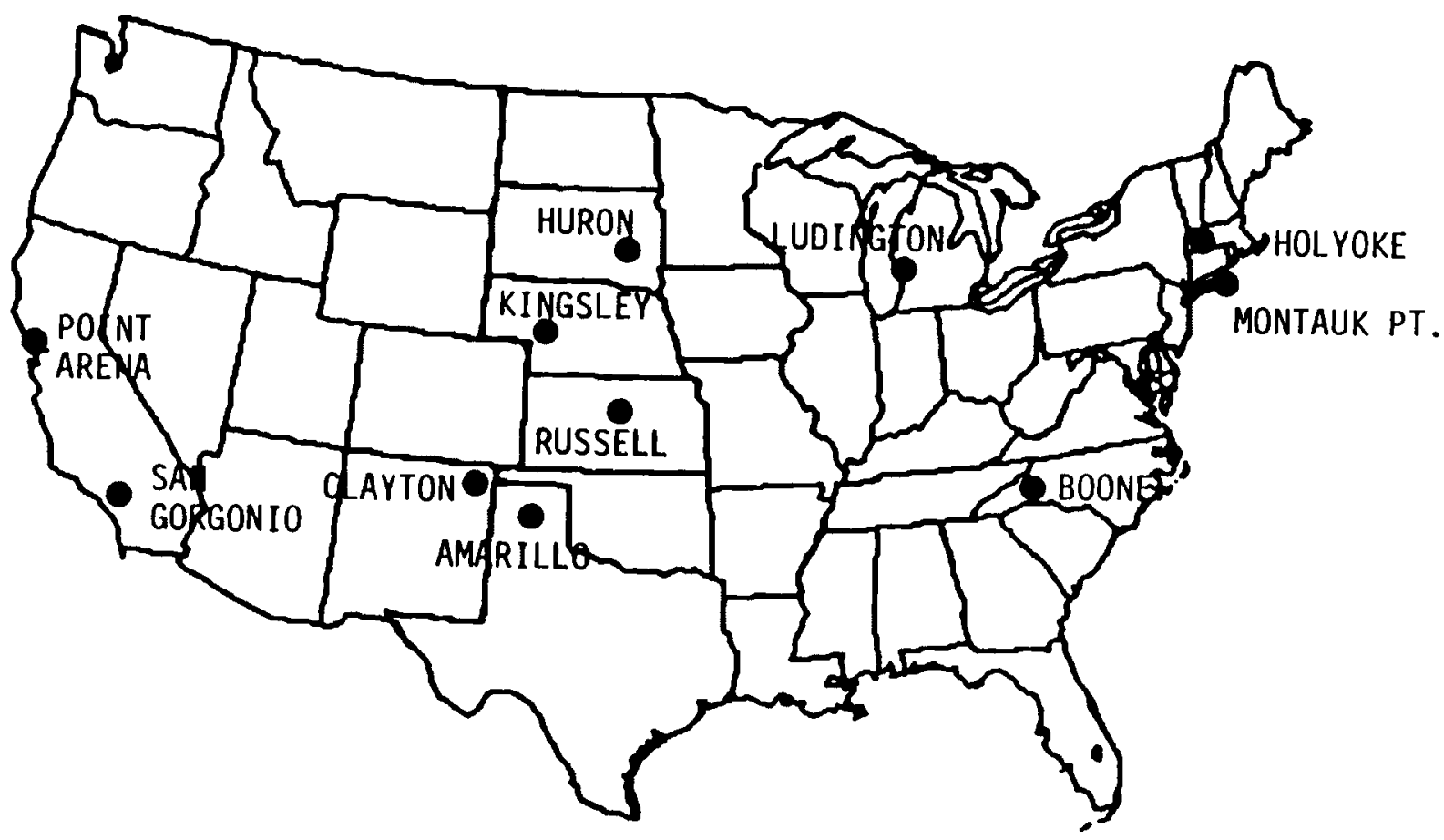

FIGURE 4-1. Eleven Sites for Which Subjective Wind Forecasts Were Produced 


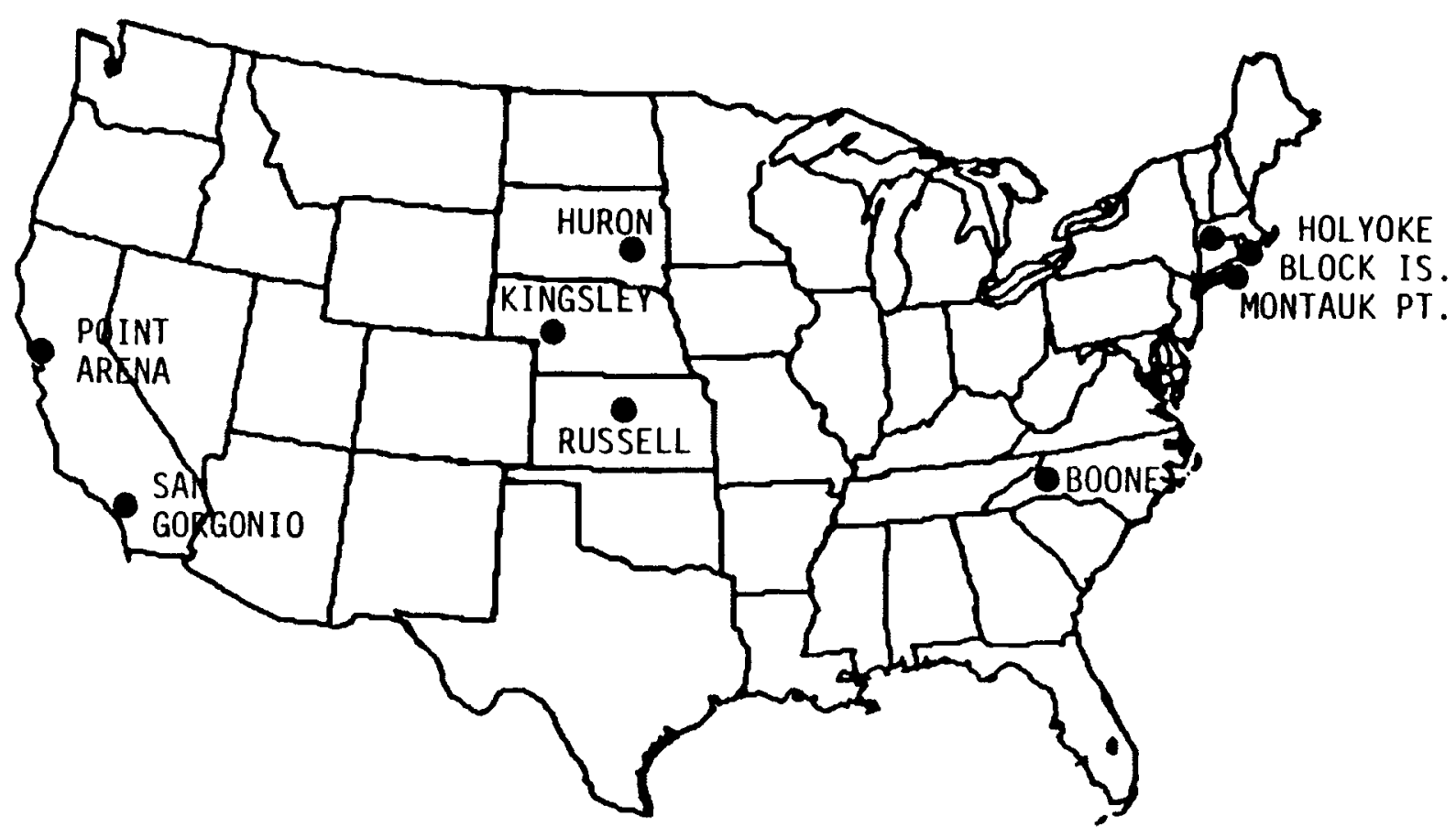

FIGURE 4-2. Nine Sites for Which MOS Wind Forecasts Were Developed and Tested 
1500 GMT) was used as a potential predictor. A second set of equations, termed "backups", was generated without the onsite observation. The backup equations covered the contingencies that either no onsite observations were available or that the observation was missing at forecast time.

In addition to the LFM model output, harmonics (sine and cosine) of the day of the year were included to help forecast seasonal wind variations. When a larger data set is available, MOS seasonal forecasting equations are generally developed to better forecast seasonal and seasonal/diurnal wind variations. Because MOS tends to underforecast the extreme wind speeds, an inflation technique employed by Klein et al. (1959) was used to enlarge the variance of the speed forecasts, thus producing forecast speed distributions more representative of the actual wind speed distribution at each site. Like the S-0 and subjective forecasts, the MOS wind forecasts are for hourly average wind speeds at the 150-ft level for each site.

\subsection{SEMI-OBJECTIVE VERSUS SUBJECTIVE FORECASTS}

The period of record for the subjective wind forecasts is May through October 1979, while S-0 forecasts have been verified for February through July 1982. Because the two wind-forecasting samples contain different months of different years, as well as a different number of months, it is difficult to provide a completely equitable comparison of the two methods. However, the differences in forecast representativeness and accuracy between the two methods are sufficiently large to permit some conclusions to be drawn.

The two forecasting methods were compared at two common sites, San Gorgonio and Block Island, for the 1800 GMT forecast. The forecasting verification comparison presented in Table 4-1 is limited to the two sites and the single forecast time. The large subjective forecasting errors, such as the bias of $-1.7 \mathrm{~m} / \mathrm{s}$ at San Gorgonio, reveal a basic lack of understanding of the wind characteristics of the site.

The normalized RMSE (NRMSE) was used to compare forecasting accuracy, because the two data records span different months and include different 
TABLE 4-1. Verification of Semi-Objective Versus Subjective Wind Forecasts for Block Island, Rhode Island, and San Gorgonio, California

\begin{tabular}{|c|c|c|c|c|}
\hline & Semi-0bje & $v e^{(a)}$ & Subject & (b) \\
\hline Site & $\operatorname{Bias}(\mathrm{m} / \mathrm{s})$ & NRMSE & $\operatorname{Bias}(\mathrm{m} / \mathrm{s})$ & $\overline{\text { NRMSE }}$ \\
\hline Block Island, RI & +0.4 & 1.06 & -1.0 & 1.09 \\
\hline San Gorgonio, CA & -0.4 & 0.97 & -1.7 & 1.54 \\
\hline Combined & +0.2 & 1.03 & -1.3 & 1.31 \\
\hline
\end{tabular}

(a) The semi-objective forecasting sample includes only forecasts made when dial-up feedback was available during the period February through Apri1 1982.

(b) The subjective forecasting sample includes forecasts made during the period May through October 1979.

years. Use of the NRMSE removes a large part of the forecasting error associated with inherent differences in the difficulty of forecasting winds for the two periods of record, thus providing a more equitable comparison (see Appendix E).

Note in the table that the S-0 forecasts appear superior for both sites. Biases, which indicate forecast representativeness, are smaller for the S-0 forecasts as are NRMSEs, which indicate the accuracy and skill of the wind forecasts.

The subjective forecasting accuracy was degraded somewhat by a lack of a real-time feedback mechanism (such as a dial-up system). Lack of feedback combined with lack of understanding of the basic site wind characteristics contributed to much of the poor performance of the subjective forecasting effort. Given adequate feedback, thorough understanding of site winds, and access to NMC weather prognoses and analyses, the subjective approach to 24-hr wind forecasting could conceivably approach the accuracy of the S-0 forecasts, providing that the more experienced and/or skillful forecasters were used to produce the wind forecasts. 


\subsection{SEMI-OBJECTIVE VERSUS MOS FORECASTS}

The forecast times and projections for the S-0 forecasts, 0600 and 1800 GMT, were selected to permit an equitable comparison between the S-0, subjective and MOS wind forecasts. The MOS forecasts were produced based upon data collected at 0000 and 1200 GMT respectively. However, since nearly 6 hours are required to collect the necessary meteorological data, to run the atmospheric models (to produce the wind predictors) and to generate the wind forecasts using the regression equations, from the forecast user's viewpoint; the MOS $+9-h r$ projection from 0000 and 1200 GMT corresponds well in time with the S-0 +3-hr projection from 0600 and 1800 GMT, respectively.

MOS forecasts for those months of 1978 corresponding to the period of record of the S-0 forecasts were selected for comparison. Figure 4-3 shows the sites compared. Note that MOS wind forecasts from Huron, South Dakota, were compared to the S-0 forecasts for Finley, North Dakota. This comparison was made because Huron is the nearest to Finley of the MOS wind forecasting sites and because both sites lie in similar terrain in the Northern Great Plains; thus, wind forecasting difficulty should be reasonably comparable.

Table 4-2 compares MOS and S-0 forecasting accuracy at Block Island by presenting monthly RMSES and NRMSEs for the two forecasting techniques. A very pronounced learning curve is evident during the first 3 months in both the RMSEs and NRMSEs for the S-0 technique. While overall (i.e., for the 6 months combined) MOS performed better than the S-0 approach, by the third month of the project (Apri1), the S-0 forecasts appear to be better than the MOS forecasts. As mentioned in Section 3, loss of real-time feedback as well as change of season caused a decline in accuracy of the $S-0$ forecasts in May.

Finley S-0 and Huron MOS forecasts are compared in Table 4-3. The results are similar to those for Block Island. A steady learning curve is clearly evident in the S-0 NRMSES; the S-0 forecasts surpass MOS by the third month. These trends are not as evident in the RMSES, because the rather steady winter winds experienced at both sites give way to more variable winds 


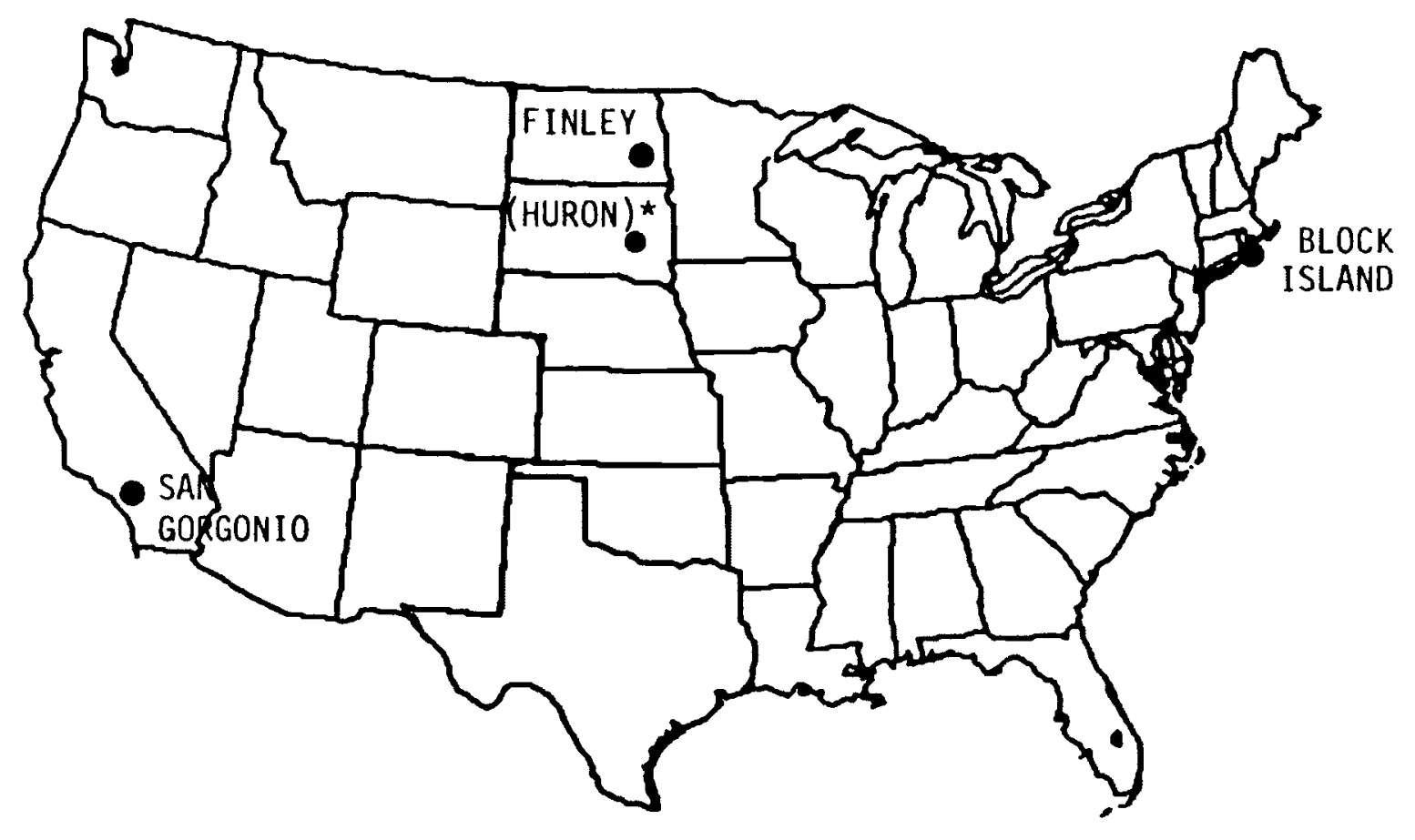

*Huron MOS forecasts were compared to Finley S-0 forecasts.

FIGURE 4-3. Sites for which Semi-Objective and MOS Wind Forecasts Were Compared 
TABLE 4-2. Verification of Semi-0bjective Versus MOS Wind Forecasts for Block Island, Rhode Island

\begin{tabular}{|c|c|c|c|c|}
\hline \multirow[b]{2}{*}{ Month } & \multicolumn{2}{|c|}{$\operatorname{RMSE}(\mathrm{m} / \mathrm{s})$} & \multicolumn{2}{|c|}{ NRMSE } \\
\hline & MOS & $s-0$ & MOS & $\underline{S-0}$ \\
\hline February & 2.84 & 4.05 & 0.71 & 0.87 \\
\hline March & 2.44 & 2.90 & 0.77 & 0.99 \\
\hline April & 2.88 & 2.06 & 0.94 & 0.61 \\
\hline May & 2.88 & 2.68 & 0.83 & 1.05 \\
\hline June $(a)$ & - & - & - & - \\
\hline Combined & 2.76 & 2.98 & 0.81 & 0.86 \\
\hline
\end{tabular}

(a) Sample size too small for valid comparison.

TABLE 4-3. Verification of Semi-0bjective Wind Forecasts for Finley, North Dakota, Versus MOS Forecasts at Huron, South Dakota

\begin{tabular}{|c|c|c|c|c|}
\hline \multirow[b]{2}{*}{ Month } & \multicolumn{2}{|c|}{$\operatorname{RMSE}(\mathrm{m} / \mathrm{s})$} & \multicolumn{2}{|c|}{ NRMSE } \\
\hline & MOS & $\underline{s-0}$ & $\overline{\mathrm{MOS}}$ & $S-0$ \\
\hline February & 2.11 & 2.91 & 1.68 & 1.04 \\
\hline March & 2.44 & 3.41 & 0.75 & 1.01 \\
\hline April & 2.99 & 2.64 & 0.93 & 0.90 \\
\hline $\operatorname{May}(a)$ & - & - & - & - \\
\hline$J_{u n e}^{(a)}$ & - & - & - & - \\
\hline July & 2.57 & 2.24 & $\underline{0.88}$ & 1.07 \\
\hline Combined & 2.53 & 3.13 & 1.05 & 1.02 \\
\hline
\end{tabular}

(a) Sample size too small for valid comparison. 
in March, thus disguising trends in forecasting skill. As in the case of Block Island, limited feedback in May and June broke the continuity necessary to tune the forecasting technique to the site. This combined with the change of season initiated a new learning curve in July.

MOS versus S-0 comparisons for San Gorgonio are shown in Table 4-4. The RMSEs seem to indicate that the S-0 forecasts are as accurate as MOS wind forecasts at this site. However, NRMSEs indicate that MOS forecasts demonstrated greater skill for the periods compared.

TABLE 4-4. Verification of Semi-0bjective Versus MOS Wind Forecasts for San Gorgonio Pass, California

\begin{tabular}{|c|c|c|c|c|}
\hline \multirow[b]{2}{*}{ Month } & \multicolumn{2}{|c|}{$\operatorname{RMSE}(\mathrm{m} / \mathrm{s})$} & \multicolumn{2}{|c|}{ NRMSE } \\
\hline & MOS & $s-0$ & MOS & $\underline{S-0}$ \\
\hline February & 5.38 & 5.00 & 1.10 & 1.24 \\
\hline March & 4.26 & 4.80 & 0.90 & 1.00 \\
\hline Apri1 & 4.44 & 4.45 & 0.78 & 0.94 \\
\hline Combined & 4.65 & 4.63 & 0.92 & 1.07 \\
\hline
\end{tabular}

Since MOS is an objective technique with fixed forecasting equations, the improvement in MOS forecasts is primarily due to changes in the "forecastability" of the winds. That is, during the period, the MOS technique was applied to wind conditions that were becoming easier to forecast using the MOS approach. On the other hand, improvements in the S-O forecasts are largely attributable to improvements in the application of the technique (learning). Comparison of trends in weekly NRMSEs for MOS and the S-0 wind forecasts provides strong evidence that a learning curve exists at each S-0 forecasting site and that a significant amount of learning took place in the first 60 to 90 days of the study. 
Figures 4-4 and 4-5 depict the weekly NRMSEs and the NRMSE trend (1 inear least squares fit) for Block Island MOS and S-0 wind forecasts, respectively. These data are for the first 12 weeks of the S-0 forecasting study (February 1 through April 25). As expected, the "mature" MOS forecasting scheme exhibits almost no trend in the NRMSEs, while, in the mean, the S-0 forecasting normalized errors were progressively growing smaller.

Comparisons of the Huron, North Dakota, MOS (Figure 4-6) to the Finley, South Dakota, S-0 (Figure 4-7) weekly NRMSEs show a similarity. However, unusably small weekly data samples limit the MOS data to the final 7 weeks of the 12-week period. Consequently, a slight trend toward increasing MOS NRMSEs is noted in Figure 4-6. Very steady winds persisted at Finley during the first 2 weeks of the study. This is reflected by the low NRMSEs for weeks 1 and 2 in Figure 4-7. The low NRMSEs for the first 2 weeks had the effect of reducing the slope of the linear fit to the weekly NRMSEs for the 12-week period. Nevertheless, in the mean, a steady decline is still evident in the S-0 wind forecasting errors while MOS indicated a slight increase in the wind forecasting error.

Appendix $E$ indicates that normalizing the RSMEs using the wind speed standard deviation removes all but about $20 \%$ of the variability in RMSEs caused by wind forecasting difficulty. Therefore, it is still possible that a slight trend in MOS NRMSEs can occur. Such a trend is observed in Figure 4-8 for the MOS weekly NRMSEs at San Gorgonio. This suggests that the MOS equations may perform better at San Gorgonio as winter gives way to spring causing a return to more regular, thus forecastable, diurnal wind patterns. By comparison, however, the $\mathrm{S}-0$ forecasts improved much more during the same weeks of the year (see Figure 4-9).

Figures 4-4 through 4-9 indicate that the forecasters employing the S-0 technique learned to tune the technique sufficiently in the first 90 days of the study to provide more accurate forecasts at each site. It is interesting to compare S-0 forecasting verification results after the first 60 days of the study to MOS for the same period of the year. Table 4-5 provides such a 


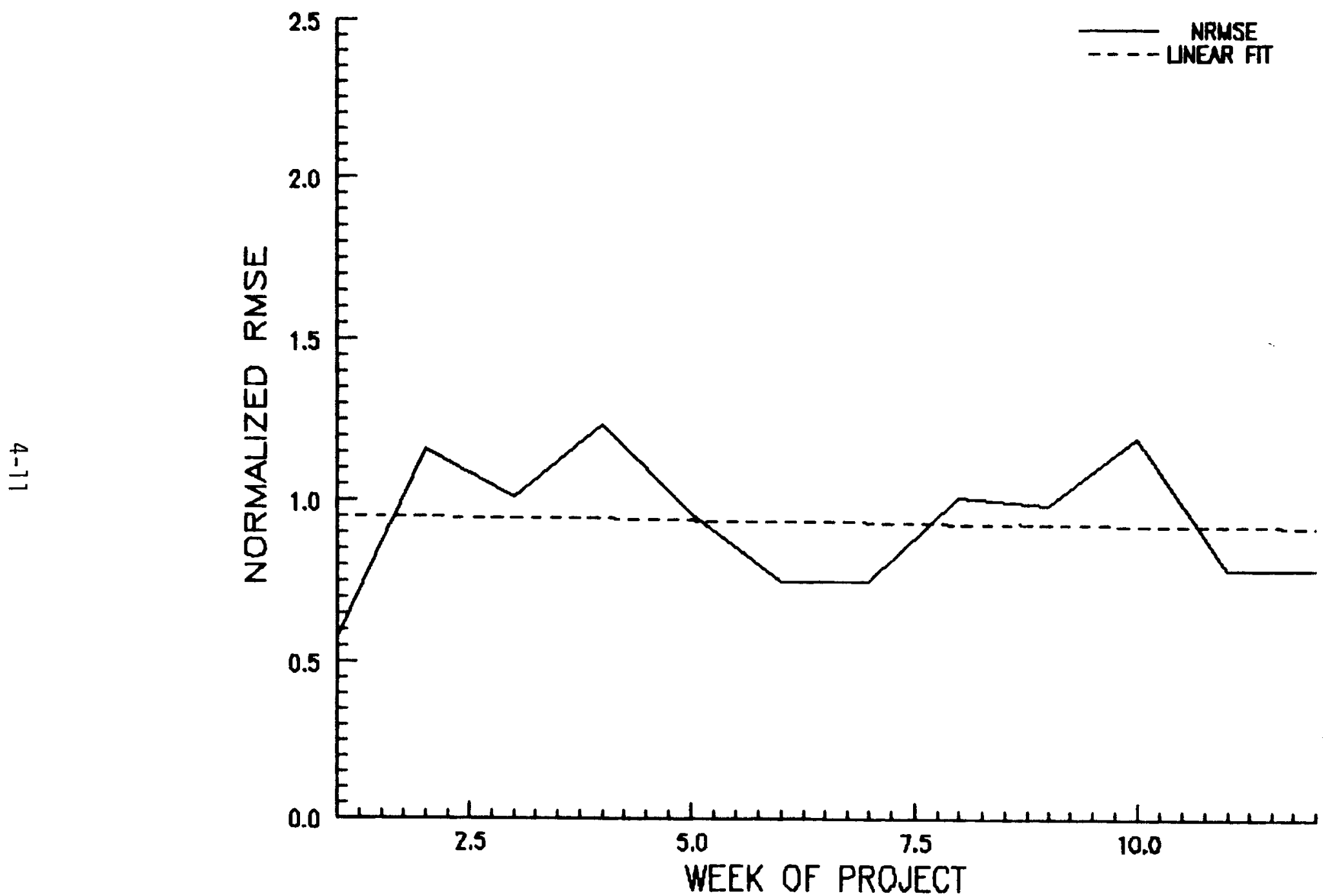

FIGURE 4-4. Block Island Weekly NRMSE Trend in MOS Wind Speed Forecasts 


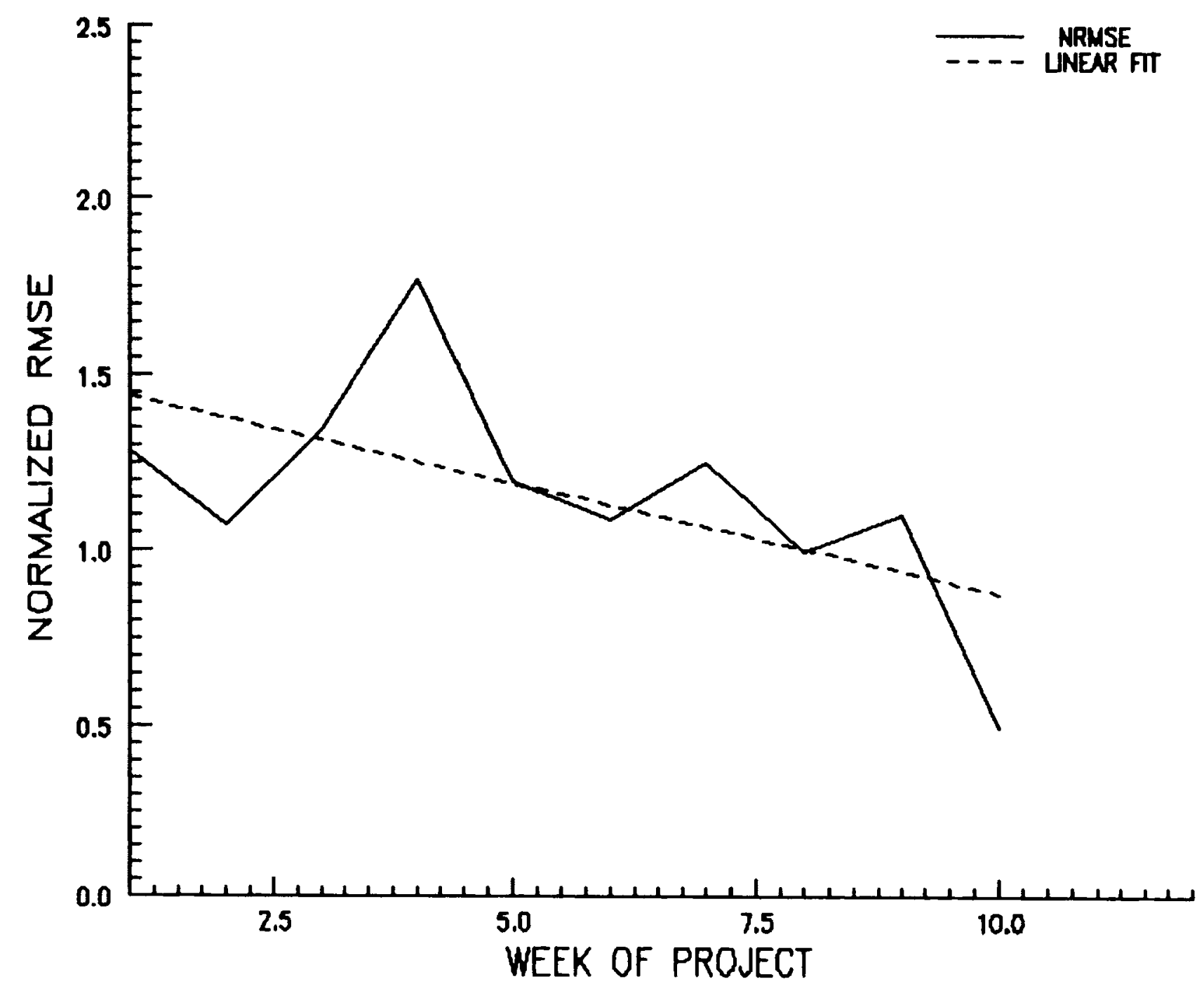

FIGURE 4-5. Block Island Weekly NRMSE Trend in Semi-Objective Wind Speed Forecasts 


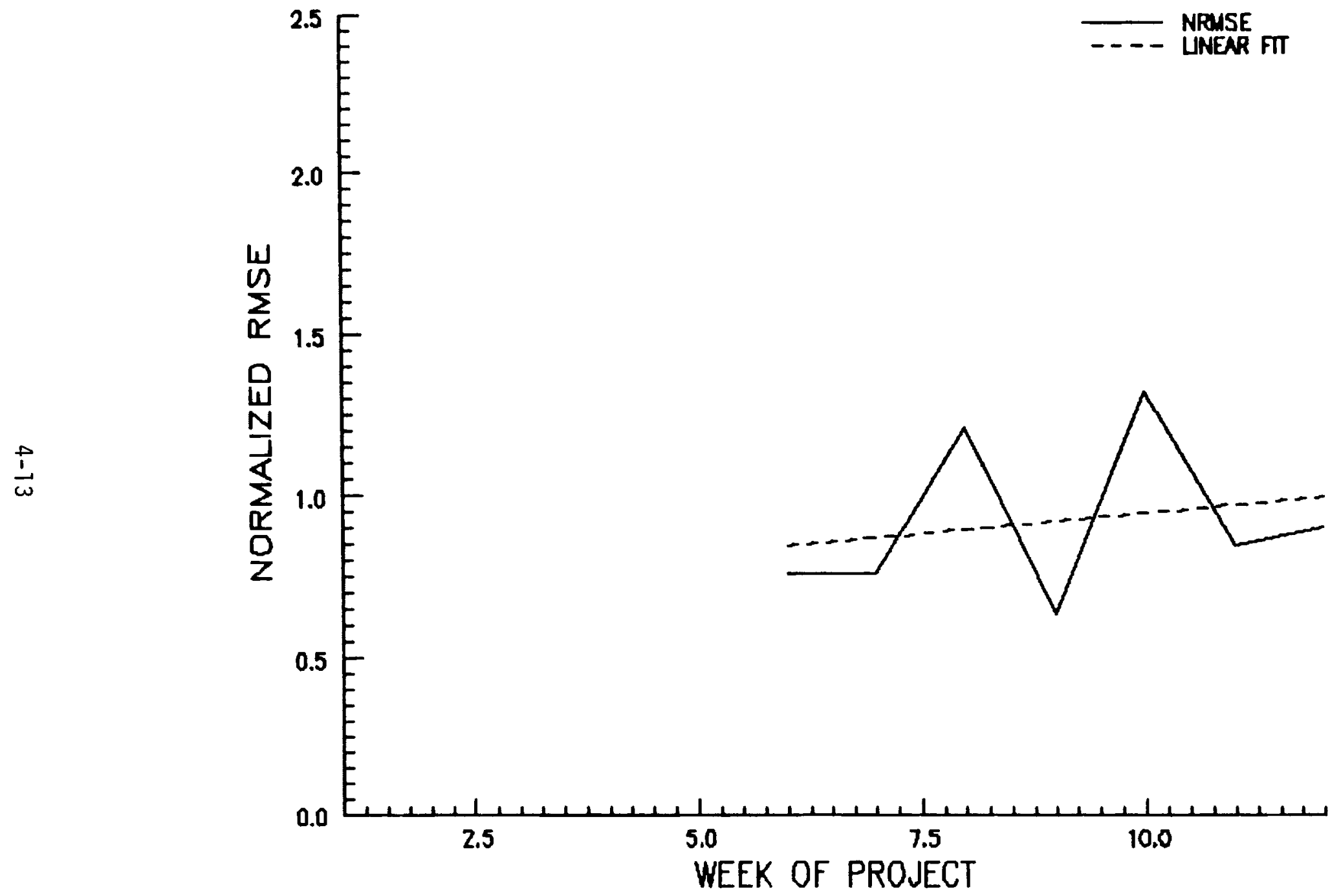

FIGURE 4-6. Huron Weekly NRMSE Trend in MOS Wind Speed Forecasts 


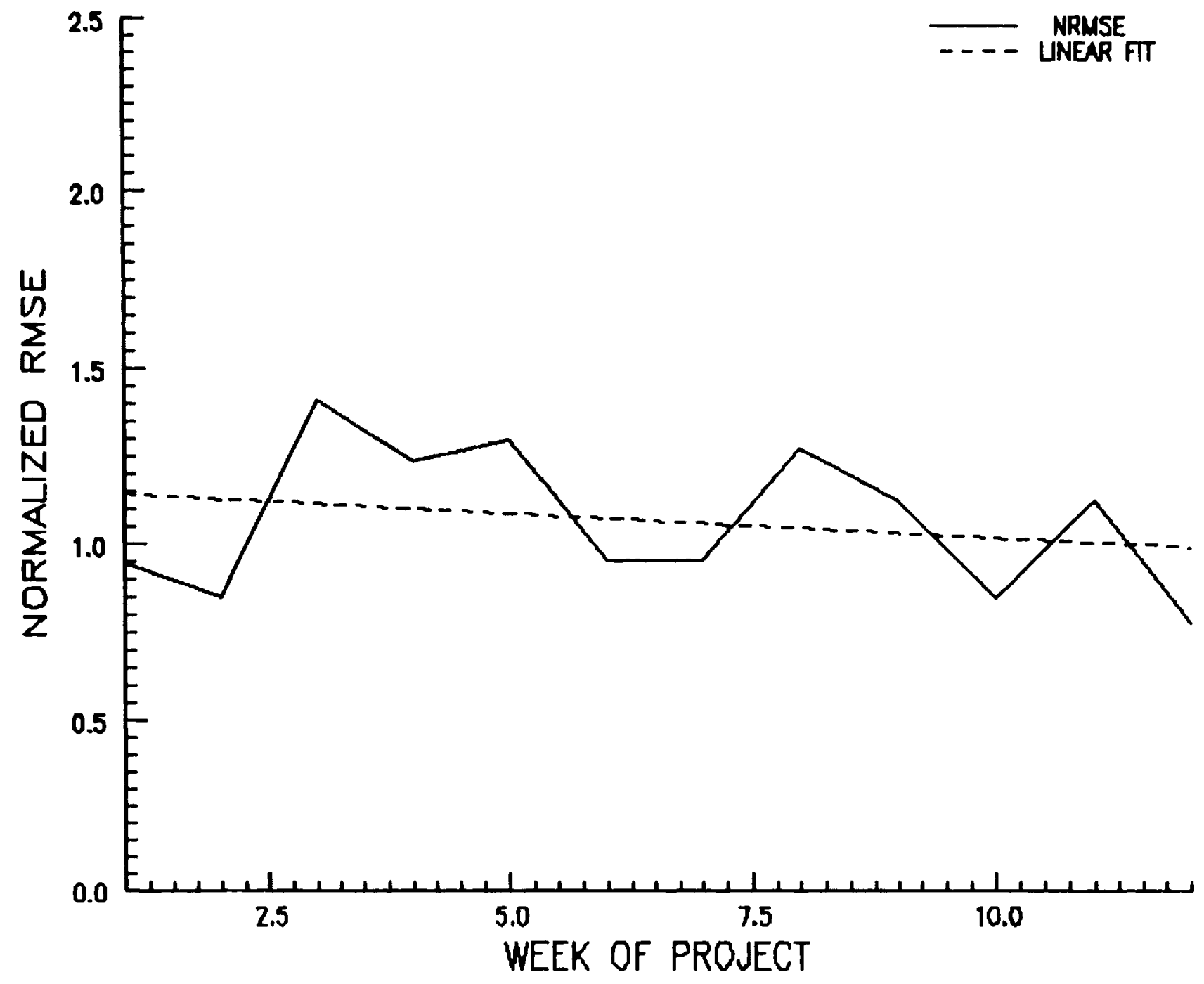

FIGURE 4-7. Finley Weekly NRMSE Trend in Semi-0bjective Wind Speed Forecasts 


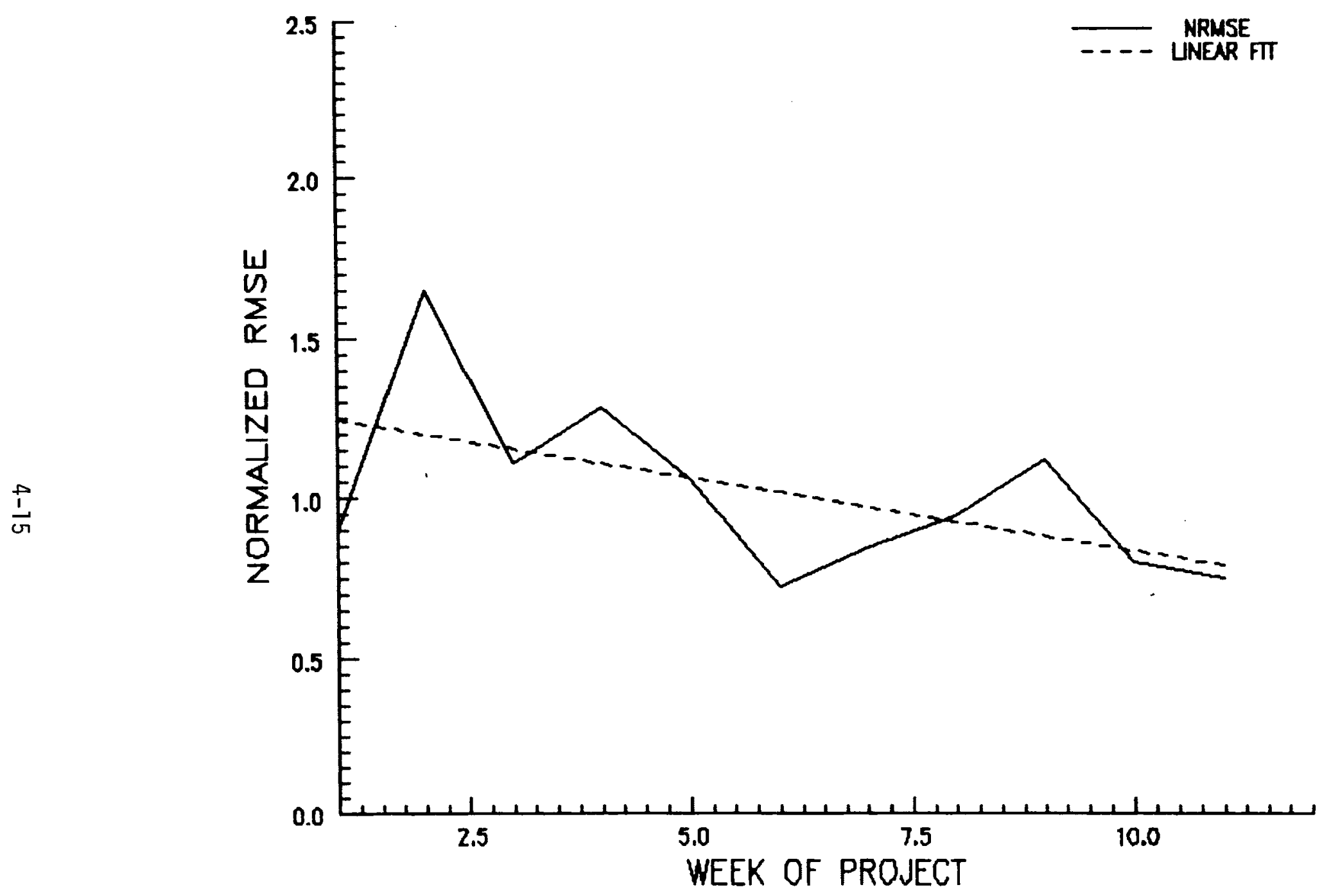

FIGURE 4-8. San Gorgonio Weekly NRMSE Trend in MOS Wind Speed Forecasts 


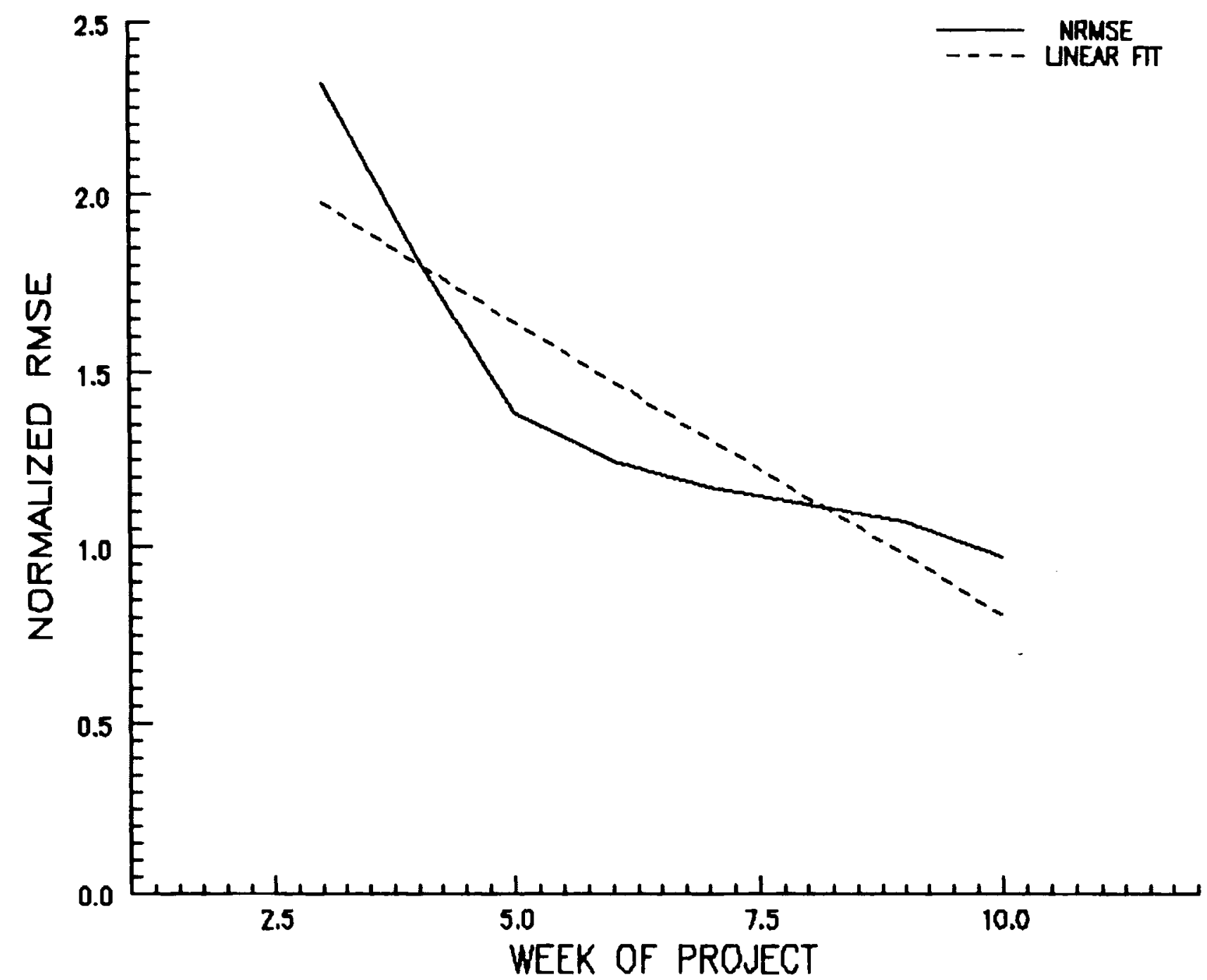

FIGURE 4-9. San Gorgonio Weekly Trend in Semi-Objective Wind Speed Forecasts 
comparison by examining the forecasting errors for the period of record for all three forecasting sites. The table shows that while the S-0 RMSEs are equal to or significantly smaller than those for MOS, normalization of these errors shows that the S-0 forecasts became slightly better at Finley, but never achieved the skillfulness of MOS at San Gorgonio.

TABLE 4-5. Comparison of MOS Forecasting Accuracy With Semi-Objective Forecasts for the Period Following Initial Learning (April to July)

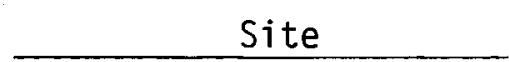

Block Island, RI

Huron (MOS)/Finley (S-0)

San Gorgonio, CA

Combined
$\operatorname{RMSE}(\mathrm{m} / \mathrm{s})$

MOS S-0

2.88

2.40

2.78

2.43

$\underline{4.44} \quad \underline{4.45}$

3.15

$\frac{\text { NRMSE }}{\text { MOS } \quad \underline{S-0}}$

0.88

0.87

0.90

0.81

$\underline{0.76 \quad 0.95}$

0.86

0.84 



\subsection{CONCLUSIONS AND RECOMMENDATIONS}

As discussed in Section 1, 24-hr forecasts of hourly average wind can be useful to utilities in reducing the operating reserves required to maintain system security. Since the $\mathrm{S}-0$ forecasting approach requires the evaluation of weather charts when implementing the forecasting rules for a given site, the approach requires skilled forecasters having access to NMC analyses and prognoses. Therefore, the S-0 wind forecasting approach is intended for use by utility staff meteorologists, or weather consultants working for a utility, rather than by utility operations personnel or other non-meteorologists.

The attempt to apply the S-0 approach developed from one site to a new site in similar terrain yielded no unexpected results. Using the forecasting rules developed for Montauk to forecast at Block Island (see Section 2.1) worked well for these two sites, near to one another, having the same general type terrain and exposure to the prevailing winds. However, when the sites are far apart, such as Amarillo and Finley (see Section 2.2), this approach did not work well. The climatologies of Amarillo and Finley are much different; the two locations are affected by different storm systems having different tracks. Their large differences in latitude mean that different winds will result from a given pressure gradient. This is reflected in the fact that it became necessary to develop new pressure gradient rules for Finley (see Appendices A and B). Therefore, it is recommended that the S-O method developed for one site be applied only to nearby sites in similar terrain having similar exposures to the prevailing wind.

There is evidence that, given an initial analysis of winds from a site of interest, or nearby site in similar terrain, the S-0 wind forecasting approach can be improved upon fairly rapidly. At some sites, such as Block Island and Finley, as little as 3 months may be required to fine-tune the forecasting technique to reach a level of accuracy equal to, or exceeding, MOS (which represents a state-of-the-art forecasting technique). However, considerably more time may be required to accomplish this in more complex 
meteorological and topographic settings, such as San Gorgonio. To more fully address the time required to "learn to forecast" at a new wind turbine site and to more accurately compare the relative forecast accuracy of MOS and S-0 forecasts, it is recommended that:

- MOS forecasting equations be developed for both warm and cool seasons

- two years of developmental data be used for both forecasting techniques

- both forecasting techniques be applied to the same two years of developmental data

- a forecast verification study be conducted for a full year.

It was expected that the persistence demonstrated by time series of hourly average winds would make real-time wind observations (obtained via the dialup system) valuable to the forecasting effort. The S-0 forecasts were much more accurate than the subjective wind forecasts, which lacked real-time feedback (see Section 4.3). However, there were insufficient data to draw conclusions about the value of having real-time feedback available when producing the S-0 wind forecasts. A more closely controlled experiment aimed specifically at assessing the value of real-time feedback would be required to draw any firm conclusions.

Semi-objective forecasts have the potential of becoming very accurate in the production of 24-hr wind forecasts for wind energy applications; however, attaining this accuracy takes time and effort. After 10 months of site data analysis and 6 months of forecasting, the forecasting rules for each site still cover only a portion of the set of all frequently occurring wind/synoptic events. Hence, there are weather situations for which no forecasting guidelines exist. In these situations, the forecasting accuracy becomes completely subject to the skill of the individual forecaster. Using techniques, such as MOS, the computer's "perfect recal1" can rapidly establish forecasting relationships (providing the necessary data have been collected). These relationships might take many months to establish by human 
analysis. Furthermore, a certain amount of subjectivity remains in the S-0 approach, as demonstrated by the range of forecaster skill scores in Table 3-2. Consequently, the reliability of this approach will always vary to a degree with the skill of the forecaster.

As the use of wind energy grows from single machines to clusters of wind turbines, forecasts for shorter time horizons, equal to the startup and shutdown times of conventional generators, will be required by utility dispatchers (Dub and Pape 1981). It is therefore recommended that techniques for making detailed, highly reliable wind/wind power forecasts for shorter time horizons be explored and tested. Furthermore, to make the hourly average forecasts more useful to utilities, it is necessary to develop reliable methods of converting hourly average wind speed forecasts into estimates of power output for single and multiple wind turbines. 


\subsection{REFERENCES}

Brier, G. W. and R. A. Allen. 1952. "Verification of Weather Forecasts." In Compendium of Meteorology. pp. 841-848, American Meteorological Society, Boston, Massachusetts.

Dub, W. and H. Pape. 1981. "Utility Operating Strategy and Requirements for the Wind Power Forecast." Paper presented at AIAA Second Terrestrial Energy Systems Conference, December 1-3, 1981, Colorado Springs, Colorado.

Gerrity, J. F. 1977. The LFM Model-1976: A Documentation. NOAA Technical Memorandum NWS-60, National Oceanic and Atmospheric Administration, U.S. Department of Commerce, Washington, D.C.

Gilhousen, D. B. 1980. Development and Testing of Model Output Statistics for Wind Forecasts at Wind Turbine Generator Sites. DOE/RL/10046-T, Techniques Development Laboratory, National Weather Service NOAA, Silver Spring, Maryland.

Glahn, H. R. and D. A. Lowry. 1972. "The Use of Model Output Statistics (MOS) in Objective Weather Forecasting." J. Appl. Meteor. 11:1203-1211.

Goldenblatt, M. K., H. L. Wegley and A. H. Miller. 1981. Analysis of the Effects of Integrating Wind Turbines into a Conventional Utility: A Case Study. PNL-3962, Pacific Northwest Laboratory, Richland, Washington.

Klein, W. H., B. M. Lewis and I. Enger. 1959. "Objective Prediction of Five-Day Mean Temperature During Winter." J. of Meteorology 16:672-682.

Notis, C., D. W. Trette1, J. T. Aquino, T. R. Piazza, L. E. Taylor, D. C. Trask, H. L. Wegley, and A. H. Miller. 1983. Learning to Forecast Wind at Remote Sites for Wind Energy Applications. PNL-4318, Pacific Northwest Laboratory, Richland, Washington.

Wegley, H. L. 1982. "The Development and Evaluation of Wind Forecasts for Wind Energy Applications." American Meteorological Society. In Proceedings of the 9 th Conference on Weather Forecasting and Analysis. pp. 120-127, American Meteorological Society, Boston, Massachusetts.

Wende11, L. L., H. L. Wegley and M. G. Verholek. 1978. Report From a Working Group Meeting on Wind Forecasts for WECS Operation. PNL-2513, Pacific Northwest Laboratory, Richland, Washington. 


\section{APPENDIX A}

ORIGINAL FORECAST GUIDELINES USED AT

BLOCK ISLAND, RHODE ISLAND

FINLEY AFB, NORTH DAKOTA

SAN GORGONIO PASS, CALIFORNIA 
FORECAST GUIDELINES USED AT BLOCK ISLAND

(Developed originally for Montauk Point)

I. Strong winds can emanate from any direction.

II. Utilize surface pressure gradients in determining the wind direction.

III. Forecast the strongest winds when there is an isobaric orientation (I-0) of NW-SE and N-S.

IV. If the pressure at La Guardia (LGA) minus the pressure at Boston (BOS) is greater than $4 \mathrm{mb}$, forecast a SW-NW wind $7 \mathrm{~m} / \mathrm{s}$ or greater. If the pressure gradient is greater than $7 \mathrm{mb}$, forecast winds over $13 \mathrm{~m} / \mathrm{s}$.

V. When the I-O is NE-SW or E-W and there is a 6 mb pressure gradient (pressure at BOS minus pressure at LGA), forecast $7 \mathrm{~m} / \mathrm{s}$ or greater wind speeds.

VI. There is a strong diurnal variation during the spring and summer from the SW sea breeze. The sea breeze is generally less than $10 \mathrm{~m} / \mathrm{s}$ and achieves its maximum about 1900 LST. 
I. The predominant wind direction is 180 to 260 degrees.

II. The pressure gradient is not a useful tool in forecasting wind characteristics except during stagnant synoptic weather patterns. When these stagnant situations occur and the pressure gradient is $3 \mathrm{mb}$ (per $180 \mathrm{~nm}$ ) or less, forecast winds less than $7 \mathrm{~m} / \mathrm{s}$ except for the $5 W$ quadrant.

III. When the winds at $850 \mathrm{mb}$ are $6 \mathrm{~m} / \mathrm{s}$ or greater, then forecast 8 or more hours of wind $7 \mathrm{~m} / \mathrm{s}$ or greater. (A $99 \%$ probability for this event exists.)

IV. Forecast the maximum wind speed at 1200 to 2200 LST. 


\section{FORECAST GUIDELINES USED AT SAN GORGONIO PASS}

(Developed originally for San Gorgonio)

I. Low pressure lying to the east.

A. Forecast strong winds when the prevailing direction is 220 to 260 degrees.

B. With NW-SE, N-S, or W-E I-0, forecast strong winds. Speeds wi11 exceed $7 \mathrm{~m} / \mathrm{s}$ sometime during the day when the pressure at Los Angeles Airport (LAX) minus the pressure at Las Vegas (LAS) is as little as $1 \mathrm{mb}$.

C. Forecast wind speeds between 13 and $22 \mathrm{~m} / \mathrm{s}$ when the pressure gradient is $7 \mathrm{mb}$ or greater. (Wind speeds will exceed $13 \mathrm{~m} / \mathrm{s} 95 \%$ of the time.)

II. Low pressure lying to the west.

A. With a NE-SW or S-N I-0, forecast SW-WSW winds during the day and E during the night. When forecasting the $E$ wind direction, forecast wind speeds $5 \mathrm{~m} / \mathrm{s}$ or less.

B. With an E-W I-0, forecast W-WNW winds during the day and switch to $\mathrm{NE}-\mathrm{E}$ wind directions during the night. When forecasting the $\mathrm{E}$ wind direction, forecast wind speeds $5 \mathrm{~m} / \mathrm{s}$ or less.

III. Diurnal variation.

A. Incorporate diurnal variation into forecast when a flat pressure gradient or a trough 1 ies over or just east of the area. Included are NE-SW, S-N, and N-S I-O. Note: A W-E I-0 will override the diurnality and continue to produce strong SW winds.

B. Forecast SW-WSW daytime winds reaching maximum speeds of 7 to $15 \mathrm{~m} / \mathrm{s}$ between 1800 to 2000 LST. Forecast 1 ight easterly winds ( 0 to $3 \mathrm{~m} / \mathrm{s}$ ) in the early morning (0700 to 0900 LST). 



\section{APPENDIX B}

REVISED FORECAST GUIDELINES FOR

BLOCK ISLAND, RHODE ISLAND

FINLEY AFB, NORTH DAKOTA

SAN GORGONIO PASS, CALIFORNIA 
REVISED FORECAST GUIDELINES FOR BLOCK ISLAND

(Revised March 10, 1982)

I. Strong winds can emanate from any direction.

II. Utilize surface pressure gradients in determining the wind direction.

III. Forecast the strongest winds when there is an isobaric orientation (I-0) of NW-SE and N-S.

IV. When the I-O is NE-SW or E-W and there is a $6 \mathrm{mb}$ pressure gradient (pressure at BOS minus pressure at LGA), forecast $7 \mathrm{~m} / \mathrm{s}$ or greater wind speeds.

V. There is a strong diurnal variation during the spring and summer from the $\mathrm{SW}$ sea breeze. The sea breeze is generally less than $10 \mathrm{~m} / \mathrm{s}$ and achieves its maximum about 1900 LST.

VI. When an E-W I-O caused by a high pressure system moving from the Great Lakes over northern New England occurs, forecast NNE-NE winds at $7 \mathrm{~m} / \mathrm{s}$ or greater if the high is strengthening and there is a difference in pressure (LGA - BOS) of $-1 \mathrm{mb}$. If the high is weakening, the difference in pressure must be $2 \mathrm{mb}$.

VII. Forecast $7 \mathrm{~m} / \mathrm{s}$ or greater NE-ENE winds when an E-W I-O caused by a low tracking off the coast has a pressure difference of $-1 \mathrm{mb}$ (LGA-BOS) and the low is deepening; and if there is a $-2 \mathrm{mb}$ pressure gradient with a filling low.

VIII. When a deepening low pressure system lies to the west of the Appalachian Mountains and pressure falls on the East Coast are $8 \mathrm{mb}$ or greater during a 12-hour period, consider the pressure gradient between Providence, Rhode Island (PVD), and Albany, New York (ALB). A pressure gradient (PVD - ALB) of $1 \mathrm{mb}$ is needed to forecast $S-S S W-S W$ winds $7 \mathrm{~m} / \mathrm{s}$ or greater. A pressure gradient of $4 \mathrm{mb}$ will yield 12 to $13 \mathrm{~m} / \mathrm{s}$ winds.

IX. Forecast WSW-W $7 \mathrm{~m} / \mathrm{s}$ or greater winds with a W-E I-0 and a pressure gradient of $1 \mathrm{mb}$ between LGA and BOS and winds 11 to $12 \mathrm{~m} / \mathrm{s}$ with a pressure gradient of $4 \mathrm{mb}$. 


\section{REVISED FORECAST GUIDELINES FOR FINLEY AFB \\ (Revised March 10, 1982)}

I. Forecast the maximum wind speed at 2100 to 2200 LST.

II. Use the pressure gradient between Huron, South Dakota (HON) and Grand Forks, North Dakota (GFK) when a W-E I-0 exists. Forecast $7 \mathrm{~m} / \mathrm{s}$ or greater winds when there is a $1 \mathrm{mb}$ pressure gradient (HON - GFK) and forecast winds 11 to $12 \mathrm{~m} / \mathrm{s}$ when there is a $4 \mathrm{mb}$ pressure gradient.

III. If the wind direction is $S E$ and there is a low pressure lying to the south, the winds will increase and back to the NE and $N$ only if Finley is under the direct circulation of the low. If Finley is not in the direct circulation, the winds will veer through the SW and NW.

IV. When the wind is veering from the NE to the SE, forecast an increase in wind speed as soon as the wind direction becomes SE. 


\section{REVISED FORECAST GUIDELINES FOR SAN GORGONIO PASS}

(Revised April 2, 1982)

I. The pressure at LAX is greater than at LAS.

A. Forecast strong winds when the prevailing direction is 220 to 260 degrees.

B. With NW-SE, N-S, or W-E I-0, forecast strong winds. Speeds will exceed $7 \mathrm{~m} / \mathrm{s}$ sometime during the day when the pressure at LOS Angeles Airport (LAX) minus the pressure at Las Vegas (LAS) is as little as $1 \mathrm{mb}$.

C. Forecast wind speeds between 13 and $22 \mathrm{~m} / \mathrm{s}$ when the pressure gradient is $7 \mathrm{mb}$ or greater. (Wind speeds will exceed $13 \mathrm{~m} / \mathrm{s} 95 \%$ of the time.)

II. The pressure at LAS is greater than the pressure at LAX.

A. With a NE-SW or S-N I-O, forecast SW-WSW winds during the day and E during the night. When forecasting the $E$ wind direction, forecast wind speeds $5 \mathrm{~m} / \mathrm{s}$ or less.

B. With an E-W I-O, forecast W-WNW winds during the day and switch to $N E-E$ wind directions during the night. When forecasting the $E$ wind direction, forecast wind speeds $5 \mathrm{~m} / \mathrm{s}$ or less.

C. If a low is lying to the south of California, forecast NW winds 4 to $9 \mathrm{~m} / \mathrm{s}$ during the night and SE winds 2 to $4 \mathrm{~m} / \mathrm{s}$ during the day.

D. Forecast SE winds 3 to $7 \mathrm{~m} / \mathrm{s}$ if the $10 \mathrm{w}$ is off the northern Cal ifornia coast.

III. The pressure gradient is changing sign.

A. The wind will briefly gust ( 1 to 2 hours) 2 to $3 \mathrm{~m} / \mathrm{s}$ higher than the speed supported by the pressure gradient and then will slow down to the speed determined by the pressure gradient.

B. The higher wind speeds associated with the switch in direction to WSW will be delayed 2 to 3 hours and then follow A above. 


\section{APPENDIX C}

HEIDKE SKILL SCORE COMPUTATION 


\section{HEIDKE SKILL SCORE COMPUTATION}

The Heidke Skill score (Brier and Allen 1952) is computed from a contingency table. To create these tables, each forecast wind speed was placed into one of five categories. The speed categories depicted in Figure $\mathrm{C}-1$ were selected to correspond roughly to power output levels of a large wind turbine generator. The power curve in the figure is similar to that of the DOE MOD-2 wind turbine generator described by Linscott et al. (1981). In category 1 there was no chance of any power being produced in that hour; category 2 contained hourly averaged wind speeds that promised about a 50\% change of some power being produced. Category 3 was for those speeds that fell on the ramp--that area of the MOD- 2 WTG power-out curve where an increase in speed led to an increase in power production. Hourly averaged wind speeds that fell within the rated range were put into category 4 and anything above the rated range (which also produced no power) was contained in category 5. The same procedure was followed for each observed wind speed.

Table C-1 shows a sample contingency table with only two categories. The equation for computing the Heidke Skill score with this contingency table is

$$
\text { HEIDKE SKILL SCORE }=\frac{(A+D)-((X \star L)+(Y * M)) / Z}{Z-((X * L)+(Y * M)) / Z} \text {. }
$$

The term $\left(\left(X^{\star} L\right)+(Y * M)\right) / Z$ is the climatological occurrence of the event happening. The "hits" or number of times the event occurs when forecast is determined by the value $(A+D)$. So the Heidke skill score is basically the number of correct forecasts divided by the total number of forecasts offset by the climatological occurrence.

The score values can range from a low of -1.0 to a high of +1.0 . A value of 0.0 indicates the forecast was only as good as climatology. 


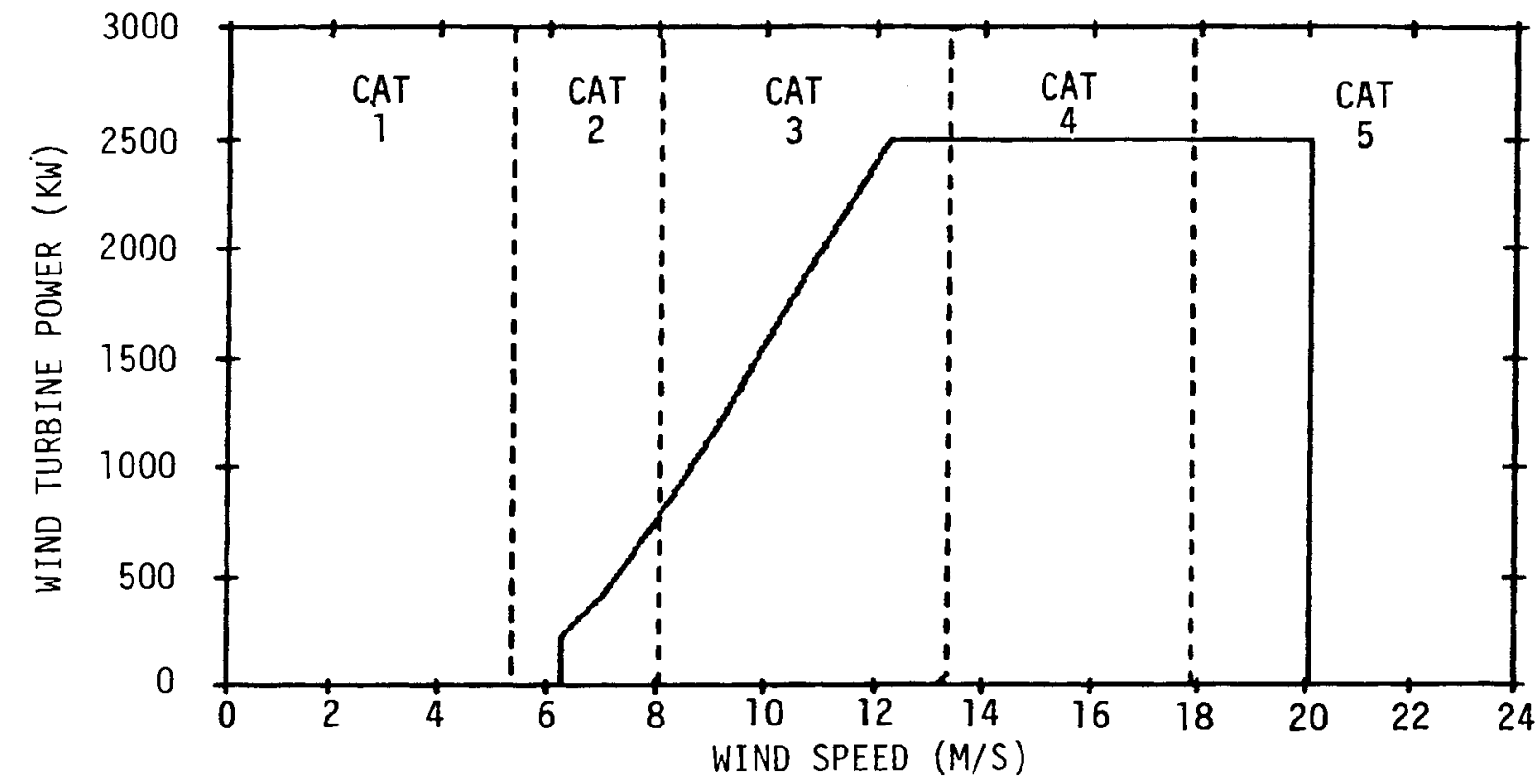

FIGURE C-1. Wind Speed Category Selection 


\section{TABLE C-1. Sample Contingency Table}

Forecast Wind Speeds

\begin{tabular}{|c|c|c|c|c|}
\hline & & Category 1 & Category 2 & Total \\
\hline \multirow{3}{*}{$\begin{array}{l}\text { Observed } \\
\text { Wind } \\
\text { Speeds }\end{array}$} & Category 1 & A & B & $x$ \\
\hline & Category 2 & c & $D$ & $Y$ \\
\hline & Total & L & M & $z$ \\
\hline
\end{tabular}

\section{REFERENCES}

Brier, G. W. and R. A. Allen. 1952. "Verification of Weather Forecasts." In: Compendium of Meteorology, pp. 841-848, American Meteorological Society, Boston, Massachusetts.

Linscott, B. S., J. T. Dennett and L. H. Gordon. 1981. The MOD-2 Wind Turbine Development Project. DOE/NASA/20305-5, NASA Lewis Research Center, Cleveland, Ohio. 

APPENDIX D

STATISTICAL ANALYSIS FOR THE PERIOD FEBRUARY THROUGH JULY 1982 
STATISTICAL ANALYSIS FOR THE PERIOD FEBRUARY THROUGH JULY 1982

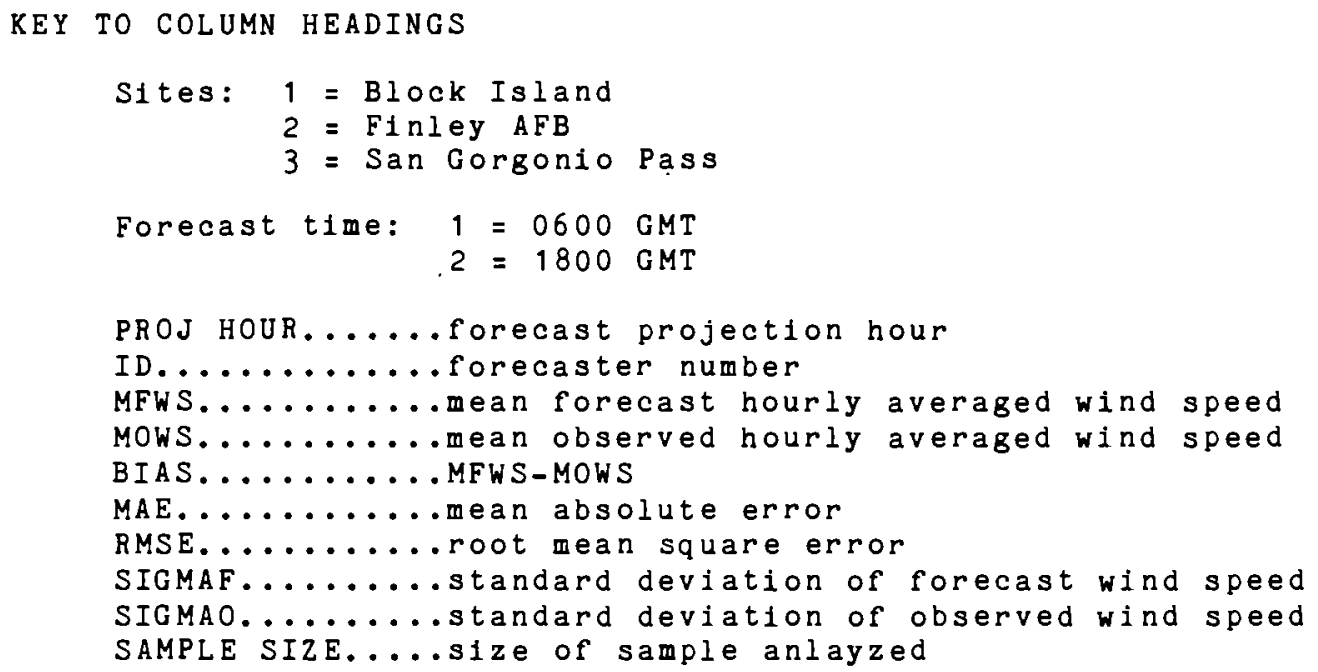

ANALYSIS BY SITE

$\begin{array}{rrrrrrrrr}\text { SITE } & \text { MFWS } & \text { MOWS } & \text { BIAS } & \text { MAE } & \text { RMSE } & \text { SIGMAF } & \text { SIGMAO } & \text { SIZE } \\ & & & & & & & & \\ 1 & 6.92 & 6.71 & 0.20 & 2.38 & 3.04 & 2.85 & 2.88 & 3121 . \\ 2 & 7.70 & 8.41 & -0.71 & 2.59 & 3.42 & 3.00 & 3.20 & 5142 . \\ 3 & 8.21 & 8.92 & -0.71 & 3.71 & 4.72 & 4.10 & 4.61 & 2666 .\end{array}$

ANALYSIS BY SITE, BY FORECAST TIME

\begin{tabular}{|c|c|c|c|c|c|c|c|c|c|}
\hline SITE & $\begin{array}{l}\text { FCST } \\
\text { TIME }\end{array}$ & MFWS & MOWS & BIAS & MAE & RMSE & SIGMAF & SIGMAO & $\begin{array}{l}\text { SAMPLE } \\
\text { SIZE }\end{array}$ \\
\hline $\begin{array}{l}1 \\
1 \\
2 \\
2 \\
3 \\
3\end{array}$ & $\begin{array}{l}1 \\
2 \\
1 \\
2 \\
1 \\
2\end{array}$ & $\begin{array}{l}6.83 \\
7.00 \\
7.68 \\
7.72 \\
7.97 \\
8.48\end{array}$ & $\begin{array}{l}6.75 \\
6.68 \\
8.43 \\
8.39 \\
8.94 \\
8.90\end{array}$ & $\begin{array}{r}0.09 \\
0.32 \\
-0.75 \\
-0.67 \\
-0.97 \\
-0.43\end{array}$ & $\begin{array}{l}2.42 \\
2.34 \\
2.62 \\
2.55 \\
3.80 \\
3.62\end{array}$ & $\begin{array}{l}3.07 \\
3.01 \\
3.49 \\
3.34 \\
4.80 \\
4.63\end{array}$ & $\begin{array}{l}2.93 \\
2.76 \\
3.00 \\
2.99 \\
4.13 \\
4.05\end{array}$ & $\begin{array}{l}2.91 \\
2.84 \\
3.19 \\
3.21 \\
4.60 \\
4.62\end{array}$ & $\begin{array}{l}1593 . \\
1528 . \\
2649 . \\
2493 . \\
1388 . \\
1278 .\end{array}$ \\
\hline
\end{tabular}

ANALYSIS BY SITE, BY HOUR OF DAY (LST), BY FORECAST TIME

$\begin{array}{rrrrrrrrrrr} & \text { PROJ } & \text { FCST } & & & & & & & & \text { SAMPLE } \\ \text { SITE } & \text { HOUR } & \text { TIME } & \text { MFWS } & \text { MOWS } & \text { BIAS } & \text { MAE } & \text { RMSE } & \text { SIGMAF } & \text { SIGMAO } & \text { SIZE } \\ 1 & 1 & 1 & 5.73 & 6.51 & -0.79 & 2.12 & 2.74 & 2.66 & 3.07 & 66 . \\ 1 & 2 & 1 & 5.69 & 6.75 & -1.06 & 2.17 & 2.76 & 2.64 & 2.83 & 67 . \\ 1 & 3 & 1 & 5.87 & 6.65 & -0.79 & 2.33 & 3.07 & 2.47 & 2.87 & 66 .\end{array}$




\begin{tabular}{|c|c|c|c|c|c|c|c|c|c|c|}
\hline SITE & $\begin{array}{l}\text { PROJ } \\
\text { HOUR }\end{array}$ & $\begin{array}{l}\text { FCST } \\
\text { TIME }\end{array}$ & MFWS & MOWS & BIAS & MAE & RMSE & SIGMAF & SIGMAO & $\begin{array}{l}\text { SAMPLE } \\
\text { SIZE }\end{array}$ \\
\hline 1 & 4 & 1 & 6.02 & 6.78 & -0.77 & 2.55 & 3.18 & 2.60 & 2.99 & 65. \\
\hline 1 & 5 & 1 & 6.26 & 6.66 & -0.39 & 2.72 & 3.34 & 2.83 & 3.11 & 65. \\
\hline 1 & 6 & 1 & 6.17 & 6.43 & -0.26 & 2.53 & 3.05 & 2.93 & 2.83 & 64. \\
\hline 1 & 7 & 1 & 6.37 & 6.38 & 0.00 & 2.46 & 2.97 & 2.97 & 2.90 & 64. \\
\hline 1 & 8 & 1 & $6 \cdot 30$ & 6.78 & -0.48 & 2.36 & 2.95 & 3.01 & 2.90 & 66. \\
\hline 1 & 9 & 1 & 6.56 & 6.69 & -0.13 & 2.34 & 2.94 & 2.97 & 2.92 & 71. \\
\hline 1 & 10 & 1 & 6.74 & 6.64 & 0.10 & 2.37 & 2.87 & 2.87 & 2.88 & 70. \\
\hline 1 & 11 & 1 & 6.90 & 6.57 & 0.33 & 2.29 & 2.76 & 3.07 & 2.92 & 67. \\
\hline 1 & 12 & 1 & 6.91 & 6.71 & 0.20 & 2.16 & 2.73 & 2.99 & 2.87 & 69. \\
\hline 1 & 13 & 1 & 6.96 & 6.93 & 0.03 & 2.09 & 2.62 & 2.88 & 2.82 & 69. \\
\hline 1 & 14 & 1 & 7.29 & 7.25 & 0.04 & 2.01 & 2.44 & 2.93 & 2.88 & 70 . \\
\hline 1 & 15 & 1 & 7.18 & 7.04 & 0.13 & 2.18 & 2.72 & 2.78 & 2.61 & 69. \\
\hline 1 & 16 & 1 & 7.16 & 7.04 & 0.12 & 2.28 & 2.86 & 2.79 & 2.84 & 68. \\
\hline 1 & 17 & 1 & 7.40 & 6.90 & 0.49 & 2.29 & 2.85 & 2.75 & 2.82 & 66. \\
\hline 1 & 18 & 1 & 7.34 & 7.00 & 0.34 & 2.15 & 2.68 & 2.87 & 2.79 & 64. \\
\hline 1 & 19 & 1 & 7.40 & 6.89 & 0.50 & 2.53 & 3.11 & 2.88 & 3.08 & 62. \\
\hline 1 & 20 & 1 & 7.55 & 6.60 & 0.94 & 2.72 & 3.61 & 2.95 & 3.06 & 64. \\
\hline 1 & 21 & 1 & 7.73 & 6.66 & 1.07 & 2.69 & 3.52 & 2.97 & 3.07 & 66. \\
\hline 1 & 22 & 1 & 7.68 & 6.58 & 1.09 & 3.10 & 3.98 & 3.14 & 3.03 & 64. \\
\hline 1 & 23 & 1 & 7.40 & 6.52 & 0.88 & 3.03 & 3.81 & 3.02 & 2.99 & 66. \\
\hline 1 & 24 & 1 & 7.45 & 6.88 & 0.57 & 2.80 & 3.58 & 3.04 & 3.17 & 65. \\
\hline 1 & 1 & 2 & 6.50 & 7.03 & -0.53 & 1.36 & 1.73 & 2.58 & 2.84 & 66. \\
\hline 1 & 2 & 2 & 6.60 & 7.29 & -0.70 & 1.55 & 1.95 & 2.71 & 2.91 & 67. \\
\hline 1 & 3 & 2 & 6.39 & 7.04 & -0.65 & 1.78 & 2.26 & 2.35 & 2.62 & 66. \\
\hline 1 & 4 & 2 & 6.43 & 7.01 & -0.58 & 1.95 & 2.49 & 2.39 & 2.81 & 65. \\
\hline 1 & 5 & 2 & 6.58 & 6.88 & -0.30 & 1.97 & 2.55 & 2.49 & 2.78 & 63. \\
\hline 1 & 6 & 2 & 6.64 & 7.00 & -0.36 & 1.96 & 2.53 & 2.54 & 2.74 & 61. \\
\hline 1 & 7 & 2 & 6.59 & 6.87 & -0.27 & 2.12 & 2.69 & 2.69 & 3.00 & 59. \\
\hline 1 & 8 & 2 & 6.75 & 6.51 & 0.24 & 2.15 & 2.86 & 2.71 & 2.97 & \\
\hline 1 & 9 & 2 & 6.93 & 6.56 & 0.37 & 2.39 & 2.95 & 2.86 & 3.10 & 63. \\
\hline 1 & 10 & 2 & 7.06 & 6.47 & 0.59 & 2.53 & 3.05 & 2.82 & 3.08 & 61. \\
\hline 1 & 11 & 2 & 7.07 & 6.41 & 0.67 & 2.41 & 3.09 & 2.76 & 3.07 & \\
\hline 1 & 12 & 2 & 7.28 & 6.74 & 0.54 & 2.60 & 3.19 & 2.79 & 3.23 & \\
\hline 1 & 13 & 2 & 7.32 & 6.52 & 0.80 & 2.69 & 3.29 & 2.73 & 3.09 & 63 \\
\hline 1 & 14 & 2 & 7.12 & 6.51 & 0.61 & 2.43 & 2.93 & 2.41 & 2.66 & \\
\hline 1 & 15 & 2 & 7.22 & 6.51 & 0.71 & 2.53 & 3.10 & 2.52 & 2.75 & \\
\hline 1 & 16 & 2 & 7.11 & 6.57 & 0.54 & 2.69 & 3.43 & 2.66 & 2.70 & 61 \\
\hline 1 & 17 & 2 & 7.18 & 6.48 & 0.70 & 2.86 & 3.71 & 2.75 & 2.82 & 62. \\
\hline 1 & 18 & 2 & 7.10 & 6.30 & 0.80 & 2.60 & 3.33 & 2.84 & 2.49 & 61 \\
\hline 1 & 19 & 2 & 7.12 & 6.26 & 0.86 & 2.51 & 3.18 & 2.97 & 2.59 & 62 \\
\hline 1 & 20 & 2 & 7.37 & 6.76 & 0.61 & 2.57 & 3.27 & 3.04 & 2.76 & \\
\hline 1 & 21 & 2 & 7.43 & 6.68 & 0.75 & 2.80 & 3.60 & 3.10 & 2.87 & \\
\hline 1 & 22 & 2 & 7.39 & 6.66 & 0.73 & 2.60 & 3.43 & 3.00 & 2.77 & \\
\hline 1 & 23 & 2 & 7.47 & 6.56 & 0.91 & 2.67 & 3.43 & 3.11 & 2.79 & \\
\hline 1 & 24 & 2 & 7.40 & 6.62 & 0.78 & 2.57 & 3.27 & 3.08 & 2.81 & \\
\hline 2 & 1 & 1 & 7.72 & 8.87 & -1.15 & 2.18 & 3.11 & 3.19 & 3.24 & 110. \\
\hline 2 & 2 & 1 & 7.72 & 8.65 & -0.93 & 2.19 & 3.03 & 3.19 & 3.17 & 110. \\
\hline 2 & 3 & 1 & 7.72 & 8.34 & -0.61 & 2.18 & 3.00 & 2.99 & 3.07 & 109. \\
\hline 2 & 4 & 1 & 7.74 & 8.27 & -0.54 & 2.34 & 3.27 & 3.00 & 3.23 & 111. \\
\hline 2 & 5 & 1 & 7.70 & 8.30 & -0.60 & 2.44 & 3.40 & 2.90 & 3.08 & 112 \\
\hline 2 & 6 & 1 & 7.56 & 8.51 & -0.95 & 2.58 & 3.59 & 2.96 & 3.34 & 111 \\
\hline 2 & 7 & 1 & 7.54 & 8.52 & -0.98 & 2.54 & 3.58 & 2.91 & 3.27 & 111 \\
\hline 2 & 8 & 1 & 7.51 & 8.35 & -0.84 & 2.40 & 3.38 & 2.96 & 3.00 & 111 \\
\hline 2 & 9 & 1 & 7.55 & 8.42 & -0.86 & 2.70 & 3.51 & 2.93 & 2.98 & 110. \\
\hline 2 & 10 & 1 & 7.64 & 8.26 & -0.62 & 2.88 & 3.63 & 2.96 & 3.16 & 112 \\
\hline 2 & 11 & 1 & 7.62 & 8.25 & -0.64 & 2.92 & 3.72 & 2.86 & 3.40 & 108 \\
\hline 2 & 12 & 1 & 7.68 & 8.26 & -0.58 & 2.89 & 3.79 & 2.99 & 3.37 & 107 \\
\hline
\end{tabular}




\begin{tabular}{|c|c|c|c|c|c|c|c|c|c|c|}
\hline SITE & $\begin{array}{l}\text { PROJ } \\
\text { HOUR }\end{array}$ & $\begin{array}{l}\text { FCS I } \\
\text { TIME }\end{array}$ & MFWS & MOWS & BI AS & MAE & RMSE & SIGMAF & SIGMAO & $\begin{array}{l}\text { SAMPLE } \\
\text { SIZE }\end{array}$ \\
\hline 2 & 13 & 1 & 7.68 & 8.24 & -0.56 & 2.70 & 3.58 & 2.83 & 3.21 & 110 \\
\hline 2 & 14 & 1 & 7.71 & 8.24 & -0.53 & 2.71 & 3.42 & 2.83 & 3.08 & 110. \\
\hline 2 & 15 & 1 & 7.73 & 8.24 & -0.51 & 2.61 & 3.36 & 2.89 & 3.16 & 108. \\
\hline 2 & 16 & 1 & 7.69 & 8.27 & -0.58 & 2.49 & 3.28 & 2.87 & 3.08 & 110. \\
\hline 2 & 17 & 1 & 7.71 & 8.42 & -0.71 & 2.71 & 3.52 & 2.98 & 2.99 & 110. \\
\hline 2 & 18 & 1 & 7.73 & 8.46 & -0.73 & 2.66 & 3.43 & 3.08 & 3.10 & 110. \\
\hline 2 & 19 & 1 & 7.66 & 8.52 & -0.86 & 2.68 & 3.45 & 3.04 & 3.10 & 111. \\
\hline 2 & 20 & 1 & 7.57 & 8.39 & -0.82 & 2.67 & 3.56 & 3.13 & 3.26 & 111. \\
\hline 2 & 21 & 1 & 7.70 & 8.55 & -0.85 & 2.78 & 3.65 & 3.21 & $3 \cdot 37$ & 112. \\
\hline 2 & 22 & 1 & 7.72 & 8.62 & -0.90 & 2.89 & 3.84 & 3.22 & 3.45 & 112. \\
\hline 2 & 23 & 1 & 7.81 & 8.67 & -0.86 & 2.87 & 3.78 & 3.18 & 3.42 & 112. \\
\hline 2 & 24 & 1 & 7.85 & 8.69 & -0.84 & 2.86 & 3.73 & 3.18 & 3.24 & 111. \\
\hline 2 & 1 & 2 & 7.55 & 8.22 & -0.68 & 2.05 & 2.99 & 3.05 & 3.18 & 104. \\
\hline 2 & 2 & 2 & 7.62 & 8.20 & -0.58 & 2.00 & 2.65 & 3.01 & 3.03 & 103. \\
\hline 2 & 3 & 2 & 7.66 & 8.24 & -0.58 & 2.07 & 2.57 & 3.06 & 3.11 & 101. \\
\hline 2 & 4 & 2 & 7.73 & 8.27 & -0.54 & 1.95 & 2.48 & 3.10 & 3.04 & 103. \\
\hline 2 & 5 & 2 & 7.76 & 8.43 & -0.67 & 2.24 & 2.86 & 3.24 & 2.97 & 103. \\
\hline 2 & 6 & 2 & 7.62 & 8.49 & -0.87 & 2.07 & 2.76 & 3.08 & 3.10 & 104. \\
\hline 2 & 7 & 2 & 7.74 & 8.51 & -0.78 & 2.25 & 2.91 & 3.13 & 3.16 & 105 \\
\hline 2 & 8 & 2 & 7.79 & 8.41 & -0.62 & 2.38 & 3.11 & 3.18 & 3.33 & 105. \\
\hline 2 & 9 & 2 & 7.88 & 8.51 & -0.63 & 2.61 & 3.35 & 3.20 & 3.50 & 106. \\
\hline 2 & 10 & 2 & 7.84 & 8.70 & -0.85 & 2.77 & 3.53 & 3.14 & 3.49 & 105. \\
\hline 2 & 11 & 2 & 7.81 & 8.76 & -0.95 & 2.78 & 3.59 & 3.12 & 3.48 & 105. \\
\hline 2 & 12 & 2 & 7.87 & 8.81 & -0.94 & 2.71 & 3.48 & 3.08 & 3.26 & 105. \\
\hline 2 & 13 & 2 & 7.85 & 8.80 & -0.95 & 2.66 & 3.61 & 3.10 & $3 \cdot 31$ & 104. \\
\hline 2 & 14 & 2 & 7.76 & 8.60 & -0.83 & 2.73 & 3.53 & 3.02 & 3.31 & 104. \\
\hline 2 & 15 & 2 & 7.75 & 8.28 & -0.52 & 2.61 & 3.39 & 2.92 & 3.17 & 103. \\
\hline 2 & 16 & 2 & 7.75 & 8.21 & -0.46 & 2.64 & 3.46 & 2.77 & 3.32 & 105. \\
\hline 2 & 17 & 2 & 7.65 & 8.25 & -0.59 & 2.65 & 3.52 & 2.83 & 3.14 & 106. \\
\hline 2 & 18 & 2 & 7.66 & 8.32 & -0.66 & 2.72 & 3.64 & 2.76 & 3.24 & 105. \\
\hline 2 & 19 & 2 & 7.63 & 8.29 & -0.66 & 2.84 & 3.76 & 2.77 & 3.24 & 105 \\
\hline 2 & 20 & 2 & 7.61 & 8.21 & -0.59 & 2.80 & 3.49 & 2.76 & 2.90 & 105 \\
\hline 2 & 21 & 2 & 7.64 & 8.08 & -0.44 & 2.75 & 3.52 & 2.83 & 2.99 & 105. \\
\hline 2 & 22 & 2 & 7.71 & 8.13 & -0.42 & 2.97 & 3.81 & 2.96 & 3.18 & 104. \\
\hline 2 & 23 & 2 & 7.60 & 8.26 & -0.66 & 2.97 & 3.85 & 2.85 & 3.38 & 100. \\
\hline 2 & 24 & 2 & 7.69 & 8.35 & -0.66 & 2.95 & 3.80 & 3.06 & 3.38 & 98 \\
\hline 3 & 1 & 1 & 8.65 & 9.73 & -1.07 & 3.57 & 4.62 & 4.73 & 4.83 & 60 \\
\hline 3 & 2 & 1 & 8.45 & 10.08 & -1.63 & 3.70 & 4.84 & 4.73 & 4.96 & 5 \\
\hline 3 & 3 & 1 & 8.03 & 10.00 & -1.97 & 3.91 & 4.90 & 4.75 & 5.11 & 60 \\
\hline 3 & 4 & 1 & 7.94 & 9.81 & -1.88 & 3.89 & 4.70 & 4.82 & 5.10 & 60 \\
\hline 3 & 5 & 1 & $7 \cdot 38$ & 9.51 & -2.12 & 4.31 & 5.20 & 4.71 & 5.01 & 5 \\
\hline 3 & 6 & 1 & 7.12 & 9.06 & -1.94 & 4.05 & 5.20 & 4.61 & 4.81 & \\
\hline 3 & 7 & 1 & 6.95 & 8.88 & -1.93 & 4.07 & 5.17 & 4.51 & 4.71 & \\
\hline 3 & 8 & 1 & 6.77 & 8.48 & -1.71 & 3.73 & 4.82 & 4.44 & 4.60 & \\
\hline 3 & 9 & 1 & 6.45 & 8.15 & -1.70 & 4.01 & 5.06 & 4.36 & 4.55 & \\
\hline 3 & 10 & 1 & 6.47 & 8.09 & -1.61 & 4.22 & 5.49 & 4.29 & 4.81 & \\
\hline 3 & 11 & 1 & 6.82 & 8.23 & -1.41 & 4.10 & 5.18 & 4.17 & 4.50 & \\
\hline 3 & 12 & 1 & 7.14 & 8.27 & -1.14 & 3.89 & 4.82 & 3.90 & 4.56 & \\
\hline 3 & 13 & 1 & 7.06 & 7.73 & -0.67 & 3.50 & 4.33 & 3.46 & 4.15 & \\
\hline 3 & 14 & 1 & $7 \cdot 34$ & 8.07 & -0.73 & 3.70 & 4.61 & 3.27 & 4.14 & \\
\hline 3 & 15 & 1 & 7.64 & 8.41 & -0.77 & 3.97 & 4.87 & 3.13 & 4.78 & \\
\hline 3 & 16 & 1 & 8.27 & 8.48 & -0.21 & 3.54 & 4.53 & 3.30 & 4.60 & \\
\hline 3 & 17 & 1 & 8.62 & 8.21 & 0.41 & 3.43 & 4.35 & 3.37 & 4.16 & \\
\hline 3 & 18 & 1 & 9.08 & 8.62 & 0.46 & 3.39 & 4.33 & 3.50 & 4.21 & \\
\hline 3 & 19 & 1 & 9.33 & 9.05 & 0.28 & 3.33 & 4.12 & 3.58 & 4.20 & 2 \\
\hline 3 & 20 & 1 & 9.26 & 9.06 & 0.20 & 3.43 & 4.36 & 3.64 & 4.13 & J \\
\hline 3 & 21 & 1 & 9.48 & 9.81 & -0.34 & 3.52 & 4.46 & 3.64 & $4 \cdot 36$ & 5 \\
\hline
\end{tabular}




\begin{tabular}{|c|c|c|c|c|c|c|c|c|c|c|}
\hline I TE & $\begin{array}{l}\text { PROJ } \\
\text { HOUR }\end{array}$ & $\begin{array}{l}\text { FCST } \\
\text { TIME }\end{array}$ & MFWS & MOWS & BI AS & MAE & RMSE & SIGMAF & SIGMAO & $\begin{array}{l}\text { SAMPLE } \\
\text { SIZE }\end{array}$ \\
\hline $\begin{array}{l}3 \\
3 \\
3 \\
3 \\
3 \\
3 \\
3 \\
3 \\
3 \\
3 \\
3 \\
3 \\
3 \\
3 \\
3 \\
3 \\
3 \\
3 \\
3 \\
3 \\
3 \\
3 \\
3 \\
3 \\
3 \\
3 \\
3\end{array}$ & $\begin{array}{r}22 \\
23 \\
24 \\
1 \\
2 \\
3 \\
4 \\
5 \\
6 \\
7 \\
8 \\
9 \\
10 \\
11 \\
12 \\
13 \\
14 \\
15 \\
16 \\
17 \\
18 \\
19 \\
20 \\
21 \\
22 \\
23 \\
24\end{array}$ & $\begin{array}{l}1 \\
1 \\
1 \\
2 \\
2 \\
2 \\
2 \\
2 \\
2 \\
2 \\
2 \\
2 \\
2 \\
2 \\
2 \\
2 \\
2 \\
2 \\
2 \\
2 \\
2 \\
2 \\
2 \\
2 \\
2 \\
2 \\
2\end{array}$ & $\begin{array}{r}9.30 \\
9.05 \\
8.82 \\
7.46 \\
7.61 \\
7.89 \\
8.18 \\
8.60 \\
8.88 \\
9.11 \\
9.45 \\
9.62 \\
9.98 \\
10.13 \\
9.98 \\
9.86 \\
9.52 \\
9.19 \\
9.09 \\
8.90 \\
8.06 \\
7.71 \\
7.18 \\
6.83 \\
6.60 \\
6.70 \\
6.69\end{array}$ & $\begin{array}{r}9.68 \\
9.36 \\
9.47 \\
7.97 \\
8.13 \\
8.44 \\
8.56 \\
8.35 \\
8.69 \\
9.24 \\
9.32 \\
10.16 \\
9.99 \\
9.79 \\
9.83 \\
9.62 \\
9.89 \\
9.68 \\
9.43 \\
9.03 \\
8.54 \\
8.60 \\
8.21 \\
7.97 \\
7.82 \\
8.06 \\
8.13\end{array}$ & $\begin{array}{r}-0.38 \\
-0.31 \\
-0.65 \\
-0.50 \\
-0.52 \\
-0.55 \\
-0.39 \\
0.25 \\
0.19 \\
-0.13 \\
0.13 \\
-0.53 \\
-0.01 \\
0.34 \\
0.14 \\
0.24 \\
-0.37 \\
-0.49 \\
-0.34 \\
-0.12 \\
-0.48 \\
-0.89 \\
-1.03 \\
-1.14 \\
-1.22 \\
-1.36 \\
-1.44\end{array}$ & $\begin{array}{l}3.59 \\
4.06 \\
4.11 \\
3.14 \\
3.05 \\
3.55 \\
3.34 \\
3.03 \\
3.40 \\
3.21 \\
3.21 \\
3.03 \\
2.91 \\
3.52 \\
3.51 \\
3.68 \\
3.61 \\
3.53 \\
3.37 \\
3.51 \\
3.78 \\
4.56 \\
3.91 \\
4.07 \\
4.56 \\
4.60 \\
4.68\end{array}$ & $\begin{array}{l}4.57 \\
5.02 \\
5.23 \\
4.09 \\
3.94 \\
4.38 \\
4.07 \\
3.66 \\
3.82 \\
3.78 \\
3.64 \\
3.64 \\
3.69 \\
4.38 \\
4.30 \\
4.54 \\
4.54 \\
4.52 \\
4.31 \\
4.41 \\
5.21 \\
5.67 \\
5.00 \\
5.50 \\
6.15 \\
6.10 \\
5.99\end{array}$ & $\begin{array}{l}3.66 \\
3.64 \\
3.67 \\
3.61 \\
3.56 \\
3.66 \\
3.49 \\
3.69 \\
3.83 \\
3.79 \\
3.82 \\
3.81 \\
3.84 \\
3.88 \\
3.96 \\
3.95 \\
3.99 \\
3.88 \\
4.07 \\
4.21 \\
4.31 \\
4.52 \\
4.04 \\
3.91 \\
4.04 \\
4.14 \\
3.96\end{array}$ & $\begin{array}{l}4.40 \\
4.44 \\
4.59 \\
4.38 \\
4.25 \\
4.88 \\
4.68 \\
4.24 \\
4.19 \\
4.22 \\
4.08 \\
4.26 \\
4.23 \\
4.50 \\
4.63 \\
4.78 \\
5.05 \\
5.20 \\
5.23 \\
5.07 \\
4.67 \\
4.59 \\
4.54 \\
4.60 \\
4.74 \\
4.56 \\
4.63\end{array}$ & $\begin{array}{l}58 . \\
58 . \\
58 . \\
51 . \\
52 . \\
51 . \\
52 . \\
52 . \\
52 . \\
52 . \\
54 . \\
54 . \\
54 . \\
54 . \\
53 . \\
54 . \\
54 . \\
55 . \\
55 . \\
54 . \\
54 . \\
54 . \\
54 . \\
54 . \\
54 . \\
53 . \\
52 .\end{array}$ \\
\hline
\end{tabular}

\section{ANALYSIS BY FORECASTER, BY SITE, BY FORECAST TIME}

\begin{tabular}{rrrrrrrrrrr}
\multicolumn{1}{c}{ ID } & SITE & TIME & MFWS & MOWS & BIAS & MAE & RMSE & SIGMAF & SIGMAO & SIZE \\
1 & 1 & 2 & 7.04 & 7.21 & -0.18 & 2.04 & 2.36 & 1.51 & 2.61 & 72. \\
1 & 2 & 1 & 4.61 & 10.34 & -5.73 & 5.76 & 6.35 & 1.04 & 2.73 & 124. \\
1 & 2 & 2 & 7.11 & 7.15 & -0.04 & 2.10 & 2.49 & 1.26 & 2.92 & 144. \\
1 & 3 & 2 & 5.80 & 8.17 & -2.37 & 3.48 & 4.32 & 3.03 & 3.63 & 96. \\
2 & 1 & 1 & 5.90 & 5.71 & 0.19 & 2.27 & 2.78 & 2.28 & 2.03 & 320. \\
2 & 1 & 2 & 7.14 & 7.47 & -0.32 & 2.61 & 3.34 & 3.13 & 2.92 & 327. \\
2 & 2 & 1 & 7.98 & 7.82 & 0.17 & 2.23 & 2.92 & 2.70 & 2.51 & 653. \\
2 & 2 & 2 & 7.36 & 8.90 & -1.54 & 3.21 & 4.21 & 3.05 & 3.38 & 504. \\
2 & 3 & 1 & 7.32 & 7.13 & 0.18 & 3.32 & 4.11 & 3.74 & 3.27 & 262. \\
2 & 3 & 2 & 11.81 & 9.45 & 2.36 & 3.86 & 4.69 & 5.31 & 5.44 & 217. \\
3 & 1 & 1 & 6.48 & 6.50 & -0.02 & 2.25 & 2.79 & 2.41 & 2.63 & 257. \\
3 & 1 & 2 & 6.36 & 5.36 & 1.00 & 2.42 & 3.12 & 2.33 & 1.95 & 272. \\
3 & 2 & 1 & 7.89 & 9.13 & -1.25 & 3.00 & 3.98 & 3.01 & 3.80 & 615. \\
3 & 2 & 2 & 8.01 & 7.78 & 0.23 & 2.17 & 2.70 & 3.24 & 2.69 & 405. \\
3 & 3 & 1 & 10.16 & 9.15 & 1.01 & 3.21 & 3.97 & 3.47 & 4.00 & 286. \\
3 & 3 & 2 & 8.74 & 6.19 & 2.55 & 3.91 & 4.80 & 2.83 & 2.49 & 168. \\
4 & 1 & 1 & 7.59 & 7.92 & -0.32 & 2.50 & 3.11 & .3 .94 & 3.52 & 307. \\
4 & 1 & 2 & 7.34 & 7.43 & -0.09 & 2.72 & 3.40 & 2.96 & 2.72 & 185. \\
4 & 2 & 1 & 6.84 & 7.07 & -0.22 & 2.46 & 2.92 & 2.59 & 2.50 & 202. \\
4 & 2 & 2 & 8.23 & 9.16 & -0.93 & 2.41 & 3.22 & 3.23 & 2.71 & 482. \\
4 & 3 & 1 & 9.71 & 10.57 & -0.86 & 3.77 & 4.81 & 4.90 & 5.56 & 216. \\
4 & 3 & 2 & 7.61 & 8.00 & -0.38 & 2.93 & 3.68 & 3.24 & 4.02 & 295.
\end{tabular}




$\begin{array}{rrrrrrrrrrr}\text { SITE } & \begin{array}{l}\text { PROJ } \\ \text { HOUR }\end{array} & \begin{array}{r}\text { FCST } \\ \text { TIME }\end{array} & \text { MFWS } & \text { MOWS } & \text { BIAS } & \text { MAE } & \text { RMSE } & \text { SIGMAF } & \text { SIGMAO } & \text { SAMPLE } \\ \text { SIZE }\end{array}$


APPENDIX E

SELECTION OF A NORMALIZING STATISTIC FOR COMPARISON OF WIND SPEED FORECASTING ERRORS 
SELECTION OF A NORMALIZING STATISTIC FOR COMPARISON OF WIND SPEED FORECASTING ERRORS

When making comparisons of the relative accuracy of different wind forecasting methods, it is often necessary to remove the effects of differences in the difficulty of forecasting the winds in order to achieve accurate comparisons. Removing these effects is required whenever any of the following comparisons are to be made:

- comparison of forecasts made during different seasons at a site

- comparison of forecasts made at different sites

- comparison of forecasts made during different years.

The process of removing the effects of differences in forecasting difficulty (in order to examine the skill of the forecasts) is often referred to as normalization. In order to normalize wind forecasting verification statistics, it is necessary to identify the wind characteristic(s) that is associated with forecasting difficulty and then to formulate statistical measures of that wind characteristic(s). The statistical measure, if numerically suitable, can be used as a divisor/multiplier to normalize the wind forecasting error statistics.

To identify characteristics of the wind that are highly correlated with wind forecasting difficulty, a data set containing nine contiguous months of Model Output Statistics (MOS) forecasts was developed for three sites. As described in Section 4.2 of the main body of this report, MOS is an objective forecasting technique using fixed forecasting equations. Therefore, MOS is a "mature" technique that has no inherent learning curve that would disguise relationships between wind characteristics and forecasting accuracy.

If the climatology of a location is sufficiently known to produce unbiased wind speed forecasts, errors made in wind forecasting can usually be associated with two general characteristics exhibited by the time-series of observed wind speeds: 1) trends in the wind speed (1asting several hours), and 2) variability (noise) in the hour-to-hour wind speed observations. 
Errors occur when trends are incorrectly forecast. Usually these errors are associated with mistiming the trend (as shown in Figure E-1). Such errors are often the result of errors made in estimating the rate of movement and/or development of weather systems. Rapidly moving storm systems that frequently move through or by a location could contribute to such errors.

Other wind forecasting errors occur due to the inability of the forecaster or forecasting scheme to predict highly variable winds. Figure E-2 depicts a time series of hourly mean wind speeds having rather high variability. The dashed line, an actual wind speed forecast, follows the general trend of the winds. Nevertheless, the RMSE of this forecast is large $(4.52 \mathrm{~m} / \mathrm{s})$. The dashed curve in Figure $E-3$ is a fourth order polynomial fit to the observed winds of Figure E-2. In essence, the polynomial fit can be considered to be the best possible forecast for these winds. Despite the mathematical fitting of a curve to the data, using the fitted curve as a forecast still results in a moderately large RMSE of $3.01 \mathrm{~m} / \mathrm{s}$.

Several wind statistics were examined to determine how well they measured both speed trends and variability (noise) in sequences of hourly average wind speeds and how well each statistic correlates with wind speed forecasting errors. Wind statistics examined for correlation with the RMSE of the forecast were:

- standard deviation of the observed wind speeds (SIGMAO)

- auto-correlation of the observed wind speed (using 1-through 12-hr lag)

- mean deviation of successive wind speed observations (using 1- through $12-\mathrm{hr}$ lag)

- mean square deviation (MSD) of observed wind speed (using 1- through $12-h r$ lag)

- root mean square deviation of observed wind speed (using a 1- through 12-hr lag).

Two statistics proved superior to the others in explaining the variance in wind speed forecasting errors. These were the monthly standard deviation of 


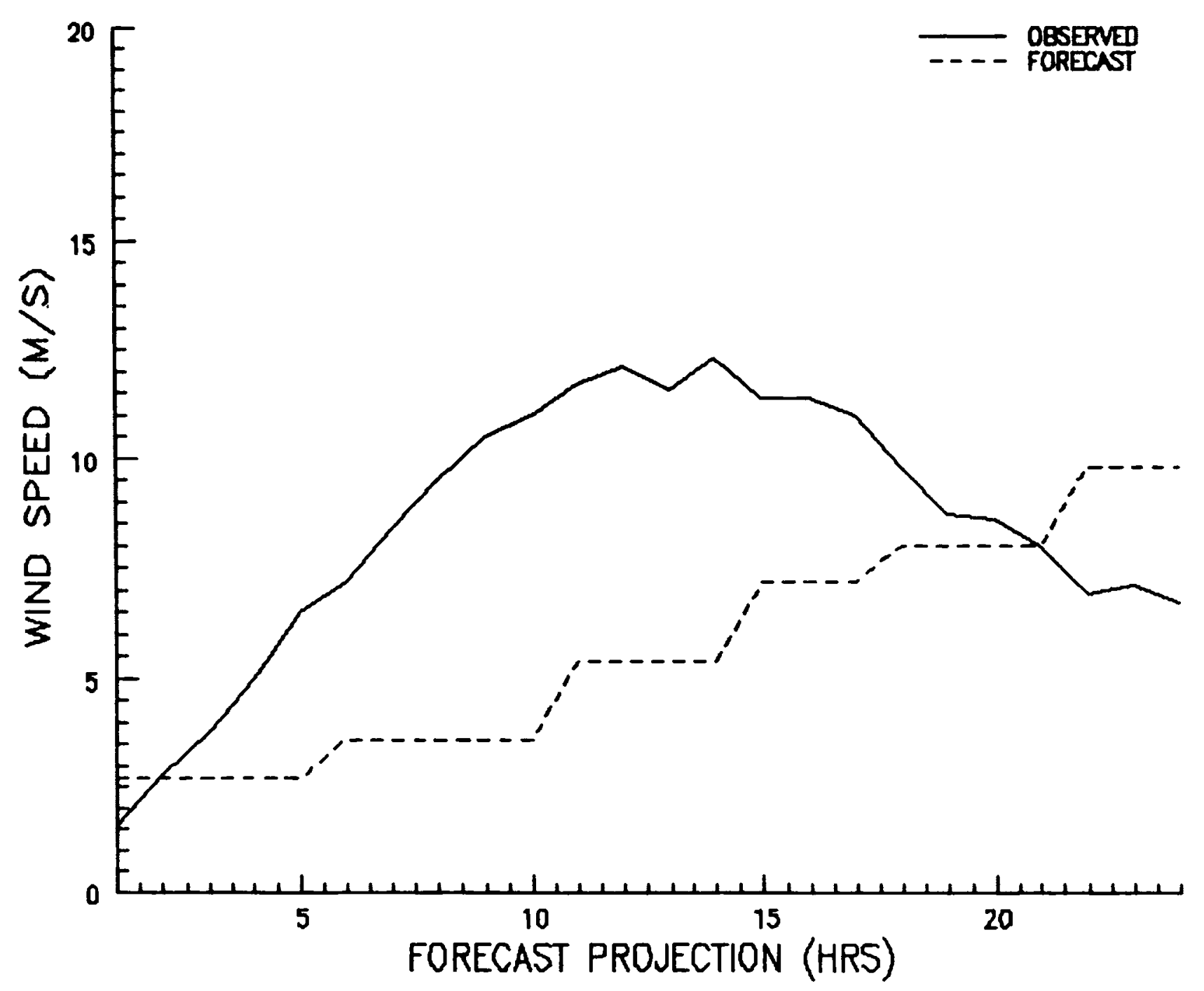

FIGURE E-1. Example of a 10-Hr Timing Error in Forecasting the Wind Speed Trend 


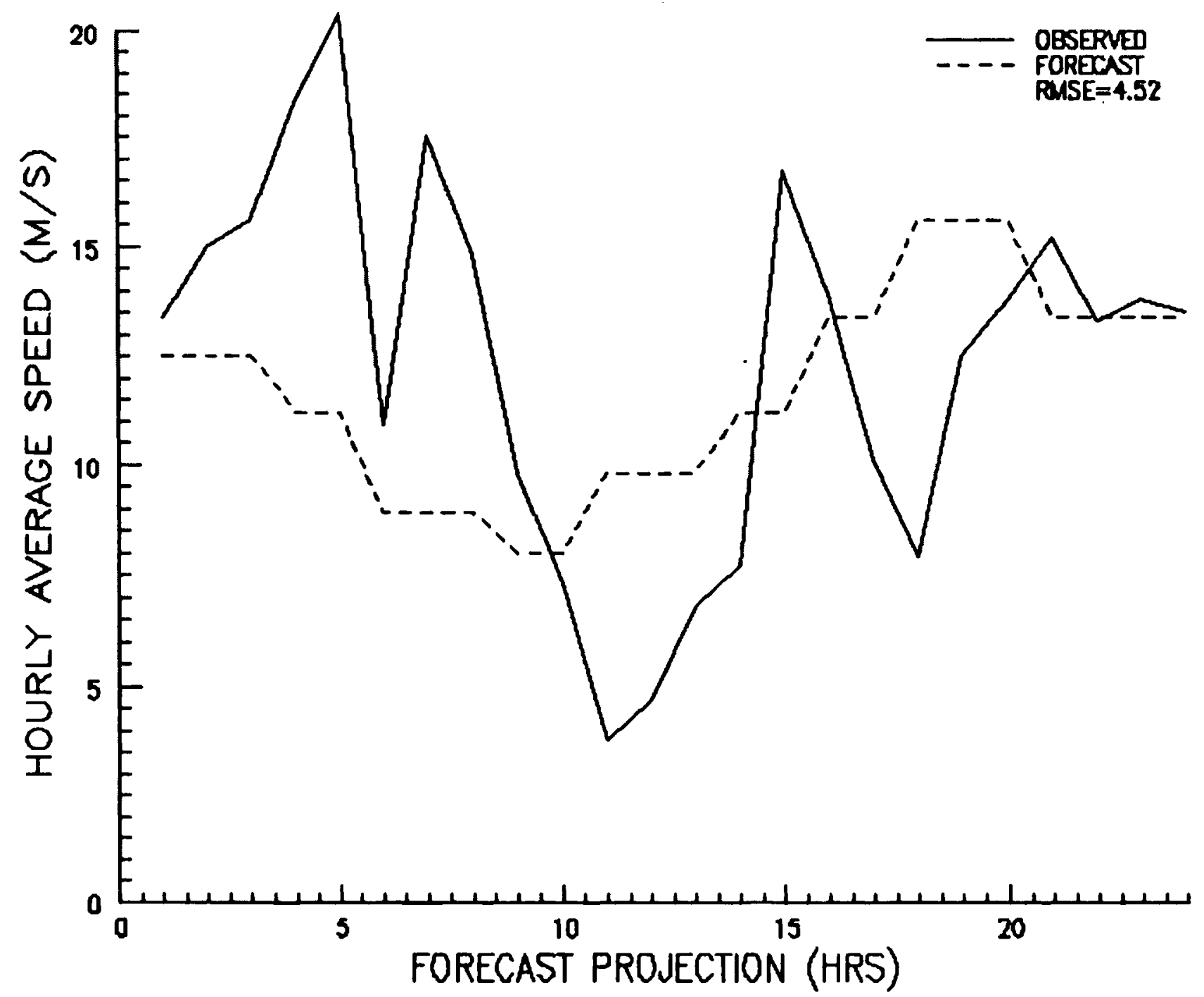

FIGURE E-2. Example of an Actual Wind Speed Forecast During a Period of High Hour-to-Hour Wind Speed Variability 


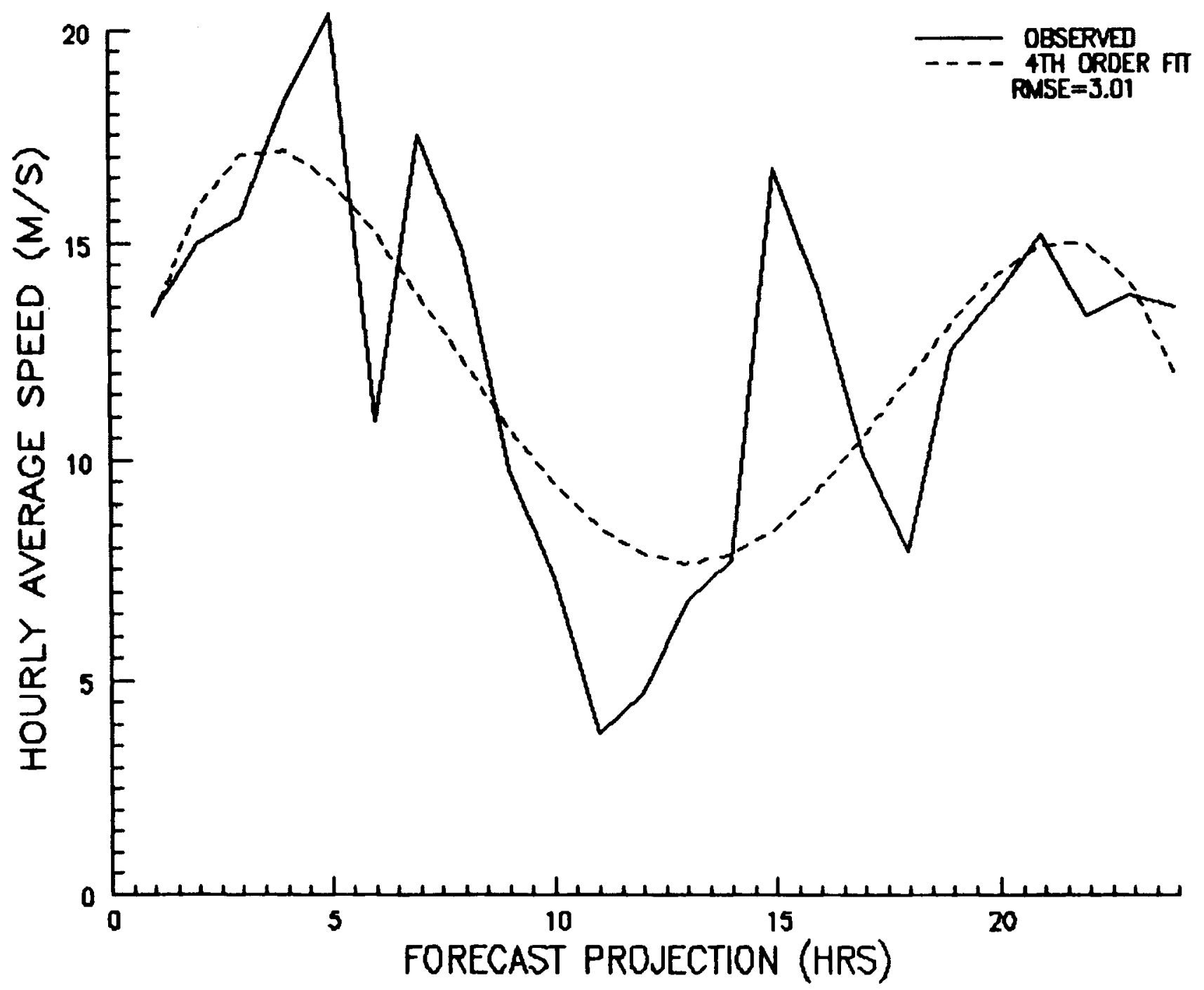

FIGURE E-3. Example of the Inability to Forecast Accurately Highly Variable Wind Speeds Several Hours in Advance 
the observed wind speed and the monthly mean square deviation of observed wind speed (computed using a $6-\mathrm{hr}$ lag). The standard deviation of speed provides a general information about the wind speed variability and thus forecasting difficulty. Though the standard deviation has been used in the past to indicate forecasting difficulty (Bodin and Fredriksson 1981), there was concern that standard deviation may not provide sufficient information on trends or the hour-to-hour variability in the wind speed on time scales important to forecasting. On the other hand, the 6-hr lagged mean square deviation of wind speed appeared to provide information about noise-type variability in speed as well as speed trends of near 6 hours duration.

Statistical analysis of the MOS wind forecasting data shown in Table E-1 was performed to select the statistic that explains the greatest amount of variation in MOS wind forecasting error (RMSE). The data in the table were sorted in order of increasing RMSE and analysis of variance (ANOVA) was performed. A plot of residuals indicated that the natural log of the MSD (lagged 6 hours) was more linearly related to RMSE than the MSD itself. Results of the ANOVA on the sorted data are shown below:

$\begin{array}{cc}\text { Standard deviation of the speed observations }- & 82 \% \text { of RMSE variance } \\ \text { explained }\end{array}$

An explanation of these results is shown in Figures E-4 and E-5. Figure E-4 contains a plot of the data of Table E-1 sorted on RMSE. It appears that SIGMAO follows the RMSE more closely than LN(MSD), particularly for larger values of RMSE. To depict this more clearly, a third order polynomial fit to the data of Figure E-4 is presented in Figure E-5. SIGMAO parallels RMSE through the entire range of RMSES, while LN(MSD) is not linearly proportional to the RMSE for values greater than $4 \mathrm{~m} / \mathrm{s}$.

For these reasons, SIGMAO was selected as the normalizing statistic. Division of RMSE by SIGMAO results in a value that is much more representative of the skill exhibited in the wind speed forecasts; thus, the relative 
accuracy of forecasts made for different times of the year and using different techniques can be more equitably determined. Normalized RMSEs also permit evaluation of the learning curve resulting from implementation by forecasters of a new forecasting technique or from forecasting for a new location.

TABLE E-1. MOS Monthly Wind Forecasting Errors and Two Candidate Normalizing Statistics for Three Selected Sites

\begin{tabular}{|c|c|c|c|c|}
\hline Site & Month & RMSE & SIGMAO & $L N(M S D)$ \\
\hline Block Island, RI & $\begin{array}{l}\text { Feb } \\
\text { Mar } \\
\text { Apr } \\
\text { May } \\
\text { Jun } \\
\text { Jul } \\
\text { Aug } \\
\text { Sep } \\
\text { Oct }\end{array}$ & $\begin{array}{l}2.84 \\
2.44 \\
2.88 \\
2.88 \\
2.01 \\
2.44 \\
2.87 \\
2.24 \\
2.90\end{array}$ & $\begin{array}{l}4.04 \\
3.18 \\
3.07 \\
3.46 \\
2.36 \\
3.01 \\
3.00 \\
3.48 \\
3.16\end{array}$ & $\begin{array}{l}2.175 \\
2.041 \\
2.129 \\
2.113 \\
1.615 \\
1.649 \\
2.285 \\
2.281 \\
2.298\end{array}$ \\
\hline Huron, SD & $\begin{array}{l}\text { Feb } \\
\text { Mar } \\
\text { Apr } \\
\text { May } \\
\text { Jun } \\
\text { Jul } \\
\text { Aug } \\
\text { Sep } \\
\text { Oct }\end{array}$ & $\begin{array}{l}-- \\
2.39 \\
2.91 \\
2.79 \\
2.98 \\
2.57 \\
2.08 \\
2.32 \\
2.24\end{array}$ & $\begin{array}{l}-- \\
3.28 \\
3.29 \\
3.02 \\
3.20 \\
2.93 \\
2.55 \\
2.82 \\
2.45\end{array}$ & $\begin{array}{l}-- \\
2.474 \\
2.561 \\
2.116 \\
2.436 \\
2.311 \\
1.650 \\
1.734 \\
1.761\end{array}$ \\
\hline San Gorgonio, CA & $\begin{array}{l}\text { Feb } \\
\text { Mar } \\
\text { Apr } \\
\text { May } \\
\text { Jun } \\
\text { Jul } \\
\text { Aug } \\
\text { Sep } \\
\text { Oct }\end{array}$ & $\begin{array}{l}-- \\
4.33 \\
4.31 \\
4.49 \\
3.27 \\
3.62 \\
3.68 \\
4.76 \\
4.01\end{array}$ & $\begin{array}{l}-- \\
4.73 \\
5.71 \\
6.06 \\
4.19 \\
5.03 \\
5.06 \\
5.51 \\
3.92\end{array}$ & $\begin{array}{l}-- \\
2.918 \\
2.96 \\
3.073 \\
2.992 \\
3.042 \\
3.237 \\
2.789 \\
2.852\end{array}$ \\
\hline
\end{tabular}




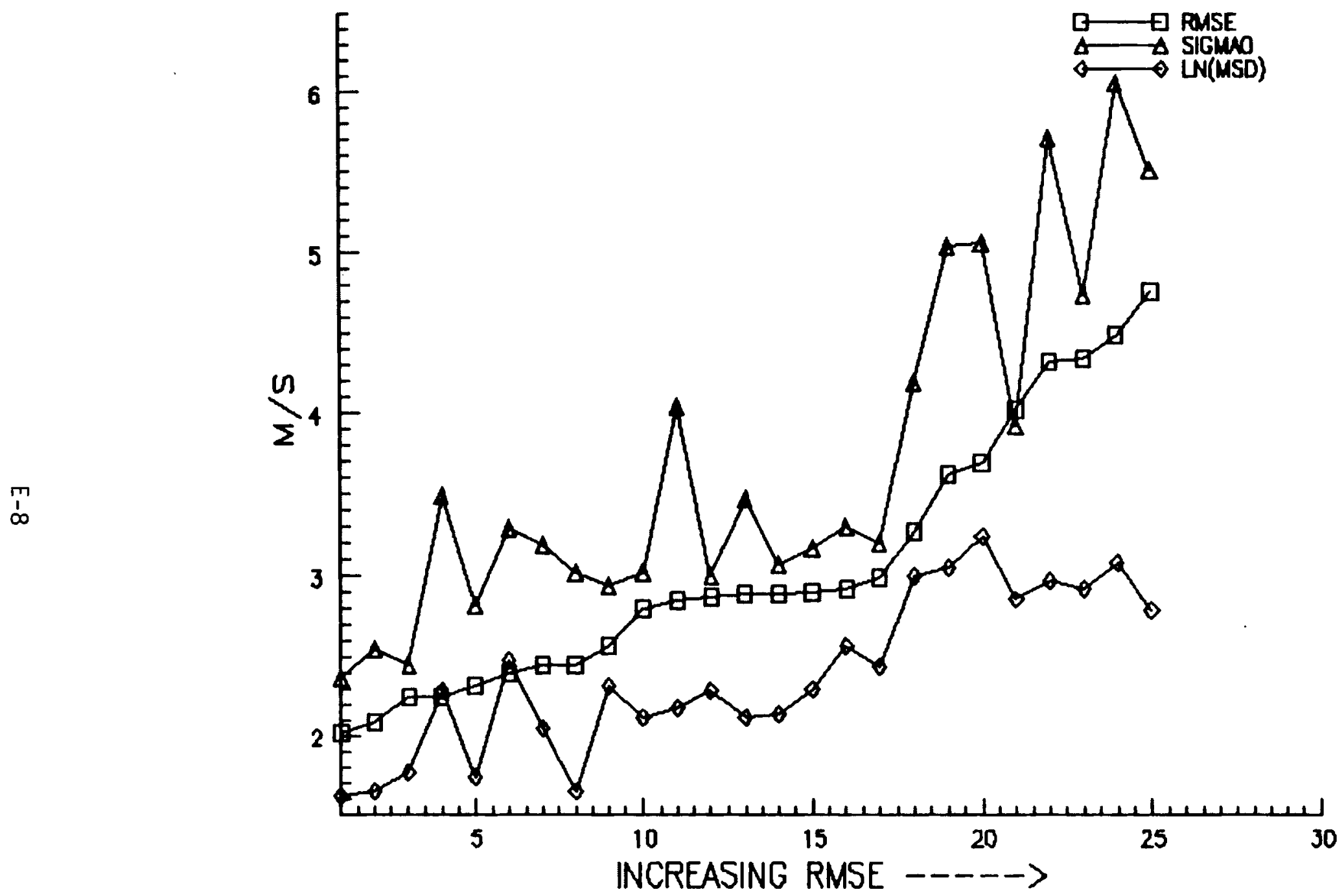

FIGURE E-4. Wind Speed Forecasting RMSE Versus Two Candidate Normalizing Statistics 


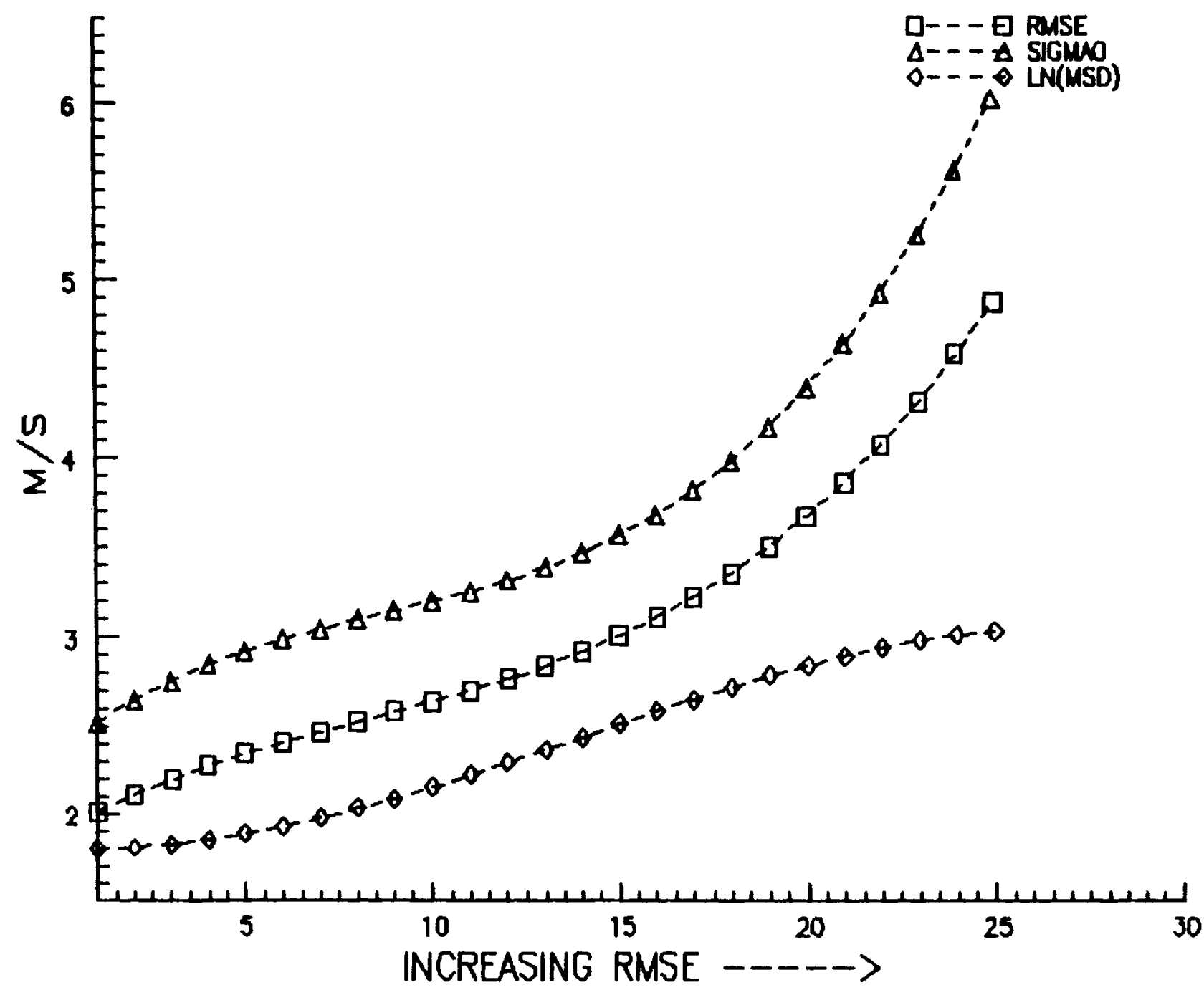

FIGURE E-5. Trends in Wind Speed Forecasting RMSE and Two Candidate Normalizing Statistics Depicted by Third Order Polynomials 
REFERENCE

Bodin, S. and U. Fredriksson. 1981. Uncertainty in Wind Forecasting for Wind Power Networks. RMK 25, Swedish Meteorological and Hydrological Institute, Norrkoping, Sweden. 


\section{$\underline{\text { DISTRIBUTION }}$}

No. of

Copies

$\underline{\text { OFFSITE }}$

C. I. Aspliden

Battelle Memorial Institute Washington Operations Office 2030 M Street, N.W.

Washington, DC 20036

G. P. Tennyson

Department of Energy

Albuquerque Operations Office

4501 Indian School Road N.E.

Albuquerque, NM 87110

3 D. Ancona/J. Cadogan/L. V. Divone Department of Energy Wind Energy Technology Division 1000 Independence Avenue S.W. Forrestal Building, Room 5F059 Washington, DC 20585

27 DOE Technical Information Center

2 P. Lissaman/A. Zalay

Aerovironment, Inc. 145 Vista Avenue

Pasadena, CA 91107

\section{A. Liljedahl}

Department of Agriculture Agriculture Wind Energy Program Building 001, Room 126 BARC-West Beltsville, MD 20705

R. N. Clark

U.S. Department of Agriculture Southwest Great Plains Research Center

Bushland, TX 79102

W. A. Vachon

Arthur D. Little, Inc.

20 Acorn Park

Cambridge, MA 02140
No. of

Copies
D. McGrew

Boeing Engineering \& Construction

P.0. Box 3707, Mail Stop 9A-67

Seattle, WA 98124

N. Butler

Bonneville Power Administration

P.0. Box 3621

Portland, OR 97208

W. J. Formica

P. 0. Box 1026 ?

Dallas, TX 75207

3 C. Notis

Freese-Notis Weather, Inc.

1453 N.E. 66th Avenue

Des Moines, IA 50313

W. Frost

FWG Associates, Inc.

271A Lakewood Drive

Tullahoma, TN 37388

S. Macklis General Electric Company Advanced Energy Systems P.0. Box 8661

Philadelphia, PA 19101

T. D. Younkins

General Electric Systems

Engineering Department

General Electric Company

1 River Road

Schenectady, NY 12345

3 D. W. Trettel

Murray and Trettel, Inc. Northfield, IL 60093 
3 P. French

NASA Scientific and Technical Information Facility

P.0. Box 8757

Baltimore/Washington International Airport

Baltimore, MD 21240

E. W. Hewson

Department of Atmospheric Sciences Oregon State University

Corvallis, OR 97331

R. L. Simon

Pacific Gas and Electric

215 Market Street

San Francisco, CA 94106

C. D. Stultz

Pacific Power

920 S.W. 6th Avenue

Portland, OR 97204

B. Bailey

Atmospheric Sciences Research Center

State University of New York at Albany

Albany, NY 12222

S. M. Chan

Systems Control, Inc.

1801 Page Mill Road

P.0. Box 10025

Palo Alto, CA 94303

W. Owens

Tennessee Valley Authority

320 Credit Union Building

715 Market Street

Chattanooga, TN 37401

R. H. Kirchhoff

Department of Mechanical

Engineering

University of Massachusetts

Amherst, MA 01003
R. A. Pielke

Department of Environmental Sciences

Clark Hall

University of Virginia

Charlottesville, VA 22903

E. L. Davis

U.S. Windpower, Inc.

6421 B. South Front Road

Livermore, CA 94550

\section{ONSITE}

DOE Richland Operations Office

H. E. Ransom/D. R. Segna

38 Pacific Northwest Laboratory

W. R. Barchet

J. R. Connell

C. E. Elderkin

D. L. Elliott

R. L. George

D. L. Hadley

A. H. Miller

E. L. Owczarski

D. C. Powell

D. S. Renné

H. L. Wegley (5)

L. L. Wendel 1

Technical Information Library (5)

Publishing Coordination (2)

WCPE Program Office (15) 